\title{
1984, 2001, 2015
}

\author{
By \\ Peter Fredrick Kelly \\ A thesis submitted to \\ Faculty of Graduate and Post-Doctoral Affairs \\ in partial fulfillment of the requirements \\ for the degree of \\ Master of Architecture \\ [M. Arch Professional] \\ Carleton University \\ Azrieli School Architecture and Urbanism \\ Ottawa, Ontario \\ (C) $2013-2014$ \\ Peter Fredrick Kelly
}




\begin{abstract}
Technology has always been a double-edged sword, ever since humans mastered fire or the creation of stone tools.

Previously, advancements in material technology drove architectural innovation. Steel allowed us to build higher than ever before, enabling the urban metropolis as we now know it. The load-bearing arch was previously the pinnacle of architectural technology. A fundamental building component of centuries past now rendered irrelevant in contemporary construction.
\end{abstract}

Emerging digital technologies are different; they present us with difficult moral and ethical questions regarding their integration into society. Autonomous Unmanned Aerial Vehicles [UAVs] are a controversial technology that boldly embodies many of our concerns, challenging our notions of privacy, security and surveillance. Drones can inflict unimaginable terror and oppression upon an entire population when weaponized. Conversely, the same technology could provide incredible new efficiencies in communications and distribution on a global scale.

In the very near-future domestic drones will operate commercially, far beyond the current confines of military applications. This creates a radically new social and spatial condition. Our existing transportation infrastructures and our built environment will have to evolve in response to wide spread integration of UAVs. 


\section{ACKNOWLEDGMENTS}

To my amazing parents, Steve and Kathy, that always believed in me.

I would not be where I am today without all your love and support.

Also many thanks to;

All of the friends and family that have always encouraged and supported many of my creative ventures,

My thesis advisor [and supervisor at CIMS] Dr Stephen Fai, for the encouragement and guidance throughout this whole process,

The whole Carleton Immersive Media Studio [CIMS] family,

Johan Voordouw, Mario Santana Quintero, Jeremy Laliberte, Mark MacGuigan, Rob Wood and Dave LePage at Carleton University. Each of you played an important role in the evolution of this thesis.

Danica Robertson, Robert Martin and the entire RMA family that unbeknownst to them sparked the beginning of this adventure.

I cannot fully express my gratitude here in words, but I am truly grateful. 
TABLE OF CONTENTS

ABSTRACT




\section{LIST OF FIGURES|ILLUSTRATIONS}

001 Reaper Drone: Indian Springs, NV; Distance - 2 miles, 2010

002 Plan of the Panoticon, 1791

003 Recovery at Ground Zero, 1945

004 The Twins from the series In the Playroom

005 Vehicle Barriers, 1989-2013

006 New Anti-Ram Perimeter Infill Wall, 2013

007 2001: A Space Odyssey [01h-07m30s]

008 Vehicular Fatalities 1991-2010

009 Flight Assembled Architecture

010 Calvin and Hobbes by Bill Watterson December 30, 1989

011 Popular Mechanics Cover, July 1957

012 Skyscraper Airport for City of Tomorrow

013 PFK drone: j.yan photo

014 PFK drone: Frame Components [a-j]

015 PFK drone: Original HT-FPV Frame

016 PFK drone: Modified Frame

017 PFK drone: Front Elevation

018 PFK drone: Plan

019 PFK drone: Side Elevation

020 PFK drone: Isometric

021 PFK drone: Wiring Diagram

022 PFK drone: Exploded Isometric

023 Gimbal: Gimbal Isometric

024 Gimbal: Front Elevation

025 Gimbal: Side Elevation

026 Current Methods of Surveying

027 UAV Aerial Surveying

028 Video Still Frame: Cheltenham Badlands, Caledon, Ontario

029 Video Still Frames [1-20]

030 Google Maps Satellite View 
031 Stitched Orthographic Photo

032 Thermal Imaging Examples

033 Drone 3D Topography Scan [a-d]

034 Drone 3D Topography Scan Detail [a-d]

035 Contour [0.5m] Digital Surface

036 Contour [0.5m] Plan

037 CNC Cut Model

038 Augmented Reality Visualization

0391909 Theorem

040 The Cosmopolis of the Future

041 Amazon Prime Air

042 Aerial Infrastructure: 3D City Map

043 Aerial Infrastructure: Existing Building

044 Aerial Infrastructure: Community Parcel Box [Rural+Suburban]

045 Aerial Infrastructure: Community Parcel Box [Urban]

046 Lolafil, 1973

047 Form vs Space

048 Public vs Private

049 Maison Dom-Ino, 1915

050 Institut Du Monde Arabe, 1987 


\section{LIST OF ACRONYMS|ABBREVIATIONS}

9/11

AGL

Al

AR

CCTV

CIMS

CNC

CSIS

DARPA

ESC

FAA

FLIR

FOV

FPS

FPV

FR-4/G-10

GB

GIS

GPS

GPT

HT-FPV

Li-Po

LIDAR

LPS

MC

NSA

n.t.s.

PDB

PFK

POV

ROV

RPA

Rx

SFOC

SMS

Tx

UAS

UAV

VU
11 September 2001

Above Ground Level

Artificial Intelligence

Augmented Reality

Closed Circuit Television

Carleton Immersive Media Studio

Computer Numerical Control [machine]

Canadian Security Intelligence Service

Defense Advanced Research Projects Agency

Electronic Speed Controller

Federal Aviation Administration [US Department of Transportation]

Forward Looking Infrared Camera

Field of View

Frames Per Second

First Person View

Fibreglass-Reinforced Epoxy Laminate Sheet

Gimbal Board [containing a gyroscope]

Geographic Information System

Global Positioning System

General Purpose Technology

HoverThings.com First Person View [pre-modified quad-copter frame model]

Lithium Polymer [battery]

Light Detection and Ranging

Local Positioning System

Main Controller [autopilot]

National Security Agency

Not to Scale

Power Distribution Board

Peter Fredrick Kelly

Point of View

Remotely Operated Vehicles

Remotely Piloted Aircraft

Receiver [radio frequency]

Special Flight Operating Certificate

Short Messaging Service [text message]

Transmitter [radio frequency]

Unmanned Aerial System

Unmanned Aerial Vehicle

Versatile Unit [Universal Serial Bus (USB) connection] 


\title{
PROLOGUE
}

Excerpt from 'Programs and Manifestoes on 20th-Century Architecture' by Ulrich Conrads, 1964;

\section{Ludwig Mies van der Rohe: \\ Technology and Architecture}

\begin{abstract}
In 1932 Mies moved to Berlin with the teachers and students of the Bauhaus and there continued it as a private institute. In July 1933 it was closed by the Gestapo. In summer 1937 Mies went to the USA; in July 1938 he received an invitation to the Illinois Institute of Technology [IIT] in Chicago and a little later was commissioned to redesign the university campus. The first buildings went up in the years 1942-3. They introduced the second great phase of his architecture. In 1950 Mies delivered to the IIT the speech reproduced here.
\end{abstract}

Technology is rooted in the past. It dominates the present and tends into the future. It is a real historical movement - one of the great movements which shape and represent their epoch. It can be compared only with the classic discovery of man as a person, the Roman will to power, and the religious movement of the Middle Ages. Technology is far more than a method; it is a world in itself. As a method it is superior in almost every respect. But only where it is left to itself, as in gigantic structures of engineering, there technology reveals its true nature. There it is evident that it is not only a useful means, but that it is something, something in itself, something that has a meaning and a powerful form - so powerful in fact, that it is not easy to name it. Is that still technology or is it Architecture? And that may be the reason why some people are convinced that architecture will be outmoded and replaced by technology. Such a conviction is not based on clear thinking. The opposite happens. Wherever technology reaches its real fulfilment, it transcends into architecture. It is true that architecture depends on facts, but its real field of activity is in the realm of significance. I hope you will understand that architecture has nothing to do with the inventions of forms. It is not a playground for children, young or old. Architecture is the real battleground of the spirit. Architecture wrote the history of the epochs and gave them their names. Architecture depends on its time. It is the crystallization of its inner structure, the slow unfolding of its form. That is the reason why technology and architecture are so closely related. Our real hope is that they will grow together, that someday the one will be the expression of the other. Only then will we have an architecture worthy of its name: Architecture as a true symbol of our time. ${ }^{1}$

p154

${ }^{1}$ (Rohe 1964, 154) 


\section{INTRODUCTION}

Mies was speaking of the vast advancements in material and industrial technologies that shaped modern civilization and the cities we currently inhabit. We are now experiencing a different stage of technological evolution. Some call it the information age, the digital age, the second machine age or third industrial revolution... We are now living with increasingly intelligent technologies, far beyond the mechanical or physical technological innovations in the past. Computational technologies are rapidly evolving, with ever-increasing capabilities. The impact of which has wide ripple-like effects throughout society. The overall sentiment remains true; these technologies define the epoch we currently exist within, but our built environment has yet to fully adapt to our new technical capabilities.

Unmanned-Aerial-Vehicles [UAVs] fully embody this progression. They are not only GPS enabled, like many of our other smart devices today [phones, watches, cameras, laptops, tablets...], they also have a unique ability to manipulate their location autonomously. This creates new potential uses - beyond the typical military applications we are familiar with - for drones to be put to work.

This Thesis will examine the practical applications for UAVs specific to the practice of architecture, propose future applications for this technology at the scale of the city and discuss the social and spatial repercussions caused by the proliferation of UAV technologies. 
"The future is but the obsolete in reverse"

- Vladimir Nabokov ${ }^{2}$

1984, 2001, 2015 is not simply a series of random 4-digit numbers of increasing magnitude. They are in fact years, each with specific connotations and cultural significance. Each framing many of the critical issues of our time;

1984:

Immediately one thinks of George Orwell's 1949 novel Nineteen-Eight-Four, and his dystopian vision of a future under an oppressive totalitarian big brother state. Naturally we will be discussing surveillance in its many forms. Highlighting the paradoxical relationship we have with digital technologies that both empower us while simultaneously creating new vulnerabilities.

Coincidentally, this was the year that the world - the general public in so-called developed nations - entered the digital age. With the release of the first mass-marketed personal computer [PC], the Macintosh 128k [the first to include a keyboard, mouse and graphic interface $\left.{ }^{3}\right]$ made digital technologies more accessible. Though digital computers had been around for several decades, this was affordable and compact enough for use at home, outside of institutions and government research facilities. This timely coincidence was not lost on those at Macintosh. Tony Scott [director of Blade Runner]

\footnotetext{
2 (Nabokov 1952)

${ }^{3}$ (Apple Inc. 2014)
} 
directed their debut commercial titled "1984" for Super Bowl XVIII with intentional overt reference to Orwell's novel.

2001:

2001 also has significance in the realm of science fiction, specifically to the work of Stanley Kubrick and his 1968 film 2001: A Space Odyssey. HAL 9000 is a sentient computer, meaning his artificial intelligence $[\mathrm{Al}]$ had progressed to the point where it becomes self-aware. This is a theme in science fiction commonly referred to as the singularity. ${ }^{5}$ We will discuss intelligent technologies, mainly limited to their current capabilities. We are still in many ways, far from creating the conscience machines depicted in many futuristic tales of science fiction. Our current technologies are progressing at an amazing rate, increasing their computational power and functional reach. The continuing developments in computing will continue to impact our economy, values and our daily lives.

11 September 2001 [9/11] is a date that is now infamous. It is a pivotal moment both culturally and politically in the western world. To such an extent that when discussing security and surveillance issues, $9 / 11$ is often used as a temporal datum point where all events are by definition pre- or post-9/11. The events of that day changed many of our government's policies and the way we secure public spaces, institutional buildings and infrastructure from potential threats. This has incredible spatial implications and the cultural impacts are still prevalent in how our contemporary society functions.

\footnotetext{
${ }^{4}$ (Coulson 2009)

${ }^{5}$ (Dagenais 2013, 184)
} 
2015:

When discussing technology, one often draws comparisons with examples in science fiction. Where yet to be realized technologies are common place. These futuristic technologies can be better representations of the desires from that time period, than they are of accurate predictions of future innovation. Though, there are consistent themes that currently escape our current reach; the ability to control time, extend life, evade death, or overcome gravity. This reference is meant to be slightly tongue-incheek, but one staple archetype in science fiction is that of the flying car.

Popular-culture icons like Doc Brown's DeLorean in the final sequence of Back to the Future;

“Roads? Where we're going, we don't need roads?"6

- Dr. Emmett Brown,

This is the foundation for Part II, where in the future [2015, of course] all cars are outfitted with hover conversions. We are not on the verge of making this a reality anytime soon, nor is it suggested we should. It is also unlikely that this was a legitimate anticipation of what the year 2015 would entail.

We have all - for a moment at least - dreamt of this hypothetical and admittedly unrealistic future. But what if we simply got the archetype wrong? We now have computers and sensors that can outperform humans in many ways. The flying car trope has many downfalls, and the human pilot is at the center of it. Removing us from the

\footnotetext{
${ }^{6}$ (Fox and Lloyd 1985)
} 
equation affords some intriguing benefits. We can remain safely on the ground. The now pilotless flying car [UAV] can now be; considerably smaller, lighter, and more efficient. Of course we are not going to replace automobiles with UAVs anytime soon, but what if we could implement a virtual network of UAVs to supplement existing transportation infrastructures. We already have the technologies required in isolation, with exception of a few. Will we see our daily transportation networks expand vertically, the way our buildings have done in the past?

We are on the verge of seeing UAVs - typically referred to as drones - used domestically for civilian and commercial purposes. This is a new breed of aerial vehicle, with impressive capabilities. The technology is racing ahead of existing laws and regulations regarding controlled airspace. In the United States, the Federal Aviation Administration [FAA] has a target deadline to release preliminary regulations in 2015 to address the integration of UAVs into public airspace. ${ }^{7}$ This particular technology has many social and spatial implications; on-going discussion is needed to examine potential utility as the technology progresses.

It is also important to note that 2015 is not meant to be a literal date or year. There is a good chance that the FAA will not meet their 2015 target. $^{8}$ Changing the status quo will take time. Many new technologies are met with fierce resistance and opposition. Will the benefits provided be able to sway the tide of public opinion and those in positions of power?

\footnotetext{
${ }^{7}$ (FAA 2013)

${ }^{8}$ (Whitlock 2014)
} 
The following is a thought experiment the takes place in the near-future. How will architects and our built environment respond if UAVs become ubiquitous? There are many obstacles that need to be overcome before such acceptance is possible, but it is not without comparable precedents in our recent history.

"Any sufficiently advanced technology is indistinguishable from magic"

- $\quad$ Arthur C. Clarke $e^{9,10}$

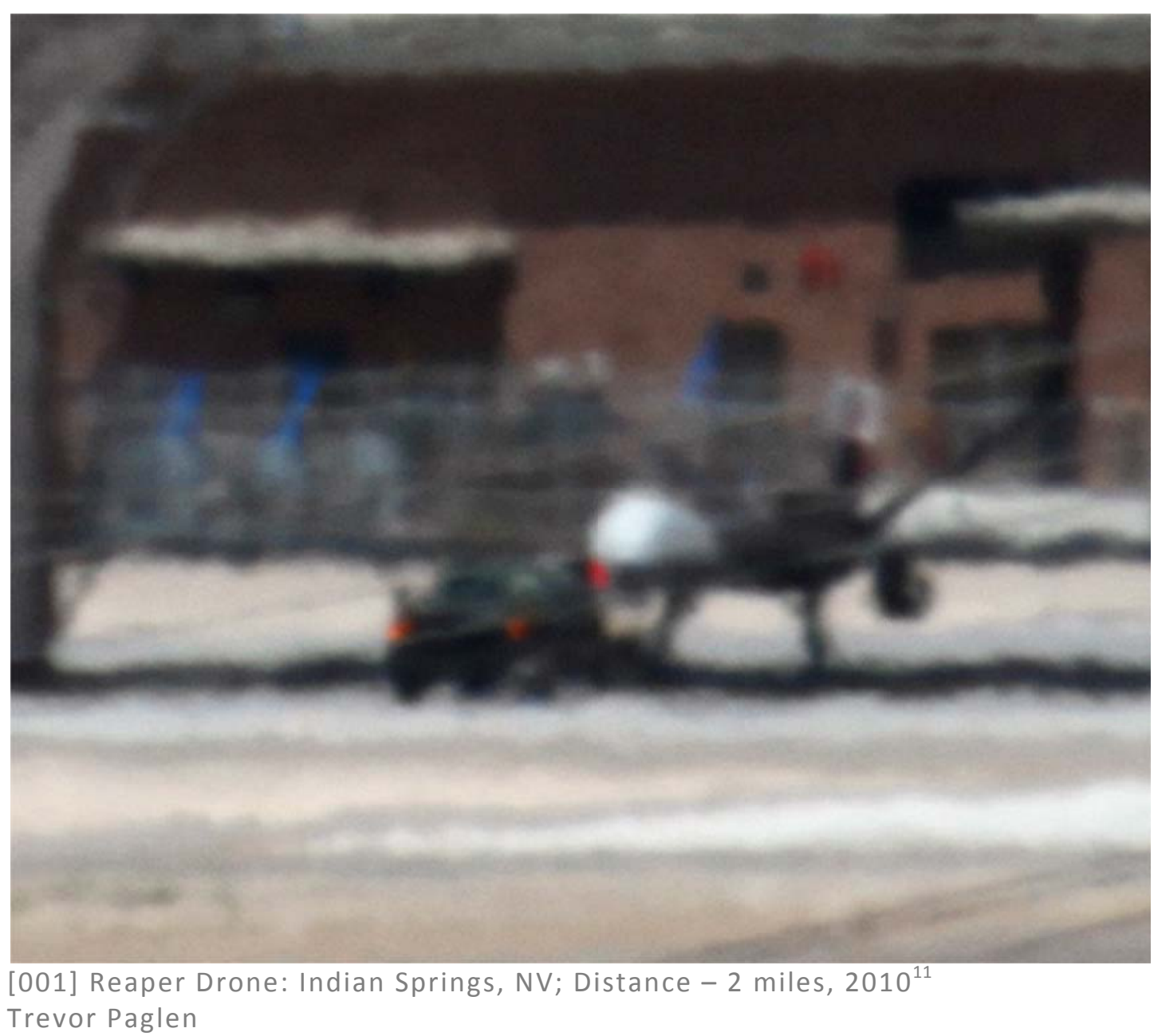

\footnotetext{
${ }^{9}$ (Clarke 1962)

${ }^{10}$ (Erik Brynjolfsson, Race Against the Machine 2011, 12)

${ }^{11}$ (Wombell 2013, 89)
} 
Technophobic or technophile, various technologies are undoubtedly deeply rooted in your daily experience and our contemporary society. As Francine Dagenais writes "We are emerging from a long era of individuality that took hold during the Renaissance ... Increasingly, we are being immersed in an era of the collective, in which a constantly interconnected hive of distributed humans is jacked into a multipartite, virtual, ubiquitous network composed of text- and voice-based devices that drive social media and the Internet, a hive."12 This level of interconnectivity and networking capabilities are unique to the $21^{\text {st }}$ century. Reaching farther than that of radio and television had done throughout the $20^{\text {th }}$ century.

Yevegeny Zamyatin's We [1924], Huxley's Brave New World [1932], Orwell's NineteenEighty-Four [1949] and Kurt Vonnegut Junior's Player Piano [1952] all depict dystopian society with repressive regimes and extreme automation that form a rift between social classes; the managers and the managed, the designers and the followers. This was a response to previous overreach of global powers, where technology became a tool of oppression. None of these authors could have anticipated the internet and the global influence it has had. An interesting dichotomy has emerged. Our dependence on digital technologies in a way enables the discrete widespread dragnet surveillance of populations; while simultaneously liberating the individual in ways never seen before.

${ }^{12}$ (Dagenais 2013, 185) 
Architect Michael Sorkin describes the dystopian literary tradition as "the most telling medium for the projective imagination of city life ... that anticipate[s] the paranoid, militarized, character of this contemporary space."13 ${ }^{13}$ Prior to the digital revolution we are currently experiencing, new building methods facilitated building higher, increasingly dense communities. Sorkin emphasizes that "The fallacy lies in the . . notion of technology's neutrality, in the idea that, if treated properly, Big Brother can be a helpful guy". ${ }^{14}$ This was in response to previous failed-attempts in Chicago and New York that result in the formation of vertical ghettos, an unintentional dystopian consequence of a modern technology. Though technologies are neutral in isolation, they rarely maintain this neutrality throughout their implementation.

\section{Digital Epoch and Moore's Law}

Paul Baran was a notable Polish-American engineer. One of two independent inventors of packet switched computer networking ${ }^{15}$ in the early 1960s, a critical development that evolved later into our current digital communication networks. In 1967, Baron wrote an essay titled The Future Computer Utility. ${ }^{16}$

\footnotetext{
"Our home computer console will be used to send and receive messages-like telegrams. We could check to see whether the local department store has the advertised sports shirt in stock in the desired color and size. We could ask when delivery would be guaranteed, if we ordered. The information would be up-to-theminute and accurate. We could pay our bills and compute our taxes via the console. We would ask questions and receive answers from 'information banks'-automated
}

\footnotetext{
${ }^{13}$ (Sorkin 2008, x)

${ }^{14}$ (Ibid, xiii)

${ }^{15}$ (Harris 2009)

${ }^{16}$ (Baran 1967)
} 
versions of today's libraries. We would obtain up-to-the-minute listing of all television and radio programs ... The computer could, itself, send a message to remind us of an impending anniversary and save us from the disastrous consequences of forgetfulness.

...

Highly sensitive personal and important business information will be stored in many of the contemplated systems ... At present, nothing more than trust - or, at best, a lack of technical sophistication - stands in the way of a would-be eavesdropper . . Today we lack the mechanisms to insure adequate safeguards. Because of the difficulty in rebuilding complex systems to incorporate safeguards at a later date, it appears desirable to anticipate these problems." ${ }^{17}$

Not only was the vast potential of these systems apparent, but so were the inherent security issues present in them. Baran envisioned how networked computing would revolutionize how we did the things we already do: research, shop, educate, and entertain ourselves. While simultaneously enabling espionage, surveillance, and voyeurism. $^{18}$

The scale of advancements made in recent decades is nearly unfathomable. There are several simplified models used to illustrate this rapid progression in technological development. One common reference model is known as Moore's Law; first proposed in an Electronics Magazine article in 1965 by Gordon Moore, the co-founder of microprocessor manufacturer Intel Corporation. ${ }^{19,20,21}$

The concept was simple, the number of transistors on a minimum-cost integrated circuit would continue to double every 2 years. ${ }^{22,23,24}$ The timeline varies depending on

\footnotetext{
${ }^{17}$ (Baran 1967, 78)

18 (Morozov, The Real Privacy Problem 2013)

${ }^{19}$ (Moore n.d.)

${ }^{20}$ (SciShow 2014)

${ }^{21}$ (Erik Brynjolfsson, Race Against the Machine 2011, 18)

${ }^{22}$ (Moore n.d.)

${ }^{23}$ (SciShow 2014)

${ }^{24}$ (Intel Corporation 2012)
} 
the source and how the doubling is measured - sometimes as rapid as 12 or 18 months. ${ }^{25}$ This law remained true for the next 40 years. Integrated circuits had roughly 2,300 transistors in 1972 and over 300 million by $2006 .^{26}$ The exact timeline is less important that the notion that this doubling has occurred both quickly and reliably in the past. ${ }^{27}$ Peter Singer is a drone and robotics expert at the Brookings Institute; postulates that if this trend continues, within 25 years available technology will be 1 billion times more powerful than it is today. ${ }^{28}$ An optimistic view of never ending exponential growth, but is this level of progression able to sustain itself?

At present, we are beginning to witness a plateau when it comes to the original definition of Moore's Law. ${ }^{29}$ The $3^{\text {rd }}$ Generation Intel ${ }^{\circledR}$ Core $^{\mathrm{TM}}$ processor [2012] has 1.4 billion transistors with only $22 \mathrm{~nm}$ separating each. ${ }^{30}$ A nanometer [nm] is on billionth of a meter. There are two major obstacles to overcome if this trend is to continue. The first is dissipating the heat generated by these hyper efficient chips. The second and more problematic is the implication of quantum mechanics. We are nearing a limitation on a molecular scale. If the transistors get any smaller or closer together, a few stray atoms could ruin a chip. If we continue to build with smaller thresholds, quantum tunneling begins to enter the equation. This is when electrons could leap across the

\footnotetext{
${ }^{25}$ (Erik Brynjolfsson, Race Against the Machine 2011, 18)

${ }^{26}$ (SciShow 2014)

27 (Erik Brynjolfsson, Race Against the Machine 2011, 18)

${ }^{28}$ (Rise of the Drones 2012)

${ }^{29}$ (SciShow 2014)

${ }^{30}$ (Intel Corporation 2012)
} 
switches gap [a transistor is essentially an incredibly small electrical switch] resulting in corrupted data sets, making chips simultaneously unreliable and more expensive. ${ }^{31}$

Fortunately there are many variations of Moore's Law that can help compensate for this possible plateau. Erik Brynjolfsson and Andrew McAfee, co-authors of both Race Against the Machine and The Second Machine Age note that software is also progressing at a similar rate;

\begin{abstract}
"Computer scientist Martin Grötschel analyzed the speed with which a standard optimization problem could be solved by computers over the period 1988-2003. He documented a 43 million fold improvement, which he broke down into two factors; faster processors and better algorithms embedded in software. Processor speeds improved by a factor 1,000 , but these gains were dwarfed by the algorithms, which got 43,000 times better over the same period. ${ }^{\prime 32}$
\end{abstract}

The astounding number of processes capable by modern computers is so large that they generally escape our comprehension, they become abstractions of themselves. To help visualize the entirety of the information currently at our fingertips via the internet; Randall Munroe [author of 'What If?'] is dedicated to illustrating "serious scientific answers to absurd hypothetical questions." ${ }^{33}$ Munroe calculates the approximate number of punch cards [used before integrated circuits] required to store all the information stored in Google's data centers globally, an estimated 15 Exabytes $[15,000,000,000,000,000,000$ bytes $]$ of information. The result is astounding. This many punch cards would cover the entirety of New England [slightly less than $200,000 \mathrm{~km}^{2}$ ] with a depth of $4.5 \mathrm{~km}$. During the last ice-age, the glacier in that region was only $1 / 3$

\footnotetext{
${ }^{31}$ (SciShow 2014)

32 (Erik Brynjolfsson, Race Against the Machine 2011, 18)

${ }^{33}$ (Munroe, What If? 2012-2014)
} 
that height. ${ }^{34}$ Our digital technologies have allowed civilization to progress to levels far beyond what was previously theorized.

The second relevant concept for understanding the power of Moore's Law goes beyond the gargantuan amount of processes modern computers can perform; it is the non-linear pace at which we experience these changes, defying our linear collective instincts. ${ }^{35}$ Brynjolfsson and McAfee reference controversial futurist and transhumanist Ray Kurzweil for the following mathematical anecdote. Regardless if you agree with Kurzweil's unconventional visions of the future, he has an intriguing track record as an inventor that is worth mentioning. He is responsible for "the first CCD flatbed scanner, the first omni-font optical character recognition . . . the first text-to-speech synthesizer, and the first commercially marketed large-vocabulary speech recognition" ${ }^{36}$ among others. Many of which are technologies we now take for granted and that were unimaginable prior to being realized. Recently, Google appointed Kurzweil as their Director of Engineering in 2012. ${ }^{37}$ With that said, the anecdote is not as controversial as the man who originally presents it in his book The Age of Spiritual Machines: When Computers Exceed Human Intelligence. It is a simplified demonstration of how our linear expectations can be fooled by a constant doubling mechanism, an example of exponential growth.

\footnotetext{
${ }^{34}$ (Munroe, Google's Datacenters on Punch Cards 2012-2014)

35 (Erik Brynjolfsson, Race Against the Machine 2011, 18-19)

${ }^{36}$ (Kurzweil Accelerating Intelligence 2014)

${ }^{37}$ (Ibid)
} 
In this legend, a king or emperor is introduced to the game of chess by its inventor. He is so pleased with the game that he allows the inventor to name his reward for such a creation. The inventor proposes to be paid in grains of rice. The amount of grains determined numerically by placing a single grain on the first square of the chess board; then two grains on the second and four grains on the third and so on. Each following square requiring double the quantity of rice as the previous square. The king agrees to the terms before realizing the sum of the final payment. A chess board has 64 tiles. The total grains of rice would equal $2^{64}-1$, a number so enormous that the king would need a pile of rice the size of Mount Everest to honour the terms reached. ${ }^{38}$

"Exponential growth confounds our intuition and expectations. It accelerates far past linear growth, yielding Everest-sized piles of rice and computers that can accomplish previously impossible tasks." ${ }^{39}$

- Erik Brynjolfsson and Andrew McAfee

Kevin Kelly is another digital visionary in the tech field, currently the Executive Editor of Wired had this to say during a 2007 lecture titled the next 5,000 days of the web;

"First lesson of the web: [We] have to get better in believing the impossible because we are unprepared for it." ${ }^{40}$

The internet as we knew it in 2007 was less than 5,000 days old. The lecture was about how the World Wide Web demonstrated that things - at the time - impossible in theory,

\footnotetext{
${ }^{38}$ (Erik Brynjolfsson, Race Against the Machine 2011, 18-19) original source: (Kurzweil 2000)

${ }^{39}$ (Ibid, 19)

${ }^{40}$ (Kelly 2007)
} 
were in fact possible in practice, citing the Internet and Wikipedia as successful examples. $^{41}$

Cautious-optimism is required when dealing with the coming unknown. There are good reasons to be skeptical moving forward. As deeply integrated as the Internet is now, there are vulnerabilities that if left unchecked could threaten the system in its entirety. Dr. Markus Jakobsson is a computer security researcher, Principal Scientist of Consumer Security for PayPal and author of the Death of the Internet. Generally the internet is perceived to provide a net-benefit for a given population. The unfettered access to information previously inaccessible is incredibly beneficial. Less often discussed publicly are the dark sides to the internet that many are not fully aware of.

INTERPOL acknowledges that "Cybercrime is a fast-growing area of crime. More and more criminals are exploiting the speed, convenience and anonymity of the Internet to commit a diverse range of criminal activities that know no borders, either physical or virtual." ${ }^{\prime 2}$ The cost to the global economy is estimated to be between $\$ 375-575$ billion annually. ${ }^{43}$ Even the most conservative of estimates is still larger than many countries national income. ${ }^{44}$ Companies and governments can underestimate the risks they face and how fast those risks can quickly grow.

Jakobsson discusses the paradoxical nature of encryption. As it helps you fend off attacks, it is also aiding criminal activities by avoiding detection. An example comes in

\footnotetext{
${ }^{41}$ (Kelly 2007)

42 (INTERPOL 2014)

${ }^{43}$ (Center for Strategic and International Studies 2014)

${ }^{44}$ (Ibid)
} 
the form of ransomeware. An attack that steals vital or sensitive data, encrypts those files on infected computers and offers a decryption key for a price. ${ }^{45}$ In essence, digital terrorism is easily committed and we are all vulnerable to such attacks. ${ }^{46}$ Sever enough attack have the potential to send shockwaves throughout society. ${ }^{47}$

"Computer scientists often mistakenly believe that computer security is all about computers. It is not. It is often also about computers being used - and misused - by humans. If we do not understand the true nature of a problem - or ignore the human aspect of it - then we are unlikely to be able to develop meaningful countermeasures." ${ }^{\prime 4}$

- Markus Jakobsson

"One begins to think differently about tools when one notices that the tools include persons as functioning parts" according to Langdon Winner. ${ }^{49}$ Humans are often the weakest link when it comes to securing our technologies. For this reason, the proliferation of the Smartphone globally, exacerbates the problem. By the end of 2012 the global population surpassed 7 billion, with the mobile subscriber base approaching 4.8 billion. $^{50}$ Granted only a percentage of these subscribers will have internet-enabled mobile devices; we have demanding expectations of functionality and performance.

\footnotetext{
"So smartphones are not just phones. But at the same time, they are not just small computers that are used to make calls. They have limited battery resources, which makes some software - and security software in particular - potentially unsuitable." ${ }^{51}$
}

- Markus Jakobsson

\footnotetext{
45 (Jakobsson 2012, 186)

46 (Ibid, 5)

47 (Ibid, 4)

48 (Ibid, 7)

49 (Wombell 2013, 13) original source: (Winner 177, 202)

50 (Jakobsson 2012, 187)

${ }^{51}$ (Ibid, 169)
} 
Leaving us vulnerable and unaware of the threats we face without certain safeguards in place.

Markus Jakobsson is not a lone technological skeptic on these issues. An outspoken figure in the tech industry is Evgeny Morozov ${ }^{52}$ author the Net Delusion: The Dark Side of Internet Freedom ${ }^{53}$ and To Save Everything, Click Here: The Folly of Technological Solutionism..$^{54}$

"Depending on whom you ask, Evgeny Morozov is either the most astute, feared, loathed, or useless writer about digital technology working today. ${ }^{\prime 55}$

- Michael Meyer [Columbia Journalism Review]

Meyer continues "Neither technophile nor technophobe, he's frequently described as "Silicon Valley's fiercest critic." But like the rest of us, he checks his late-model iPhone during pauses in conversation." ${ }^{56}$ Morozov claims his work is really an attempt to integrate technology into the broader discussions we have surrounding economics, politics and culture. ${ }^{57}$ Often technology is presented in black or white terms and in isolation. On opposing ends of the spectrum are the marketers promoting a new technology, and on the other is the fear mongering of those resistant to change. Reality is rarely if ever this polarized, the debate needs to continue between these opposing ideologies. An example would be companies like Uber that transform a city's taxi service. When discussed purely in digital terms; it makes perfect sense. But when you

\footnotetext{
${ }^{52}$ (Morozov, Personal Web Site 2013)

53 (Morozov, The Net Delusion: The Dark Side of Internet Freedom 2011)

54 (Morozov, To Save Everything, Click Here: The Folly of Technological Solutionism 2014)

55 (Meyer 2014)

56 (Ibid)

57 (Ibid)
} 
analyze this scenario in a broader context, it is complicated by the lack regulations and the rights of licensed cab drivers. ${ }^{58}$ This doesn't even hit on the topic of driverless cars that we will discuss in a later section. There are countless examples that demonstrate the virtues of each side of the argument. Clearly they both can't be right.

Big Data is a term used broadly to describe vast collection of extremely large data sets for the purpose of analysis. This data is generated online, or by the many devices we interact with on a daily basis. Big data analytics reveals patterns that can be used to create efficiencies previously beyond our perception. Crowdsourcing GPS data from mobile phones allows the monitoring and prediction of traffic patterns, but this data could also determine how fast an individual is traveling and track their destinations. ${ }^{59}$ When viewed at different scales, the information appears incredibly useful or invasive. Morozov writes "You think about Big Pharma, Big Oil . . . The mere fact that we use the term 'big' to talk about them means we've figured out that they probably have [self] interests that diverge from those of the public. Nobody uses the term 'big data' in that sense [currently]" ${ }^{60}$

"Too little privacy can endanger democracy. But so can too much privacy."161

- Evgeny Morozov [MIT Technology Review]

Hindsight is always 20-20. This is especially true when dealing with groundbreaking technological innovations. It is impossible to accurately predict the overall impact such

\footnotetext{
58 (Meyer 2014)

59 (Greene 2008)

${ }^{60}$ (Meyer 2014)

${ }^{61}$ (Morozov, The Real Privacy Problem 2013)
} 
manifestations have on society. The technology often out paces the laws and regulations; this allows unchallenged overreach that is difficult to rein in after inception. Morozov describes his desire to "erase the decade we lost and return to the utopia of the 1980 s and 1990 s by passing stricter laws, giving users more control, and building better encryption tools!" Back to the digital utopia; present prior to the colonization of the pristine digital landscape by Google, Facebook, and before the vast acceleration of NSA surveillance post-9/11. ${ }^{62}$

These issues will be impossible to fully resolve, but the debate needs to expand. We cannot continue to analysis technology in a vacuum. The implications can be wide spread throughout any and all aspect of our lives. The concern is that "This is the future we are sleepwalking into. Everything seems to work, and things might even be getting better-it's just that we don't know exactly why or how." ${ }^{63}$ These technologies will continue to develop, but it is an open question if our forethought, regulations, safeguards can keep up.

\footnotetext{
62 (Morozov, The Real Privacy Problem 2013)

${ }^{63}$ (Ibid)
} 


\title{
Surveillance
}

\begin{abstract}
"Some villagers in Sikhim betrayed a lively horror and hid away whenever the lens of a camera, or "the evil eye of the box" as they called it, was turned on them. They thought it took away their souls with their pictures, and so put it in the power of the owner of the pictures to cast spells on them, and they alleged that the photograph of the scenery blighted the landscape." ${ }^{\prime 64}$
\end{abstract}

- $\quad$ L.A. Waddell, 1899

The principals of the camera obscura have been known for millennia, but the feat of freezing and retaining the optically projected image wasn't resolved until 1826 by Nicéphore Niépce [1765-1833]. ${ }^{65}$ The French inventor's eight-hour exposure of an image was preserved on a sheet of pewter, coated with bitumen and lavender oil. ${ }^{66}$ Photography was born, and debate continues today - nearly 200 years later - about its role and place within society. The ability to seemingly freeze time in place has far reaching implications. The ability to record, document and disseminate images has truly changed the world, only compounded by the ability to distribute these images instantaneously on a global scale via the World Wide Web.

The camera is more than simply an extension of human sight; into places where we cannot travel due to distance, danger or time. ${ }^{67}$ It forms a new relationship between the photographer and everything caught by the gaze of the cameras lens. This voyeuristic relationship can now be exploited, creating a certain control over the subject. This is at its core, the nature of surveillance. Perhaps this control is what the villagers in Sikhim were acutely aware of; the profound relationship between humans

\footnotetext{
${ }^{64}$ (Wombell 2013, 13) original source: (Waddell 1899, 85)

65 (Legrady 2013, 209)

${ }^{66}$ (Ibid, 209)

${ }^{67}$ (Wombell 2013, 27)
} 
and technology. ${ }^{68}$ As Paul Wombell concludes in his essay entitle Black Box "the camera might be our friend, but it might also be our enemy and have hostile intent.." ${ }^{19}$

Surveillance and Big Brother are loaded terms that take on many forms. ${ }^{70}$ This phenomenon has manifested itself physically in Architecture, long before the invention of photography in many ways. None demonstrated with greater clarity than that of Jeremy Bentham's Panopticon [fig002], a revolutionary design for the modern prison.

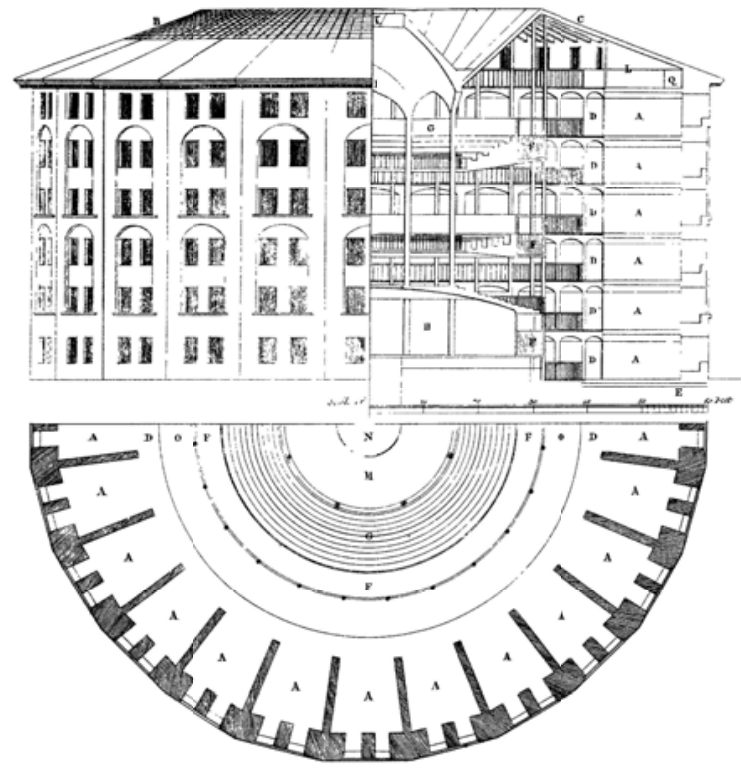

[002] Plan of the Panopticon, $1791^{71}$ Jeremy Bentham

Michel Foucault founded what has become perhaps the central metaphor for contemporary dystopian space in Discipline and Punish. Jeremy Benthams's Panopticon has become a resonating symbol for the contemporary surveillance systems that "leave

\footnotetext{
${ }^{68}$ (Wombell 2013, 27)

69 (Ibid, 27)

${ }^{70}$ (Katja Franko Aas 2009, 4)

${ }^{71}$ (Foucault 1977, Plate 3) original source: (Bentham 1843, 172-173)
} 
no corner of earth unseen and the mental life that they produce." 72 The plan was elegant, efficient and purely functional. A ring of individual prison cells radiating around a central observation tower at its core. ${ }^{73,74}$ Without any corners, hallways or walls, there was nowhere for the prisoners to hide. The prisoners had to live under constant supervision by authorities, or did they?

"The genius of the panoptic scheme lay less in the efficient supervisory geometry than in [the] invisibility of the eyes at its center. Once the prisoners had been inculcated with the idea of their perpetual exposure, the prison could function even when the guard was absent. Persuaded that there was no escape from the gaze of authority, prisoners internalized the means of their own repression and behaved as if they were being watched, even without any concrete evidence that they were." ${ }^{\prime 75}$

- Michael Sorkin

The layout allowed the central tower to be enclosed in glass, the interior darkened to cloak the guard's whereabouts. Unable to determine if and where the guards were on post. The design disconnects the physical presence of guards from the act of being directly surveilled; enabling fewer guards to monitor larger inmate populations within the system. The belief that you might be under the watch of the guards was enough to subconsciously impose a level of self-discipline, making the inmates active components in their own supervision. ${ }^{76}$

Canada's oldest prison, Kingston Penitentiary is a variation of the panoptic configuration. $^{77}$ Four cell-blocks - or wings - radiate outwards from a central lobby.

\footnotetext{
${ }^{72}$ (Sorkin 2008, xi)

73 (Foucault 1977)

74 (Lyon, Bentham's Panopticon: From Moral Architecture to Electronic Surveillance 2006, 13)

${ }^{75}$ (Sorkin 2008, xi)

${ }^{76}$ (Lyon, Bentham's Panopticon: From Moral Architecture to Electronic Surveillance 2006, 16)

${ }^{77}$ (Ibid, 14)
} 
Though the guards cannot see into each cell individually, they can see down each wing allowing the monitoring of even larger inmate populations in a single institution.

The brilliance of Foucault was positioning the Panopticon at the historical precipice between modern era and all that came before it. ${ }^{78}$ For Foucault, the modern prison was the equivalent of the factory for Karl Marx as the epitome of modernity. ${ }^{79}$ Prior to this passive alteration of behaviour, it was common place to assault, torture and execute criminals. The past system was vengeful and not designed to rehabilitate those incarcerated.

"Thus, at a stroke, it dispensed with the straightjacket in the asylum, the shackles in the prison, and the personal tyranny of the workhouse master. The Panopticon was an impersonal, automatic machine, appropriate to modernity." 80

David Lyon

Soon after the successes of the Panopticon were proven, many institutions began to implement similar principles. Schools, factories, and hospitals were among those that adopted these new architectural ideals. ${ }^{81}$

The effectiveness of the Panopticon was fundamental in the formation of what many describe as moral architecture. David Lyon directs the Surveillance Studies Centre and is a professor of sociology and law at Queen's University in Kingston, Ontario. Lyon has written extensively about surveillance and how we've moved past the panoptic model. The advancements in contemporary surveillance systems like closed circuit television

\footnotetext{
${ }^{78}$ (Lyon, Bentham's Panopticon: From Moral Architecture to Electronic Surveillance 2006, 21)

79 (Ibid, 21)

80 (Ibid, 21)

${ }^{81}$ (Ibid, 14)
} 
cameras [CCTV] and motion activated digital recording systems extend the reach of the panoptic scenario without the rigid limitation of the architectural form.

How does this voyeuristic relationship change when expanded beyond the walls of the prison and into the public realm? What if the voyeur is no longer human, but machine instead? The streets of London in the United Kingdom have been the central focus of this discussion about big brother for several decades now, due to the wide spread installation of CCTV monitoring.

It is important to note a possible reason for initial [not immediate] acceptance of CCTV cameras in the late 80 s and early 90 s, prior to the digitization of these systems. ${ }^{82}$ In the age of magnetic tapes and film, an interesting paradox was developing. Similar to the altering of a prisoner's behaviour, through passive coercion; they were marketed as crime deterrents in public space, by recording the culprits in the event of a crime. ${ }^{83,84}$ Conversely the proliferation of the then semi-analog system meant the creation of far too much data, more than could be realistically sifted through. The resulting utility was limited to reacting to a crime, rather than the intended pre-emptive deterrent of crime. This was a common revelation at the time. The following is a quote from David Lyon in 1994 highlighting this scenario;

"Claims of technological takeover such as these rely upon a curious denial of human agency, attention to which requires us to consider other casual factors that may render it altogether less powerful than at first appears. The terrifying technological possibility of total surveillance, promised for example by CCTV, may be undermined by the less

\footnotetext{
${ }^{82}$ (N. Taylor 2006, 175)

83 (Ibid, 175)

${ }^{84}$ (Katja Franko Aas 2009, 3)
} 
exciting actuality that no one is watching or, at least, that no one is watching all the time" ${ }^{\prime \prime 5}$

This sentiment predates the vast improvements and impact the internet has had. Long before the evolution of cloud-computing and massive digital storage capabilities. The paradox is not rendered obsolete with these innovations; opinions are instead both reinforced and polarized. ${ }^{86}$ We now can record and store exponentially more information, but also have the capability to access virtually all of it instantaneously. With the aid of digital algorithmic tools - like facial recognition - we can filter massive quantities of this information in real-time without an army of human eyes performing the analysis. The ease of access to the digital camera has assisted what Lyon later describes as the transition from moral architecture to unfettered electronic surveillance. ${ }^{87}$

These forms of optical surveillance, in the form of video monitoring represent the emergence of technologies of [in]security. This technology represents a loss of trust in the general population, no one is beyond suspicion. ${ }^{88}$ Producing a paradoxical relationship, where the untrusting state requests that the public trust in them, as they expand the surveillance apparatus. ${ }^{89}$

"Conformity and uniformity may increase - squashing diversity, innovation, and vitality."

- Gary T. Marx

\footnotetext{
${ }^{85}$ (Katja Franko Aas 2009, 259) original source: (Lyon, The Electric Eye 1994)

${ }^{86}$ (Katja Franko Aas 2009, 3)

87 (Lyon, Bentham's Panopticon: From Moral Architecture to Electronic Surveillance 2006, 15)

88 (Katja Franko Aas 2009, 11)

89 (Ibid, 11)

${ }^{90}$ (Marx 2006, 10)
} 
Beyond the gaze of CCTV and optical surveillance systems, we now have technologies that can detect and surveil beyond line-of-sight on a nearly global scale. Technologies like GPS [global positioning systems] and later GSM [Global System for Mobile communications] are geolocation systems originally developed by the US military to gain strategic advantages during the cold war. ${ }^{91}$ These were quickly adapted to improve the safety and efficiency of our commercial air and marine traffic systems. ${ }^{92}$ The successes of GPS prompted the expansion of its use into other fields. Monitoring criminal's locations on probation was now possible; eventually evolving into the GPS enabled devices we all now have in our cars, computers and phones that provide maps and directions in unfamiliar territory. Though not yet perfect, there is theoretically no hiding within such a global system. Previously we could relocate beyond the field of view of the camera; now the objects we use [cars, computers, and phones] have become the tools of surveillance..$^{93}$

Our attitudes are changing concerning these various forms of technologies as they become normalized. We know that there is often potential for over reach by those with access to the data, but there is a disconnect within our perception of the act of surveillance. Similar to the tower in the Panopticon, the voyeur is watching remotely, out of sight. Electronic forms of surveillance reproduce many of Foucault's criteria for Bantheamite Panopticism. ${ }^{94}$ The presence of the voyeur - digital or human - is both

\footnotetext{
${ }^{91}$ (Nellis 2009, 107)

92 (Ibid, 107)

${ }^{93}$ (Ibid, 107)

${ }^{94}$ (Lyon, Bentham's Panopticon: From Moral Architecture to Electronic Surveillance 2006, 26)
} 
invisible and unverifiable; David Lyon poses the question "Is this the Panopticon, electronically recycled" ${ }^{\prime 95}$ or is it something else entirely?

25 years ago [1989] Tim Berners-Lee essentially invented the World Wide Web. The growth of global access to the Web is astounding. Only $5 \%$ of the global population was online in the year $2000,17 \%$ by 2007 and current estimates hover around $40 \%$ globally today in 2014. ${ }^{96}$ Today, the tremendous technical power of computers and telecommunications is used to process and analyse personal data on a scale undreamed of by Bentham and Foucault. ${ }^{97}$ Police can run instant checks on people. Every time you purchase with a credit card, or visit the doctor your personal data is stored, accessed and updated in these virtual information banks. ${ }^{98}$ We leave personalized data-trails everywhere we go.

This is changing the role of the Guard in the Panopticon's Tower from one of authority, to that of a marketer. Immense power is now in the hands of organizations outside of the government. Private corporations are now able to perform analysis via Big Data to predict trends and track spending habits. It begins as targeted, personalized emails and advertisements, but can balloon into what many in the tech industry describe as filterbubbles. The creation of a digital isolation based on previously tracked activity;

“Granted, consumer 'choices' are often a commercially-engineered mirage, and granted, our preferences have been unwittingly disclosed to marketers to a discomforting degree [that is, discomforting when we know it]; nonetheless, the social order of consumer

\footnotetext{
95 (Lyon, Bentham's Panopticon: From Moral Architecture to Electronic Surveillance 2006, 26)

96 (Berners-Lee 2014)

${ }^{97}$ (Lyon, Bentham's Panopticon: From Moral Architecture to Electronic Surveillance 2006, 26)

98 (Ibid, 26)
} 
society is not carceral in the sense that the Panopticon was. Today we are seduced into conformity, not coerced into compliance." ${ }^{99}$

- David Lyon

Theses virtual forms of surveillance are particularly problematic to address because there is no tangible or material solution to curb their spread. Only regulation, legislation and consumer countermeasures can be taken to avoid and restrict their use. Due to this, there is limited impact on our built environment when compared to the affect they have on our behaviour.

Photographic technologies remain central to this debate. It is nearly impossible to buy a mobile phone, tablet or laptop that does not have an imbedded camera. This has lead to an interesting reversal in the way public space is monitored. The small size and sheer number of cameras in people's possession has democratized surveillance. The notions of 'top-down' hierarchies of surveillance are breaking down, as is the binary moral opposition between good and bad, the public and the authorities. ${ }^{100}$ The current reality provides no assurances of privacy in the public realm as nearly anyone, anywhere has the ability to record you activities.

Google Street View ${ }^{101}$ is a recent example that raises concerns around the issue of privacy in public. Since its launch in 2007, Street View has been the focus of much controversy. ${ }^{102}$ Google has a fleet of vehicles roaming the earth with roof mounted cameras. Taking full $360^{\circ}$ panoramic images tagged with geospatial data that reference

\footnotetext{
${ }^{99}$ (Lyon, Bentham's Panopticon: From Moral Architecture to Electronic Surveillance 2006, 29)

${ }^{100}$ (Katja Franko Aas 2009, 5)

101 (Google 2014)

102 (Miles 2013, 174)
} 
where the photos were taken. These can then be embedded into other platforms like Google Maps ${ }^{103}$ and Google Earth. ${ }^{104}$ Allowing anyone to virtually inhabit and navigate through the streets remotely.

Melissa Miles is an art historian that has written extensively about photography and its historical entanglement with privacy in public. As part to the Peter Wombell's 20143 exhibit Drone: the Automated Image, she wrote an essay titled Privacy in Google Street: Webcams, Street View, and the Transformation of Photography and Privacy in Public highlighting many of these concerns.

Google Street View has been met with some resistance. In 2009, concerned residents of Broughton, a village in Buckinghamshire, United Kingdom blocked the Google Street View vehicle from entering their town. ${ }^{105}$ The residents of the town were concern about the possible invasion of privacy that could occur. This reaction in the UK is quite odd, where an estimated 1.85 million CCTV cameras watch over the streets and public spaces every day. ${ }^{106}$ Similarly, the small private gated community of North Oaks, Minnesota successfully banned Street View on the grounds of trespassing; as a result the town was subsequently erased from the application altogether in $2008 .^{107}$

Photography has long traversed the perceived boundary between the public and private realms. ${ }^{108}$ There is a growing trend in the US where private property rights are

\footnotetext{
103 (Google 2014)

104 (Ibid)

105 (Miles 2013, 174) original source: (Ahmed 2009)

106 (Miles 2013, 175) original source: (Lewis 2011)

107 (Miles 2013, 177)

108 (Ibid, 175)
} 
conflated with the definition of personal privacy as "the right to be left alone". ${ }^{109,110}$ Google's response to these claims are that Street View "is no different from what you might see driving or walking down the street". ${ }^{111}$ Google has made some modification to ease concerns, by enabling requests to blur out private property if desired. Software also automatically blurs people's faces and licence plates on vehicles prior to publication. $^{112}$

"If we stop struggling to fix photography's fraught relationship with privacy and acknowledge that privacy is intimately tied to the construction of certain social norms and values, debate can be shifted away from specific technologies and toward the deeper social and cultural anxieties that lie at the heart of these controversies." 113

- Melissa Miles

Privacy is a very complex set of ideas and expectations that may differ between cultural contexts. It is interesting that tensions around public photography and surveillance continue to rise; even in an era where people frequently upload photos to social media platforms, sharing "the most intimate parts of their lives."114

\footnotetext{
109 (Miles 2013, 176) original source: (Warren and Brandeis 1890, 193)

110 (Miles 2013, 176)

111 (Miles 2013, 177-178) original source: (Google 2013)

112 (Miles 2013)

113 (Ibid, 181-182)

${ }^{114}$ (Ibid, 180-181)
} 
At 8:45 a.m. on the $11^{\text {th }}$ of September 2001 an American Airlines Boeing 767 crashed into the north tower of the World Trade Centers in New York City. ${ }^{115}$ Initially thought to be a freak accident, but only 18 minutes later a second Boeing 767-United Airlines 175 crashed into the $60^{\text {th }}$ floor of the south tower. ${ }^{116}$ The events of that day are still fresh in our collective minds. The horrific images broadcast live around the world, with a bewildered audience unable to fathom the lasting impact of the events they were witness to.

These attacks were - in part - justification for governments worldwide to redesign policies regarding public and national security. The result was a global boost to the current surveillance apparatus, and the creation of entirely new programs of surveillance. Horrific tragedies and attacks on governments or civilian populations have happened countless times before. But it was our newly available multi-media technologies that amplified the impact on a global scale.

As our technologies progress, we face new threats that were previously unimaginable. We are tasked with simultaneously developing new methods to detect and prevent such threats. Mitigating the risks we face regardless if there is any imminent danger, as falling very far behind could have catastrophic repercussions. We already rely heavily on digital technologies to manage critical systems. How are emerging technologies

\footnotetext{
${ }^{115}$ (A\&E Television Networks, LLC 2014)

${ }^{116}$ (Ibid)
} 
going to be integrated into society? How can we possibly all benefit? What unforeseen threats will we face?

\section{Post-9/11}

"Now, I am become Death, the destroyer of worlds."117,118,i

-J. Robert Oppenheimer

We do not have to look very far into our past to find an example of new technology having a tragic impact on civilization. On the $16^{\text {th }}$ of July 1945, the 20 kiloton Trinity device detonated in the New Mexico desert. It was the first successful test of a nuclear weapon. Oppenheimer later famously recalled thinking of the above passage from the Hindu text Bhagavad Gita immediately after seeing the first explosion. ${ }^{119}$ Oppenheimer was one of the chief scientists that oversaw the development of the United States nuclear program.

This monumental technological achievement was a critical stepping stone towards the deployment of nuclear weapons by the United States over Japan. Exactly 3 weeks later on the $6^{\text {th }}$ of August 1945 the Enola Gay dropped a bomb codenamed Little Boy over Hiroshima, Japan. ${ }^{120,121} 3$ days later the second bomb - Fat Man - was dropped over Nagasaki on the 9th of August. ${ }^{122,123}$ A combined estimate of over 150,000 people were

\footnotetext{
117 (Hijiya 2000)

${ }^{118}$ (Oppenheimer 1980)

119 (Hijiya 2000)

120 (The Manhattan Project Heritage Preservation Association, Inc. 2005)

${ }^{121}$ (Campbell 2005)

122 (The Manhattan Project Heritage Preservation Association, Inc. 2005)
} 
killed by the bombs and resulting fires, not to mention the countless deaths that would result due to exposure to radiation. ${ }^{124}$

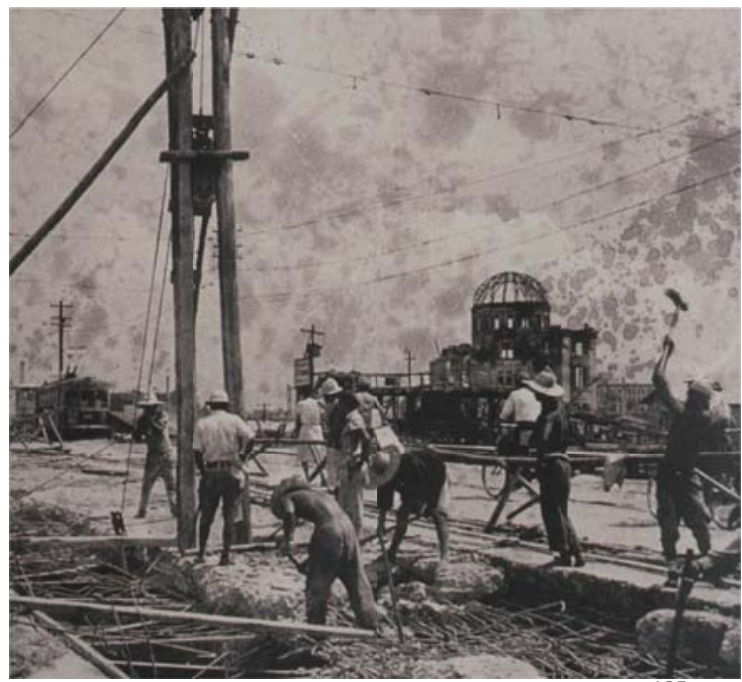

[003] Recovery at Ground Zero, $1945^{125}$

Photo by: Atsushi Shimokobe

Hiroshima, Japan

"Until recently, our species did not have the ability to destroy itself. Today it does. What's more, that power will reach the hands of more and more individuals as technologies become both more powerful and cheaper - and thus more ubiquitous. Not all of those individuals will be both sane and well intentioned."

- Erik Brynjolfsson

We will continue to have fears and concerns surrounding possible catastrophic events, genuine existential threats and other unintended side effects as technologies evolve. ${ }^{127}$ Is our ability to detect and counteract these destructive uses of technology going to advance rapidly enough to ensure our safety? ${ }^{128}$

\footnotetext{
${ }^{123}$ (Campbell 2005, 32)

${ }^{124}$ (The Manhattan Project Heritage Preservation Association, Inc. 2005)

${ }^{125}$ (Koolhaas and Obrist, Project Japan: Metabolism Talks... 2011, 642)

${ }^{126}$ (Erik Brynjolfsson, The Second Machine Age 2014, 253)

${ }^{127}$ (Ibid, 252)

${ }^{128}$ (Ibid, 253)
} 
The death toll on 9/11 pales in comparison to that of Japan nearly 70 years ago. Why has this event had such a lasting impact on contemporary society other than its proximity to the present day? Perhaps because it was an act outside the context of a traditional war, or the full color images broadcast globally in nearly real-time. It made everyone feel vulnerable, like we were all targets. Worst of all the attacks were relatively low-tech, exploiting weaknesses in current systems to achieve their objective.

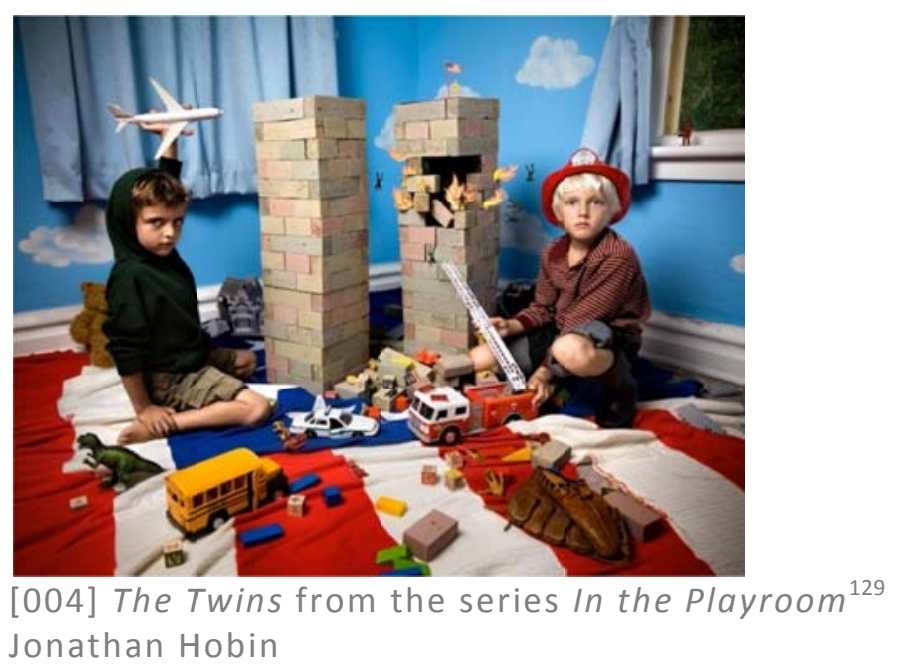

Fear is promoted by creating suspicion in the ordinary objects and activities within society. Daniel Neyland describes several examples in his essay Mundane Terror and the Threat of Everyday Objects. Neyland explains that "Getting on a bus or train in London, walking past a rubbish bin or working in a tall office tower have quite rapidly become matters of concern." ${ }^{130}$ Letter-bombings orchestrated by the IRA [Irish Republican Army] made those in the UK fearful of their own mailbox, ${ }^{131}$ much like the FLQ [Front de libération du Québec/Quebec Liberation Front] did in Canada during the late 1960's.

\footnotetext{
${ }^{129}$ (Casey and Hobin 2013)

130 (Neyland 2009, 21)

${ }^{131}$ (Ibid, 21)
} 
Ordinary objects were subsequently brought under suspicion; luggage, backpacks, cars, vans and even water bottles have since been called into question. ${ }^{132}$

Post-9/11 we have seen a dramatic surge in surveillance technologies, exacerbated by our recent ability to make these devices and systems smaller and more powerful. ${ }^{133}$ Security checkpoints permeate our built environment. From schools and libraries to prisons, from courthouses to border posts, all these checkpoints filter the traffic through them. ${ }^{134}$ Even with all of these systems in place, is it possible to rely on them to quell our insecurities? ${ }^{135}$

Beyond the surveillance technologies we also began to see the raise of what Trevor Boddy calls Passive-Aggressive Urban Design, ${ }^{136}$ defensive architectures that scatter the urban landscape; blast barriers, public set-backs, cameras, police dogs, even drones and satellites monitoring overhead. ${ }^{137}$

The United States Embassy in Ottawa by David Childs is a prime example of this new defensive mentality. Fears sparked long before $9 / 11$ and can be traced back to the US embassy bombings in Beirut in $1983 .{ }^{138}$ The embassy - in Ottawa - is located downtown, situated between two busy streets. To the east along Sussex Drive, dozens of bollards line the curbside. This is to prevent vehicles from mounting the sidewalk, and setting off a car bomb next to the building. To the West is Mackenzie Avenue,

\footnotetext{
132 (Neyland 2009, 21)

133 (Dagenais 2013, 185)

134 (Jones 2009, 99)

135 (Ibid, 99)

136 (Boddy 2008)

137 (Sorkin 2008, viii)

138 (Boddy 2008)
} 
where an entire lane has been permanently closed to vehicle traffic for the same reason. The US State Department originally wanted a more isolated site in Rockcliffe Park. Trevor Boddy proposes that they were shamed into accepting the downtown location due to the recent completion of the Canadian Embassy on Pennsylvania Avenue by Arthur Ericson. ${ }^{139}$ Instead of a welcoming embassy, the result is a militarized, fortified base in the heart of downtown.

The Canadian Government has made a conscious decision to increase our own security, but in a Canadian way where possible. Parliament Hill is a perfect example of this ambition; a stark contrast to the White House compound in the US. The grounds are open to the public, but no longer to public vehicle traffic.

In April of 1989 Charles Yacoub hijacked a Greyhound coach bus bound for New York City and parked it in front of the Peace Tower. The hostage situation was eventually resolved, but public vehicular access to the hill was then permanently suspended. ${ }^{140}$ Large precast concrete blocks were places at the vehicle entrances soon after and remained in place for nearly 14 years [see fig005]. Eventually the driveways were landscaped and infill walls would permanently erase the old vehicular entrances [see fig006]. ${ }^{\mathrm{ii}}$

\footnotetext{
139 (Boddy 2008, 284)

${ }^{140}$ (Associated Press 1990)
} 


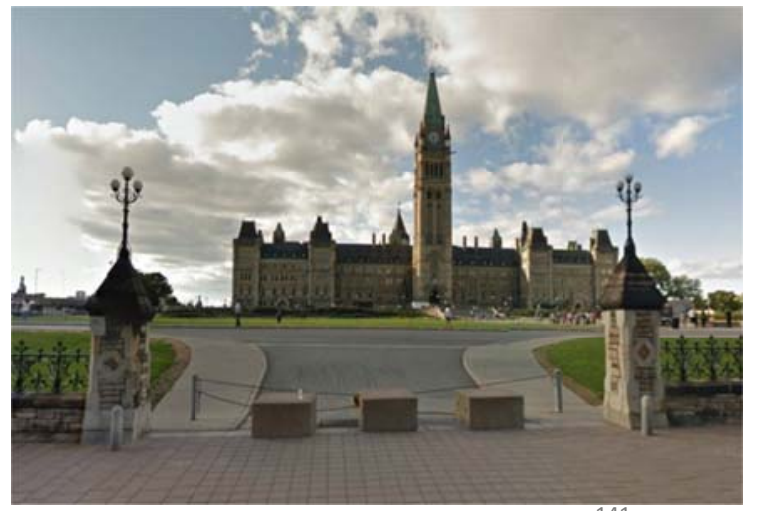

[005] Vehicle Barriers, 1989-2013 $3^{14}$

Google Street View Image, August 2012

Though the infill walls appear to match the existing perimeter wall, the inner construction is contemporary. A reinforced anti-ram concrete core hides beneath the matching limestone cladding instead of the original stone rubble cores in the neighbouring walls.

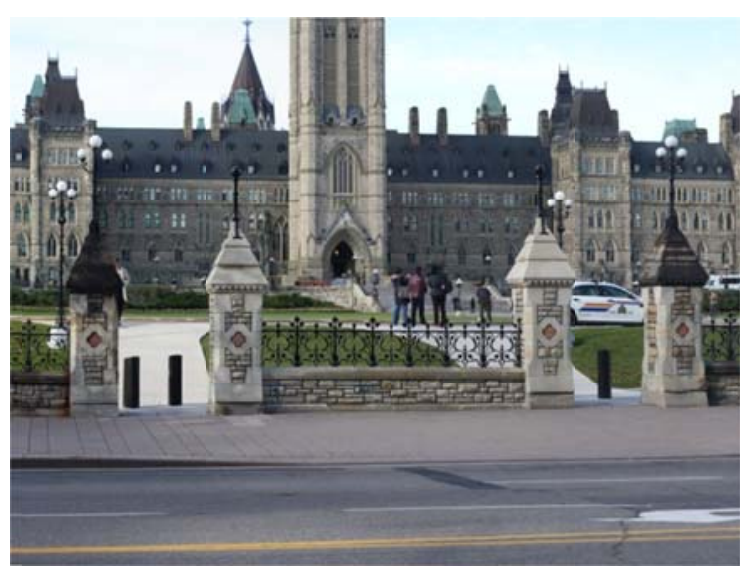

New Anti-Ram Perimeter Infill Wall, 2013 [006] PFK Photo

It is understandable to reinforce the walls in new construction, but there is little stopping a large SUV from breaching the adjacent rubble core walls. The grounds are still open to the public so the threat is not completely erased, it simply mutates. As long

${ }^{141}$ (Google 2014) 
as we are aware of this, we can anticipate threats in different ways. Does this mean the hill should be closed to pedestrian traffic as well? No, but we do have to draw a line somewhere. This is where the USA and Canada differs, if only slightly.

There will always be threats we cannot adequately prepare for. According to Boddy "The pedestrian suicide bomber confounds all of this research and design innovation aimed almost entirely to date at stopping car and truck bombs. There is no strategy for the physical design of public building and public spaces that can discourage, never-mind prevent, a determined suicide bomber, acting alone." ${ }^{142}$ Likewise, kamikaze airplanes are a threat we cannot reasonably prevent through architecture alone, unless we are to live in uninhabitable bunkers of ludicrous expense. ${ }^{143}$

Note: This thesis was presented in September 2014, a month prior to the shootings that occurred on October $22^{\text {nd }}$ of 2014 . Corporal Nathan Cirillo was fatally shot while on guard at the Tomb of the Unknown Soldier. Cirillo was a sentry from the Ceremonial Guard posted at the National War Memorial located across from Parliament Hill. RCMP officers killed the lone gunman.

We see new laws passed in an effort to improve security after 9/11. The controversial Uniting and Strengthening America by Providing Appropriate Tools Required to Intercept and Obstruct Terrorism Act, better known as the USA Patriot Act is the most notable; due to its rapid deployment after 9/11 and it's far reaching implications beyond the

\footnotetext{
142 (Boddy 2008, 300)

${ }^{143}$ (Ibid, 301)
} 
United States national borders. ${ }^{144}$ Organizations like the ACLU have criticized the Patriot Act because the terminology is not clearly defined. Section 2.15 authorizes the government to obtain all tangible things relevant to a terrorism investigation. ${ }^{145}$ This has lead to what is known as mass-warrantless-wiretapping of the population. ${ }^{146}$ The vague language in the act has been used to justify several other covert programs of mass surveillance that have recently been exposed to the public.

Programs like Bullrun in the USA and Edgehill in the UK are decryption programs that gather encrypted communications of citizens. ${ }^{147}$ The NSA's program PRISM uses corporate entities to perform warrantless wiretapping of individuals worldwide. This siphons more than just meta-data, it also can include content. ${ }^{148}$

\begin{abstract}
"Terrorism has always been what we in the intelligence world would call a cover for action. Terrorism is something that provokes an emotional response that allows people to rationalize authorizing powers and programs that they wouldn't give otherwise ... . the NSA asked for these authorities back in the 1990's. They asked the FBI to go to congress to make a case ... congress and the American people said no. They said it was not worth the risk to our economy, but what we saw in the post 9-11 era they [NSA] used secrecy and they used the justification of terrorism to start these programs in secret without asking congress, without asking the American people." ${ }^{149}$

- Edward Snowden

Speaking via video conference [from Moscow] at TED2014

Vancouver, Canada
\end{abstract}

In recent years there have been two critical series of revelations, which have shed light on government actions and general overreach by the authorities. The leaks from

\footnotetext{
${ }^{144}$ (ACLU 2011)

145 (Ibid)

${ }^{146}$ (Snowden 2014)

147 (Ibid)

148 (Ibid)

149 (Ibid)
} 
Chelsea [formerly Bradley] Manning via WikiLeaks in $2010^{150}$ and those from Edward Snowden through the Guardian and the Washington Post in $2013 .{ }^{151}$ Julian Assange and Glen Greenwald played crucial roles in publishing the leaked material.

Chelsea Manning was convicted and sentenced to 35 years for leaking over 700,000 government files; ${ }^{152}$ what are now known as the Iraq War Logs were published by WikiLeaks on 22 October 2010, detailed accounts of civilian deaths, torture, summary executions and various war crimes. ${ }^{153}$ As of the $18^{\text {th }}$ of August 2014, Julian Assange has been under house arrest in the Embassy of Ecuador in London, UK. ${ }^{154}$ It has been 2 years since Ecuador granted Assange asylum in August of $2012 .{ }^{155}$

Edward Snowden has been living in Moscow, for the past year. Russia granted Snowden temporary asylum in August of $2013 .{ }^{156}$ On the $7^{\text {th }}$ of August 2014 Snowden was granted a 3 year residency permit in Russia. ${ }^{157}$ Though the title is superfluous, Snowden is widely regarded as the 'Man of the year' for 2013 by several organizations. ${ }^{158,159,160,161}$ Glen Greenwald is a practicing journalist that - since the revelations - co-founded the Intercept with Laura Poitras, Jeremy Scahill ${ }^{162}$ in direct

\footnotetext{
${ }^{150}$ (WikiLeaks 2014)

151 (The Guardian 2014)

152 (Savage and Huetteman 2013)

153 (theguardian.com 2013)

${ }^{154}$ (Erlanger 2014)

155 (Ibid)

${ }^{156}$ (BBC News 2014)

157 (Ibid)

${ }^{158}$ (Cassidy 2013)

159 (Rice-Oxley, Haddou and Perraudin 2013)

160 (Sheffield 2013)

161 (Robinson 2013)

162 (The Intercept 2014)
} 
response to the NSA leaks. Both The Washington Post and The Guardian won a Pulitzer Prize for public service for their reporting on NSA surveillance. ${ }^{163}$

It is not clear how these revelations will truly impact how we live or how the government operates, but we are already witnessing change. We are only at the beginning of a global conversation that really needed to take place decades ago. The general population was not aware of how vulnerable they were and as discussed earlier, educating the public or end-user is fundamental in ensuring that privacy can realistically be maintained. The value of our personal information - and data - is now becoming apparent.

As awareness grows regarding how data is generated, tracked and [mis]used, the demand for secure devices and methods of communication will also grow. Device manufacturers are beginning to create secure devices like; the CryptoPhone by GSMK, ${ }^{164}$ the Blackphone ${ }^{165}$ by Spanish smartphone manufacturer Geeksphone. ${ }^{166}$ Telecommunications companies like Silent $\operatorname{Circle}^{167}$ provide fully encrypted mobile coverage plans. It appears that this is a rapidly growing market as the industry redesigns their encryption techniques independently, to avoid built-in back-doors from the NSA in standardized forms of encryption. ${ }^{168}$

163 (Chappell 2014)

164 (GSMK 2014)

165 (SGP Technologies 2014)

${ }^{166}$ (Geeksphone 2014)

167 (Silent Circle 2014)

${ }^{168}$ (Snowden 2014) 
Duckduckgo is "the search engine that doesn't track you", a direct response to Google's methods of monetized data collection for the purpose of targeted marketing. The private search engine experienced a sharp increase to 3 million searches per day shortly after Snowden's NSA revelations on $10^{\text {th }}$ of June $2013 .{ }^{169}$ Though this still pales in comparison to the over 5.9billion average searches per day on Google during 2013. ${ }^{170}$

The Big Data giants like Google are making policies to ensure consumer protections. Google is beginning to encrypt user searches to address these growing concerns. ${ }^{171,172}$ This is going to be problematic for foreign governments that routinely monitor the online activity of their population. China's censorship system known as the Great Firewall for example, would no longer be able to track user searches via Google. ${ }^{173}$ China is not the only government to censor the internet on a national level; countries like Saudi Arabia and Vietnam will also have to make the decision to relinquish this power of surveillance or block access to the search engine entirely. ${ }^{174}$

The internet is still relatively young; it has and will continue to evolve in ways we are not yet able to fully understand. As more and more people globally have access to technologies like the internet and mobile telecommunications, our collective knowledge and experience will continue to grow as these technologies mature. As our digital storage capacities grow exponentially, we were introduced to new vocabulary; from

\footnotetext{
${ }^{169}$ (DuckDuckGo 2014) https://duckduckgo.com/about

170 (Institute, Statistic Brain Research 2014)

171 (Nicks, Google Will Start Encrypting Your Searches 2014)

${ }^{172}$ (Yang 2014)

${ }^{173}$ (Ibid)

${ }^{174}$ (Ibid)
} 
kilobyte, megabyte to gigabyte, terabyte, and soon petabyte and exabyte. As those outside of the tech industry familiarize themselves with digital securities, terms like VPN [virtual private network] and proxy servers will also enter the public vocabulary.

\section{Artificial Intelligence}

In 1964 Buckminster Fuller predicted that by 2014 "the word worker will have disappeared . . We will have to look it up in the dictionary" ${ }^{175}$ Fuller believed that computers and robots would produce the end of work scenario popular with futurist of the time; $;^{176}$ an optimistic view in stark contrast with Kurt Vonnegut Junior's dystopian novel Player Piano. This extreme level of automation has yet to materialize publicly, as companies found it more economical to relocate jobs abroad. ${ }^{177}$ With the progression of developing countries, will this trend continue? We have already seen the manufacturing and warehousing industries invest heavily in automation, but these are relatively unseen, behind closed doors.

We are beginning to experience a dramatic restructuring of our economies due to the increasing intelligence - or more accurately, the abilities - of our digital technologies, the whole of society will eventually be affected. We have seen this before in multiple stages of our collective human development; notably with the steam engine and the [first] industrial revolution, later with electricity during what Erik Brynjolfsson and Andrew McAfee call the second industrial revolution. These general purpose technologies [GPT]

\footnotetext{
${ }^{175}$ (Kirby 2014)

${ }^{176}$ (Erik Brynjolfsson, Race Against the Machine 2011, 6)

${ }^{177}$ (Kirby 2014)
} 
are grouped into the first machine age, where the advancements were mechanical in nature. What we have recently entered is the second machine age [or the third industrial revolution]. ${ }^{178}$

\footnotetext{
"Now comes the second machine age. Computers and other digital advances are doing for mental power - the ability to use our brains to understand and shape our environments - what the steam engine and its descendants did for muscle power."179
}

- Erik Brynjolfsson

During the previous industrial revolutions, there were massive disruptions and crises as society responded to their new technological capabilities. This digital revolution will require similar adjustments, as certain jobs become obsolete and demand increases for skilled employees in emerging fields. As in the past, in the end humanity will be able to prosper. ${ }^{180}$ Our new computing technologies and networking capabilities are enabling new large scale efficiencies, were fewer and fewer people are required to produce, manufacture and distribute the goods and services for the entire global demand. ${ }^{181}$

This has become more evident after the most recent economic downturn in 2008. As the recession ended companies resumed investing heavily in machinery and equipment, but were reluctant to returning to pre-2008 rate of investment in hiring personnel. ${ }^{182}$ Does this mean that we are moving closer to the end of work scenario popularised by economic and social theorist Jeremy Rifkin's 1995 book The End of Work? ${ }^{183}$ Rifkin expects that technological displacement [not technological unemployment] is "likely to

\footnotetext{
178 (Erik Brynjolfsson, Race Against the Machine 2011, 76)

179 (Erik Brynjolfsson, The Second Machine Age 2014, 8)

180 (Erik Brynjolfsson, Race Against the Machine 2011, 76)

181 (Ibid, 6)

182 (Ibid, 3)

183 (Ibid, 6)
} 
be the single most pressing social issue of the coming century." ${ }^{184}$ Similarly Wassily Leontief, economist and Nobel Laureate stated in 1983 that "the role of humans as the most important factor of production is bound to diminish in the same way the role of horses in agricultural production was first diminished and then eliminated by the introduction of tractors." ${ }^{185}$ The effects are not immediate; rather the changes become clearer over time. The population of working horses actually peaked at 3.25 million in England; this was long after the Industrial Revolution. By 1924, that number fell to well below 2 million $^{186}$

Radical restructuring of employment was not isolated to that of the horse. In 1800, $90 \%$ of Americans worked in agriculture, this dropped to $41 \%$ by 1900 and now only $2 \%$ in the year $2000 .^{187}$ So where did the $88 \%$ of employees go? Throughout the $19^{\text {th }}$ and $20^{\text {th }}$ centuries millions of people migrated into the manufacturing and service sectors. ${ }^{188}$ Manufacturing has been greatly impacted by automation, but now many of the employment in the service industries are facing similar threat.

Mention Artificial Intelligence [AI] and dystopian visions of Terminator-esque killer robots come to mind, much like the depictions of Big Brother discussed earlier, but are these fears justified? In 1950 Alan Turing first proposed the question "Can machines think?" in his essay Computing Machinery and Intelligence. ${ }^{189}$ The essay had to be

\footnotetext{
${ }^{184}$ (Erik Brynjolfsson, Race Against the Machine 2011, 6)

${ }^{185}$ (Ibid, 6)

${ }^{186}$ (Ibid, 37-38)

187 (Ibid, 49)

188 (Ibid, 51)

189 (Turing 1950)
} 
published in a psychology and philosophy journal because the field of Integrated Technology [IT] did not yet exist. This is a difficult question to answer to this day.

The technological singularity is a term coined by science fiction author Vernor Vinge to describe theories discussed by critical thinkers like Isaac Asimov and Alan Turing. ${ }^{190,191}$ In physics, the term singularity often refers to the unpredictable nature of events that occur beyond a black holes event horizon. ${ }^{192,193}$ This is the boundary where gravity becomes so powerful that even light cannot escape, making direct observation impossible. In the technological singularity, computational technology surpasses that of the human brain. ${ }^{194,195}$ It is theorized that technology would achieve an equivalent of human consciousness, becoming sentient beings. This would facilitate a feedback loop that would accelerate innovation to speeds and in directions outside of our understanding. ${ }^{196}$ Current forms of Al appear intelligent, but - for now - it is only a resemblance. ${ }^{197}$

The Turing Test is thought to be a critical milestone in this evolution. ${ }^{198}$ There have been intelligent machines that have claimed to pass this test in recent years, but none that have been unilaterally accepted [yet]. There are several variations of the format, but the basic concept remains the same. A human would engage in a conversation

\footnotetext{
190 (Dagenais 2013, 184)

191 (Erik Brynjolfsson, The Second Machine Age 2014, 255)

192 (Dagenais 2013, 184)

193 (Erik Brynjolfsson, The Second Machine Age 2014, 255)

194 (Ibid, 254)

195 (Cadwalladr 2014)

196 (Erik Brynjolfsson, The Second Machine Age 2014, 255)

197 (Ibid, 255)

198 (Cadwalladr 2014)
} 
[usually via text] with a human or a computer. By asking several questions over a short period of time, the administrator attempts to determine if the entity on the other end is human or machine. Success would require the machine to pass as a human more often than not, with several independent administrators and an array of tested question. An equivalent in popular science fiction would be the Voight-Kampff Test in Ridley Scott's 1982 film Blade Runner, though this test is given to a humanoid Replicant rather than through a text-based computer interface. ${ }^{199}$

Deep Blue - a \$10million supercomputer developed by IBM - made headlines in 1997 by beating the world's best chess master Gary Kasparov at his own game. ${ }^{200}$ The achievement was incredible at the time. What is lesser known today is that the world's greatest chess 'player' is no longer a computer, nor is it human. Teams of humans develop software to compete against other human/computer teams. Kasparov notes that a "weak human + machine + better process was superior to a strong computer alone and, more remarkably, superior to a strong human + machine + inferior process." ${ }^{201}$ This produces an interesting result; Erik Brynjolfsson suggests we apply this strategy in an array of fields. Law, medicine, finance, retail and manufacturing could all benefit from this way of thinking; competing with the machines and not against them. $^{202}$

\footnotetext{
${ }^{199}$ (Ford 1982)

${ }^{200}$ (Erik Brynjolfsson, Race Against the Machine 2011, 54)

201 (Ibid, 55)

202 (Ibid, 55)
} 
Watson is a direct descendant of Deep Blue. IBM developed the supercomputer notorious for annihilating the two most accomplished human contestants on the game show Jeopardy! $!^{203}$ In February of 2011 Watson had scored more than $300 \%$ higher than the nearest human opponent, Ken Jennings. ${ }^{204}$ Jeopardy! requires contestants to use complex communication skills to understand a variety of questions [in the form of answers], interpret the meaning - often involving puns and other indirect wordplay and formulate the correct answer [in the form of a question]. ${ }^{205}$ Ken Jennings is famous for winning 74 Jeopardy! games in a row, after his defeat to Watson Ken famously quoted the following line from The Simpsons. ${ }^{206}$

“I for one welcome our new computer overlords." 207

- Ken Jennings

[February 2011]

These are impressive feats, but these machines are not able to understand what exactly they are doing, they are not self-aware. Unfortunately [or fortunately] the leap from passing the Turing Test to achieving the singularity is an enormous one. The discussion is still important as technology evolves, but the event horizon is still several decades away and poses no immediate danger.

We are no longer talking about the possibility of HAL 9000 levels of sentient technology [fig007]. An order of magnitude below self-aware conscious machines, we have a category of machines that have already become spatially self-aware. You very likely

\footnotetext{
${ }^{203}$ (Erik Brynjolfsson, Race Against the Machine 2011, 16)

204 (Ibid, 17)

205 (Ibid, 16)

${ }^{206}$ (Friedman 2011)

207 (Erik Brynjolfsson, Race Against the Machine 2011, 17)
} 
have a GPS enabled smart phone or device within reach. These inanimate objects know their global position, but lack the ability to directly affect that location. A small step above these are ROVs [Remotely Operated Vehicles] and UAVs [Unmanned Aerial Vehicles] that can be semi or fully autonomous. These emerging technologies can manipulate their measured location, and react to their surroundings in various ways in real-time.

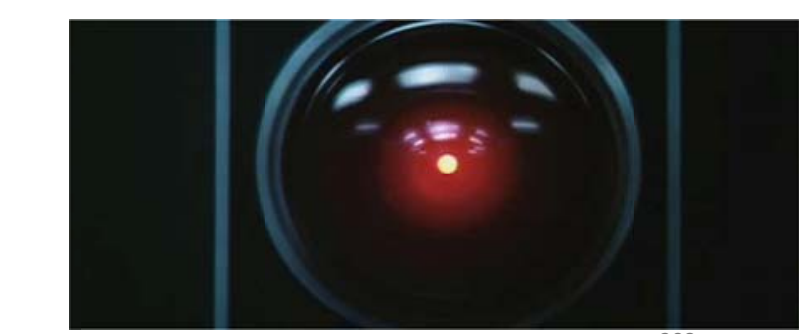

2001: A Space Odyssey [01h-07m30s] ${ }^{208}[007]$

Stanley Kubrick

Only a decade ago, self-driving cars were limited to the realm science fiction. Frank Levy and Richard Murnane are economists and authors of The New Division of Labor [2004], they discuss emerging computing technologies and how they will distort our economies and employment. Levy and Murnane provide driving a truck in traffic as an example of "where people still matter". ${ }^{209}$ Computers had long surpassed humans at algorithmic calculation by this time, but struggled with complex pattern-recognition.

\footnotetext{
"[the] truck driver is processing a constant stream of [visual, aural, and tactile] information from his environment... To program this behaviour we could begin with a video camera and other sensors to capture the sensory input. But executing a left turn against oncoming traffic involves so many factors that it is hard to imagine discovering the set of rules that can replicate a driver's behaviour.,"10
}

\footnotetext{
208 (Kubrick 1968)

${ }^{209}$ (Erik Brynjolfsson, Race Against the Machine 2011, 12)

${ }^{210}$ (Ibid, 12)
} 
The available technology at the time supported this theory. The first DARPA Grand Challenge was held in 2004. The challenge required an unpiloted fully autonomous vehicle to successfully navigate a $240 \mathrm{~km}$ [150-mile] course through the Mohave Desert. The best competitor that year traversed less than $1 \%$ of the total distance [less than $13 \mathrm{~km}] .^{211}$ Fast forward 6 years and what was once an impossible task to automate was now a [primitive] reality. In October 2010 Google announced that it had developed a fleet of driverless cars. One vehicle had already autonomously driven over $1,600 \mathrm{~km}$ $\left[1,000\right.$ miles] on public roads, without any driver input, ${ }^{212}$ though a human legally had to be in the driver's seat alert and ready to take over.

The driverless cars use massive quantities of data from GPS, Google Maps to determine the vehicles approximate location. Video cameras, radar and LIDAR [Light Detection and Ranging] instruments provided real-time environmental data. Onboard software could analyze the sensory inputs to determine the location, trajectory of obstacles and react to traffic signals. ${ }^{213}$

Driving has consistently become safer over time as vehicle technology improves. Safety glass, seatbelts, crumple-zones and airbags were all dramatic improvements, but all of these safety features have also added considerable weight to our vehicles. The

${ }^{211}$ (Erik Brynjolfsson, Race Against the Machine 2011, 13)

212 (Ibid, 13)

${ }^{213}$ (Ibid, 14) 
trade off is energy efficiency. A larger, heavier car requires more fuel to drive. ${ }^{214}$ MIT economist Christopher Knittel published a paper titled Automobiles on Steroids analyzing this effect between 1980 and 2006. Knittel determined that the average weight of an American vehicle increases by $26 \%$, horse power increased by $107 \%{ }^{215}$ The overall fuel efficiency of vehicles did improve by $26 \%$ due to technical innovations, but Knittel calculates that the net fuel efficiency would have increased by $60 \%$ if vehicle weight and power maintained at the 1980 level. ${ }^{216}$ Unfortunately, removing the excess weight would compromise previous safety innovations. As the vast majority of collisions are caused by human error, this would have negative effect. According to Transport Canada approximately 60,000 Canadians were killed in collisions over a 20 year period. ${ }^{217}$ There were 4,303,931 injuries, of which 347,187 were serious in nature over the same period. ${ }^{218}$ A report by the World Health Organization in 2013 estimated that vehicle collisions cause $1,420,000$ fatalities globally every year. ${ }^{219}$

\footnotetext{
${ }^{214}$ (Dizikes 2012) original source: (Knittel 2011)

215 (Dizikes 2012)

216 (Ibid)

${ }^{217}$ (Canada, Transport 2013)

218 (Ibid)

${ }^{219}$ (World Health Organization 2013, 242-255)
} 


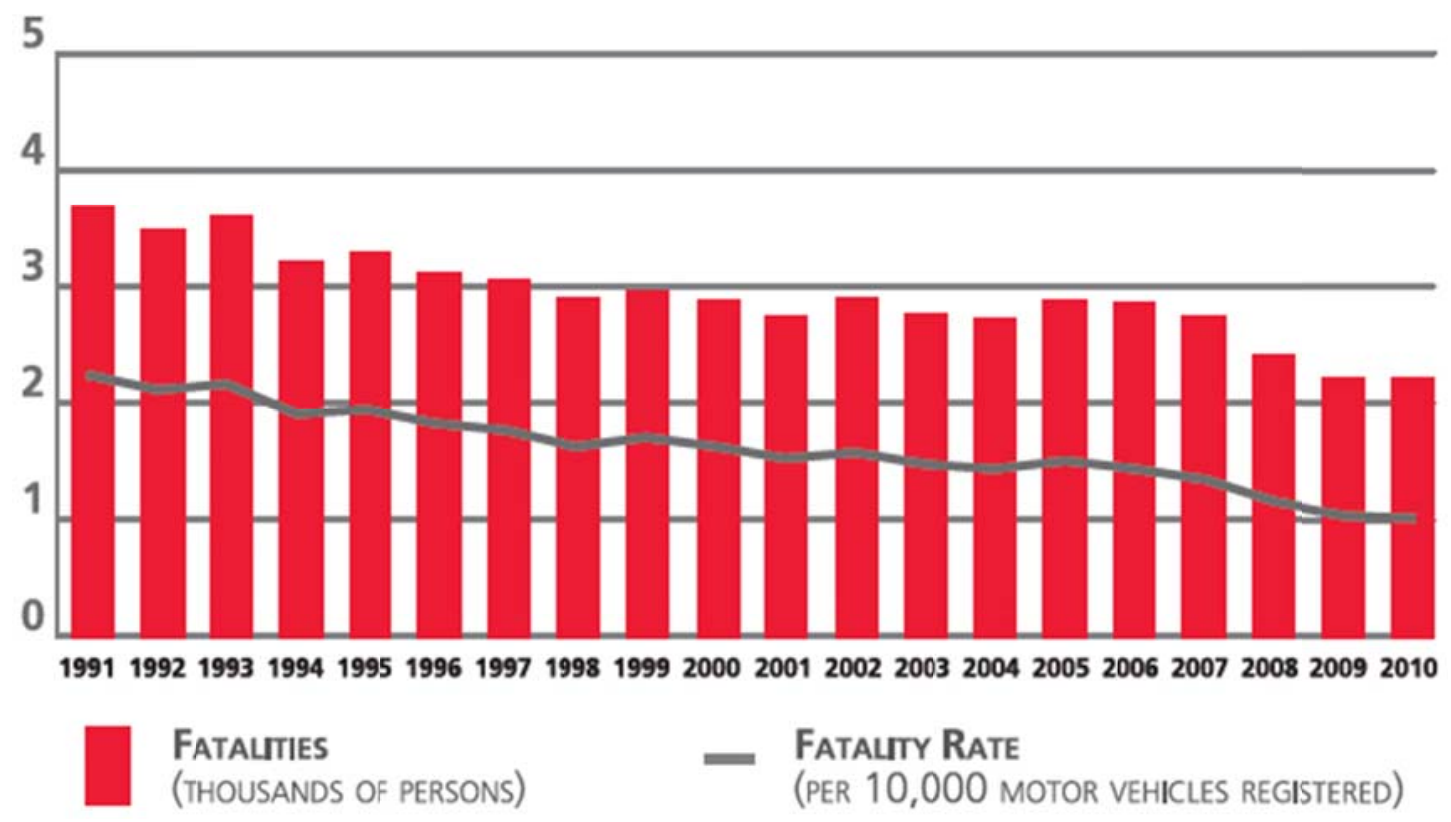

[008] Vehicular Fatalities 1991-2010220

Canadian Motor Vehicle Traffic Collision Statistics: 2010

Transport Canada

The transition to driverless cars will not happen overnight, but we are already seeing various technologies cross over into consumer grade vehicles. Lane-assist, autonomous parallel parking, radar cruise control and automatic breaking are examples of this shift. Industrial mining companies in Australia and Chili have heavily invested in fleets of fully autonomous dump trucks to operate on their private property. ${ }^{221,222}$ The house-sized trucks do not need to take breaks or sleep, and they can be controlled from a central location with minimal staffing. There is a huge potential to save lives when these technologies mature, becoming more robust and ubiquitous.

\footnotetext{
${ }^{220}$ (Canada, Transport 2013)

221 (Chambers 2012)

222 (Make: 2014, 40)
} 
The machine precision could lead to increased energy efficiency by allowing cars to travel closer together at consistent speeds without sacrificing safety. As more of the global populations enter the middle class, cities will struggle with congestion as the volume of vehicles out paces developments in infrastructure. Japan is an extreme example, but between 1966 and 1988 the total number of cars increased by 625\%, while the length of roadway only increased by $12 \%{ }^{223}$

The more driverless vehicles there are on the road, the greater the benefits. In the [very] long term, theoretically as the system becomes safer due to the removal of human error, we could dramatically reduce the weight of these vehicles to further improve efficiency.

Autonomous UAVs are proving useful for an ever increasing amount of applications. In the USA manned agricultural aviation [crop dusting] is fighting a losing battle against the UAVs, but the extinction of the profession is inevitable. UAVs are cheaper, safer, and more accurate when spraying fields. ${ }^{224}$ A drone flying a grid pattern with the ability to hover in place ensures $100 \%$ coverage without flying over adjacent crops or property. Japan has already made the transition, only $5 \%$ of the nation's farmland is sprayed by manned aircraft, the rest use unmanned helicopters and drones. ${ }^{225,226}$

\footnotetext{
${ }^{223}$ (Kaijima, Kuroda and Tsukamoto 2001, 26)

${ }^{224}$ (Koebler, Drones Are About to Take Over One of the World's Most Dangerous Jobs 2014)

225 (Ackerman 2013)

${ }^{226}$ (Koebler, Drones Are About to Take Over One of the World's Most Dangerous Jobs 2014)
} 
Architects are beginning to take notice of UAVs and explore their possible uses. The work of Swiss architect team Gramazio \& Kohler $^{227}$ in partnership with Raffaello $D^{\prime}$ Andrea ${ }^{228}$ is particularly interesting. Flight Assembled Architecture [fig009] was an experimental installation constructed entirely autonomously by small UAV quadcopters. $^{229}$ The UAVs would pick up a foam brick, and drop it into place according to a digital 3D model of the desired structure. The only predetermined points in space where the pickup location that remained constant and the end point that remained variable. The most efficient route while avoiding the other vehicles was determined autonomously. ${ }^{230}$

\footnotetext{
${ }^{227}$ (Gramazio \& Kohler Architects 2011-2012)

228 (D'Andrea, Dynamic Works 2014)

${ }^{229}$ (D'Andrea, Flight Assembled Architecture 2012)

${ }^{230}$ (Ibid)

${ }^{231}$ (Ibid)
}

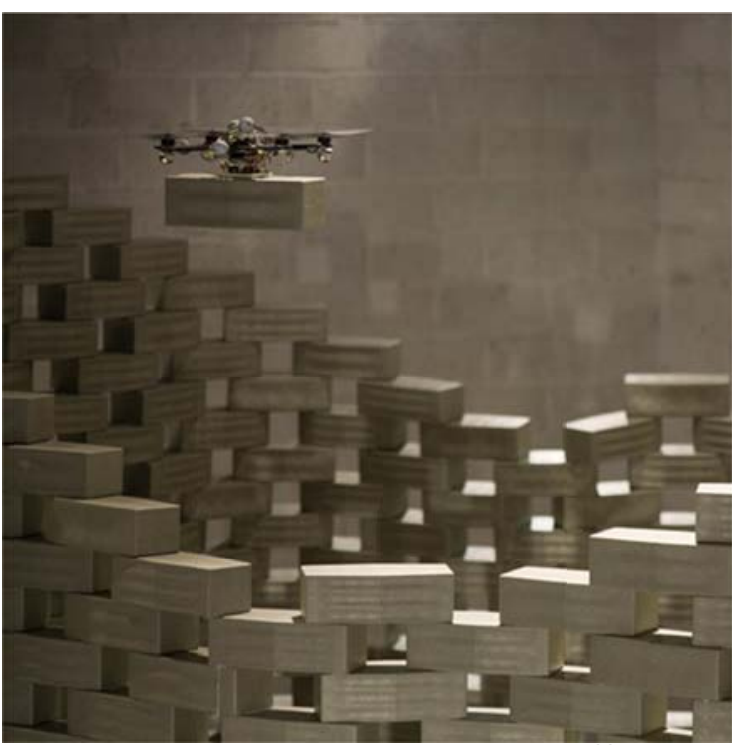

Flight Assembled Architecture ${ }^{231}$ [009] Gramazio \& Kohler and Raffaello D'Andrea 
The resulting structure is intriguing, but the method of construction and the network required to control the UAVs during flight is the most impressive aspect. Raffaello D'Andrea directs the Flying Machine Arena research team in Switzerland. ${ }^{232}$ They developed what they call Collision Avoidance and Freeway Based Flight. ${ }^{233}$ According to their website;

"To coordinate flying and avoid collisions, the vehicles use two freeways that encircle the structure. Usage of the freeways is controlled by a space-reservation system, whereby each vehicle reserves the space required for a trajectory before the trajectory is flown. This space is then unreserved once the trajectory is completed. This system ensures that while a space is reserved, only the reserving flying vehicle has access - all other vehicles must wait before flying through this space.

This system is also used to stop collisions with the tower. In this situation, the entire tower is reserved, thus preventing any vehicle from planning a trajectory through this space." ${ }^{234}$

This method of communication has potential in many of our transportations systems.

Our cars could communicate with other vehicles to anticipate their actions faster than a human could react.

As these spatially-aware autonomous technologies proliferate, we will face many difficult choices; socially, environmentally and economically. We will need to innovate where our current systems are inadequate, the structure of our economic system will be challenged to reorganize. We currently are subsidizing corporations that invest in automation, but the robots are not active participants in the economic system. ${ }^{235}$ Globe and Mail Columnist Konrad Yakabuski sums up this form of automation by how "taxes

\footnotetext{
${ }^{232}$ (D'Andrea, Flight Assembled Architecture 2012)

${ }^{233}$ (D'Andrea, Flying Machine Enabled Construction 2011)

234 (Ibid)

${ }^{235}$ (Yakabuski 2014)
} 
pay for robots, but robots don't pay for taxes". ${ }^{236}$ Our economic systems [capitalism] will have to adjust to this new reality in coming decades. The Industrial Revolution was accompanied by soot-filled skies and the deplorable exploitation of child labour. ${ }^{237}$ The modern equivalents are not entirely known, but as with any technological innovation there will be unpleasant consequences that must be overcome.

"Technology is not destiny. We shape our destiny."238

Erik Brynjolfsson

${ }^{236}$ (Yakabuski 2014)

237 (Erik Brynjolfsson, The Second Machine Age 2014, 9-11)

238 (Ibid, 257) 


\section{5}

It is not often that we can realistically contemplate introducing an entirely new form of transportation. Modernity's global transportation has long been dominated by ocean liners, trains, planes and automobiles, but in the near future UAVs [or drones] will enter the equation. In the United States, the Federal Aviation Administration [FAA] has been tasked with developing regulations for the integration of Unmanned Aerial Systems into public airspace. ${ }^{239}$ The original goal was to have partial implementation in 2015 , though it is not clear if the FAA will maintain this timeline. ${ }^{240,241,242}$

At the time of writing this, 2015 hasn't happened yet. We are talking about the near future, a difficult subject to objectively predict or discuss. We often get it terribly wrong, but we can examine existing trajectories to propose scenarios that are possible, though not yet true.
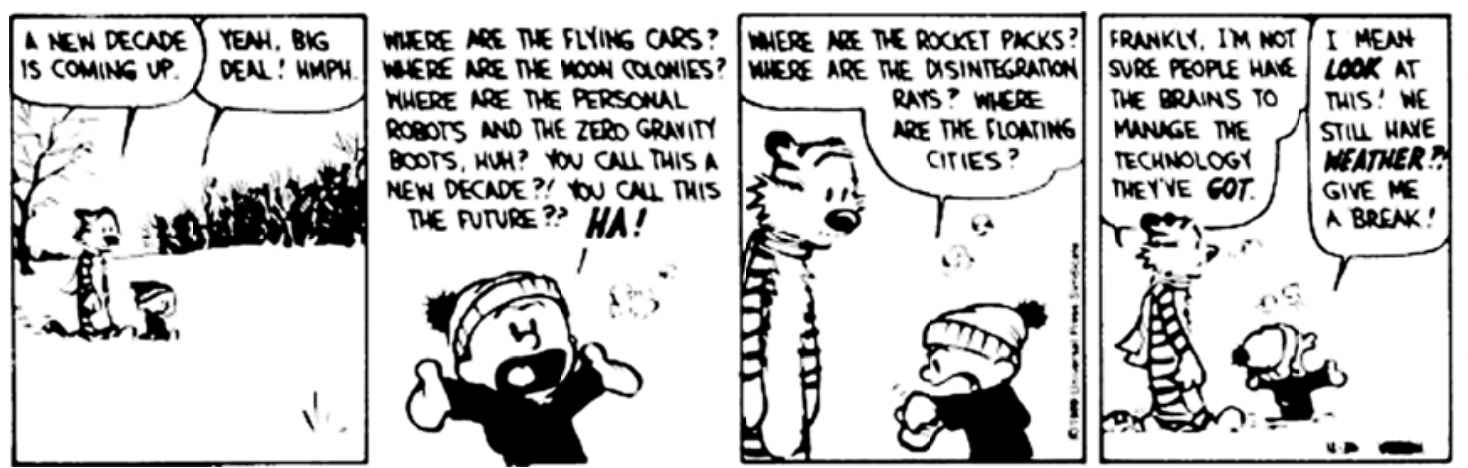

[010] Calvin and Hobbes by Bill Watterson December 30, 1989

\footnotetext{
${ }^{239}$ (FAA 2013)

240 (Waterman 2012)

241 (Nicks, Amazon's Drone Strike 2013)

242 (Thompson 2013)

243 (GoComics 2014)
} 
The automobile is the form of transportation we interact with most on a daily basis. As a form of personal transportation they provide freedom and convenience, but in congested urban areas there are often limitations to these benefits. The pitfalls become apparent when idling in traffic. It is understandable - though not realistic - why the flying car has long been an object of fantasy. No longer constrained by gravity, congestion would become extinct; there are no traffic jams for birds in the sky or for fish in the ocean when vertical movement is an option. A sentiment that Kevin Smith humorously depicts in his 2002 short film The Flying Car; where Dante Hicks and Randal Graves debate what lengths one would go to achieve the coveted flying car while stuck in traffic. ${ }^{244}$

[011] Popular Mechanics Cover, July $1957^{245}$
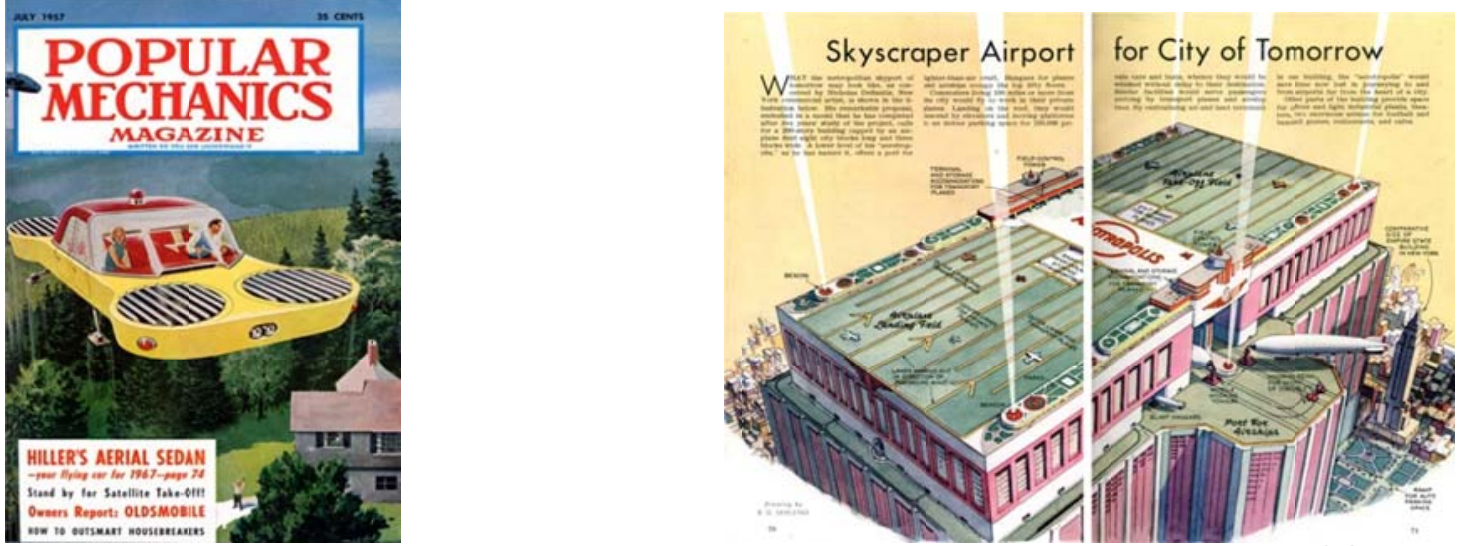

Skyscraper Airport for City of Tomorrow ${ }^{246}$ [012]

There are a select few that never given up on this dream. Companies like Aeromobil ${ }^{247}$ in Slovakia, Terrafugia ${ }^{248}$ in Massachusetts and Moller International ${ }^{249}$ in California are

\footnotetext{
244 (Smith 2002)

245 (Popular Mechanics Magazine 1957)

${ }^{246}$ (DeSantis 1939)
} 
attempting to develop variations of the flying car. Though the ambition is admirable, the reality is that the archetype is obsolete. The prototypes are essentially light aircrafts that can be driven legally on public roads when their wings are retracted or removed. ${ }^{250}$ The vehicles are unable to revolutionize transportation because they do not produce a surplus benefit beyond what current cars and light aircraft can provide. These hybrid vehicles are large, heavy, energy intensive and extremely expensive. Moller claims their Skycar [M400] would cost $\$ 500,000$ USD if in production and Terrafugia estimates their Transition would be roughly $\$ 280,000$ USD. ${ }^{251,252}$ This is where small unmanned Drones may fill the void.

At present, references to drones are typically in the context of military operations. It is helpful to compare the stages of the drone's evolution to that of its predecessor, the airplane. The Wright brothers are widely regarded to have flown the first sustained flight in a vehicle heavier than air in $1903 .{ }^{253}$ The military quickly adapted the technology during World War 1. At first for reconnaissance and surveillance, a clear strategic advantage when monitoring the movement of ground troops. ${ }^{254}$ Towards the end of the war, pilots began dropping grenades from above. Purpose built bombers were not developed and widely used until several years later. ${ }^{255}$ The military

\footnotetext{
${ }^{247}$ (Aeromobil 2013)

248 (Terrafugia 2013)

${ }^{249}$ (Moller International 2013)

250 (Dodson 2012)

${ }^{251}$ (Moller International 2013)

252 (Dodson 2012)

253 (Grant 2007)

254 (Ibid)

${ }^{255}$ (Rise of the Drones 2012)
} 
investment accelerated innovation, making flight safer and more reliable. Due to this, commercial passenger flight rapidly became available after the end of WWII. ${ }^{256}$

Drones have experienced similar stages of evolution, from conception to military surveillance and later weaponization. Drones were first used in mass during the Vietnam War, where one thousand AQM-34 Ryan Firebees flew over 34,000 surveillance missions. ${ }^{257}$ In October of 2001 - a month after 9/11 - we saw the first weaponized drone strike by an armed MQ-1 Predator, by the US military in Afghanistan. ${ }^{258}$ Drones have proven so effective that now the US Air Force trains more drones pilots than traditional pilots. ${ }^{259,260}$ We are now on the verge of entering the first stage of evolution beyond military use, democratization.

Many architects have been infatuated with airplanes and human flight, possibly none more than Le Corbusier. In Towards and new Architecture [1923] Le Corbusier devotes considerable mention to aeronautical innovations in the chapter Eyes Which Do Not See. ${ }^{261}$ Later in 1935 he publishes Aircraft devoted entirely to the subject of flight. The following is an excerpt from a letter sent to Le Corbusier from Colonel Vauthier, a member of Marshal Péltain's staff attached to the Aerial Defense Service, published in Aircraft. ${ }^{262}$

\footnotetext{
${ }^{256}$ (Grant 2007)

257 (Popular Mechanics 2005)

${ }^{258}$ (Yost 2013)

259 (Ibid)

260 (Rise of the Drones 2012)

${ }^{261}$ (Corbusier, Towards a New Architecture 2008)

262 (Corbusier, Aircraft 1967, 3)
} 
"The officials still believe that aviation could be introduced into our lives by a nice juxtaposition, modestly settling down into a small corner, while in fact it is bursting through everything: our customs, our law, our economy. The soldiers also have tried to persuade themselves that aviation would politely adapt itself to the old rules, while in fact it compels the general revision of previously accepted values." ${ }^{263}$

Colonel Vauthier

[5 $5^{\text {th }}$ March 1935]

An attempt must be made to anticipate the impact unmanned aerial vehicles will have when democratized. Their fight capabilities in many regards, already far surpass those of traditional manned aircraft. Human pilots are concerned that airspace is already too congested to incorporate these vehicles safely. ${ }^{264}$ Estimates vary widely, but there may be $10,000-30,000$ drones operating commercially in the US alone by $2020 .{ }^{265,266}$

\section{Flying Cars Domestic Drones}

Emerging technologies present enormous hurdles that we must overcome prior to successful adoption by the general population. This will be an ongoing task as it is with other democratized military technologies like airplanes, GPS and the internet. Criminal entities are often quick to adopt new tech to gain a strategic advantages. This was true with new methods of communication via pagers and cells phones. Now, drones are used to smuggle weapons and drugs into prisons by discretely dropping them into courtyards from above. ${ }^{267}$ Unfortunately, we are not capable of preventing hobbyists and terrorists from weaponizing drones for nefarious purposes. ${ }^{268}$ This alone is not

\footnotetext{
${ }^{263}$ (Corbusier, Aircraft 1967, 3)

264 (Schilling 2013)

265 (Ibid)

${ }^{266}$ (Waterman 2012)

267 (Aubry 2013)

${ }^{268}$ (Goodman, A View From The Unfriendly Skies: How Criminals Are Using Drones 2013)
} 
reason enough to ban the technology outright. Complete restriction would not be effective because individuals like this would already be working outside of the law.

"Innovation cannot be stopped and that means the drones are coming."269

- Marc Goodman

The general public is not aware that military grade drones currently operate domestically in North America. Drones are used to monitor the borders between Mexico, the United States and Canada. ${ }^{270}$ Robert Mueller - director of the FBI - has openly admitted to using drones for domestic surveillance over American soil. ${ }^{271}$

Drones have a negative connotation at present. This is due to their current use in military drone-strike operations. In 2012 alone the USA performed hundreds of drone strikes across 6 countries; Afghanistan, Iraq, Pakistan, Yemen, Somalia and Libya. ${ }^{272}$

Many in the industry avoid the $D$-word, preferring the term UAV or UAS to distance themselves from the military's weaponized fleet of drones. ${ }^{273}$ The public does generally not trust these forms of autonomously controlled technology [yet]. Skepticism is understandable when dealing with the unknown. Only time will tell if UAV technologies will win over public opinion the way countless previous innovations have.

Drones can also fulfill humanitarian purposes. The Bill Gates foundation is investing in these technologies, planning to deliver medication and vaccines to remote locations in

\footnotetext{
${ }^{269}$ (Goodman, A View From The Unfriendly Skies: How Criminals Are Using Drones 2013)

270 (Yost 2013)

271 (Roberts 2013)

272 (Yost 2013)

${ }^{273}$ (Dougherty 2014, 6)
} 
the developing world. ${ }^{274}$ Further development of compelling drone applications will begin to turn the tide of public opinion, once we are informed about the vast potential of civilian benefits. ${ }^{275}$

As the popularity of UAVs increases, so does the risk of incident with existing commercial air traffic. ${ }^{276}$ Commercial aviation is highly regulated to provide the necessary safety and quality controls. A similar framework for small civilian/commercial UAVs does not yet universally exist. Though rapid innovation is occurring in drone technologies, they are still far from the safety and reliability standards of manned aircraft. According to the FAA, law enforcement agencies, universities and registered drone operators in the US have reported more than 20 serious accidents and well over 200 unsafe incidents since $2009 .^{277}$ The military grade surveillance drones also occasionally malfunction. On January $27^{\text {th }}, 2014$ a $\$ 12$ million Predator drone operated by the United States Customs and Border Protection agency did not have enough fuel to return to its base. The pilots were forced to ditch the drone in international waters southwest of San Diego. ${ }^{278}$

The United States does not face this challenge alone. It is estimates that between 55 and 70 other nations are developing remotely piloted drones, including Canada. ${ }^{279,280}$ Small UAVs are used by police departments for reconnaissance in smaller municipalities

\footnotetext{
${ }^{274}$ (Anderson, Bill Gates wants to use drones to deliver vaccines 2012)

275 (Dougherty 2014, 6)

276 (Whitlock 2014)

277 (Ibid)

278 (Ibid)

279 (Suarez 2013)

${ }^{280}$ (Yost 2013)
} 
with insufficient budgets for traditional police helicopters. ${ }^{281}$ DARPA has developed a single drone called ARGUS-IS [Autonomous Re al-Time G round Ubi quitous Surveillance Imaging System] capable of m onitoring a medium sized city. The e quivalent of having 100 Predator drones recording up to 1 mil lion TB of data per day [equal to $+5,000$ hours of HD Video, per day]. ${ }^{282}$

$10^{\text {th }}$ June 2014 , the FAA released a statement that it had approved the first commercial UAS/UAV operation over land. ${ }^{283}$ Energy Corporation BP and UAS manufacturer AeroVironment will fly drones in Alaska to monitor remote oil pipelines.

“These surveys on Alaska's North Slope are another important step toward broader commercial use of unmanned aircraft ... The technology is quickly changing, and the opportunities are growing." 284

- Transportation Secretary Anthony Foxx

Now that we know that a wave of UAVs is on the horizon, we need to debate and anticipate how this will affect our society. Unlike static CCTV in the UK, drones are kinetic. Creating a new spatial relationship unlike anything we have seen before.

\footnotetext{
${ }^{281}$ (Yost 2013)

282 (Ibid)

283 (FAA 2014)

284 (Ibid)
} 


\section{DESIGN PROJECT $[i-i i]$}

Part i: Drones for Architects

- Design and build a drone.

- Determine and demonstrate applications specific to architects and architecture.

Part ii: Toward an Aerial Infrastructure

- How can drones be put to work domestically?

- Propose an infrastructure [nodes] to receive this technology at various scales of the city. 



\section{Part : DRONES FOR ARCHITECTS}

\section{Design Requirements}

- Remotely operated Unmanned Aerial System [UAS] Includes; the vehicle + ground control/data link

- Lightweight for ease of transportation and maximum flight time

- Compact design to minimize storage requirements

- High definition video capability

- High resolution photography capability

- Vibration dampening for camera mount

- Camera live-view from ground station

- Allow for future upgrade [flexible layout]

- Easily replaceable components [if damaged]

- Low profile design [storage and in-flight maneuverability]

- Self-stabilization during flight

- Incorporate various fail-safes/redundancies in the design

\section{PFK Drone}

The PFK Drone is a custom built one-of-a-kind UAV. Though most of the components are commercially available, the specific combination had to be designed to achieve the desired specifications and functionality. Several stock components were modified or replaced with custom designed pieces. The result is a unified design that incorporates components that are not originally design to function together.

There were many critical design challenges/decisions that needed to be overcome to achieve the desired functionality with the UAV.

Fixed wing or Rotary Propeller [prop] design?

Fixed wing UAVs are great when covering expansive areas. This is useful in search and rescue applications, pipeline or LIDAR surveying large sites. They are fuel efficient 
because they passively generate lift during flight without expending excessive energy, but they cannot pause [hover] in mid-flight the way rotary blade UAVs can.

For aerial surveying [both photo and video, photogrammetric scanning] the ability to hover is incredible valuable. This is especially true when working close to obstacles like buildings and foliage. This allows UAVs to land and swap batteries easily for extended flight durations. Here manoeuvrability trumps range and lift efficiency. A rotary prop design is preferable in this case.

What prop configuration [how many props] is best?

Common configurations include heli [1], tri [3], quad [4], hex [6], octo [8]. UAV helicopters are unstable without more sophisticated autopilot systems. The pilot requires a higher skill level to fly safely. There are bicopter [2] and tricopter [3] layouts, but these are still less stable than a UAV with a minimum of 4 props. With 4 or more propellers, all of the rotational forces can be cancelled out or exploited by mirroring the direction of the props in pairs.

Hexcopter and octocopter configurations have more redundancy build into the layout. This would be favourable for commercial applications. These layouts require more motors, ESCs, battery power and often a more sophisticated autopilot. Each of these factors increases the weight, size and expense of the UAV. With 4 props, the fight is stable and the costs are minimized. The PFK drone is a quadcopter for these reasons. 
The next major step is to select or design the quadcopter frame. In this case a stock frame was purchased and then significantly modified to improve its performance and functionality.

After examining several options the HT-FPV frame [now discontinued] by Hoverthings.com was used as the base. Many quadcotpers are designed symmetrically with the camera mounted beneath the frame at the centroid.

The HT-FPV frame has a unique asymmetrical design. This was a key feature of the frame. It was designed specifically to mount a GoPro ${ }^{\circledR}$ directly on the frame’s front end. The front arms are bent backwards slightly, allowing the camera to be mounted away from the frame's centroid. This removes the landing gear legs and props from the cameras Field of View [FOV], a typical issue with other available designs.

Mobility was also a concern with the overall design when not flying. The stock landing legs raise the main body off of the ground. Without any equipment - like a camera mounted beneath the frame, the legs could be shortened to lower the UAVs profile, allowing for compact storage and transport. More sophisticated UAVs can incorporate retractable landing gears.

To improve the video output some modifications were required. A 2-axis camera gimbal was mounted on the front end. This involved designing and fabricating a new top plate extension and also cutting away the lower plate [see fig015-fig016]. The gimbal levels the camera by counteracting the tilt and roll of the UAV during flight. This 
essentially converts the UAV into an aerial steady-cam. The gimbal is also mounted on rubber bushings to dampen any vibrations caused by the motors and propellers.

A digital 3D model was constructed to create the following drawings and diagrams [see fig014-025]. The model is accurate enough to extract part profiles for the fabrication of replacement parts. The custom designed frame parts are CNC cut from carbon-fiberreinforced polymer sheets. 

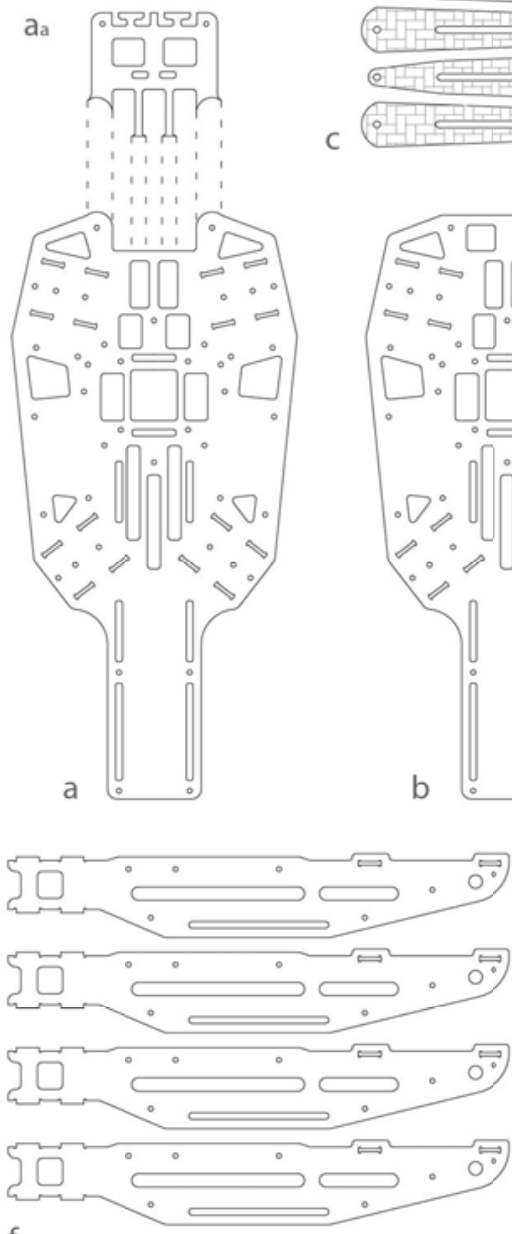

f

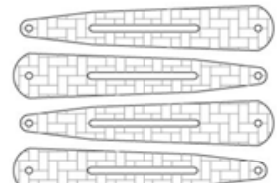

c

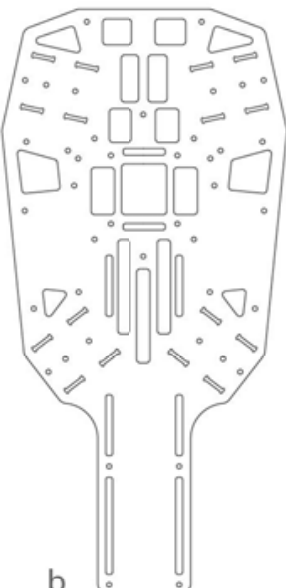

h
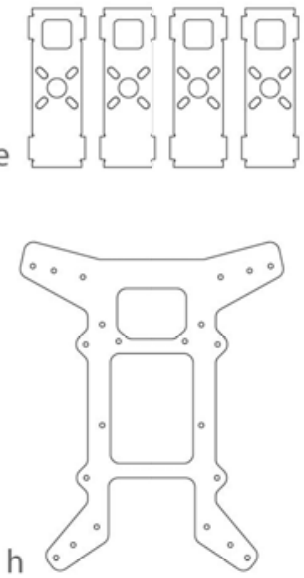
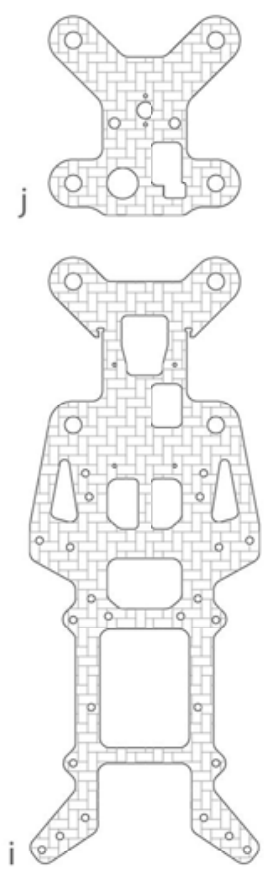

[014]

Frame Components

$1: 4$

lower plate cut away [ from lower plate ] middle plate

custom rear landing gear [ $x 4$ ] custom front landing gear $[x 4]$ motor mounting plate [ $x 4$ ]

front arm plate [ $x 4$ ]

rear arm plate $[x 4]$

top plate [ discard ] custom cnc cut top plate gimbal mounting plate
FR-4/G-10 composite

FR-4/G-10 composite

FR-4/G-10 composite

carbon-fiber-reinforced polymer carbon-fiber-reinforced polymer

FR-4/G-10 composite

FR-4/G-10 composite

FR-4/G-10 composite

FR-4/G-10 composite

carbon-fiber-reinforced polymer carbon-fiber-reinforced polymer 
[015]

Original HT-FPV Frame
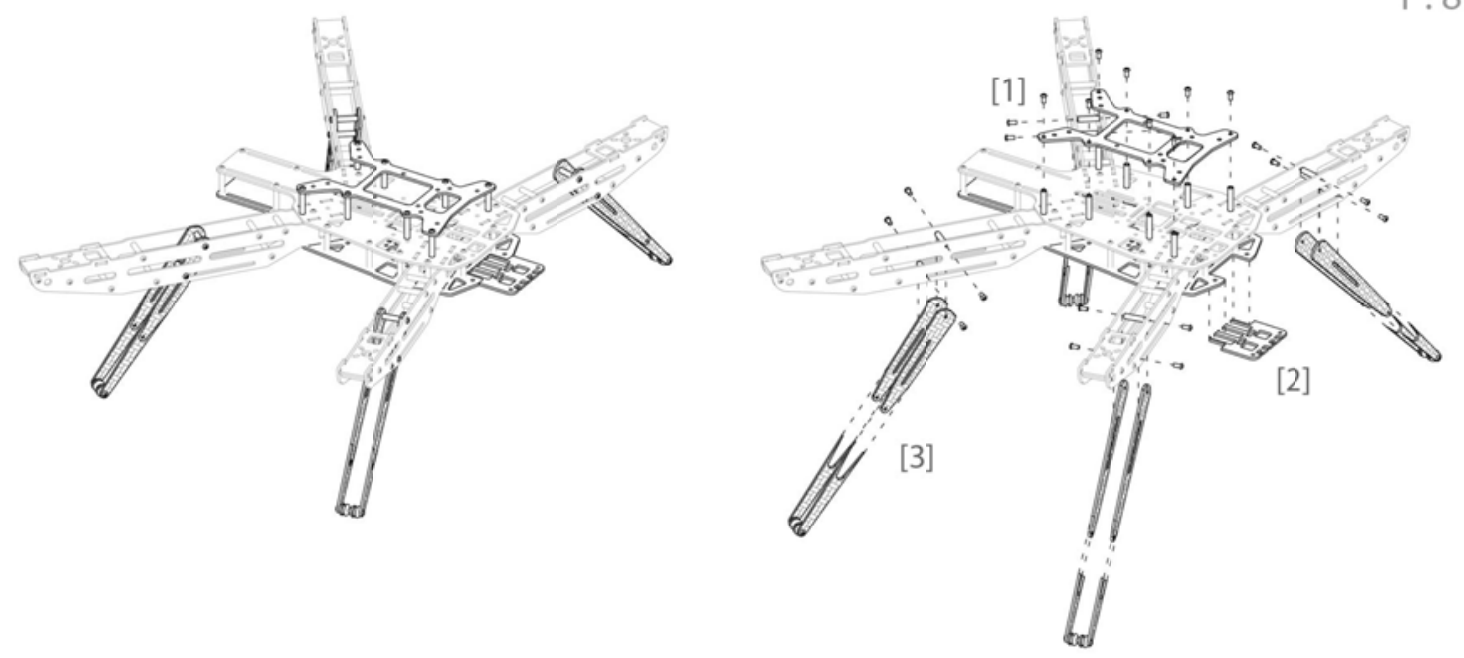

1 discard top plate

2 trim lower plate to make room for hung gimbal

3 trim landing gear legs
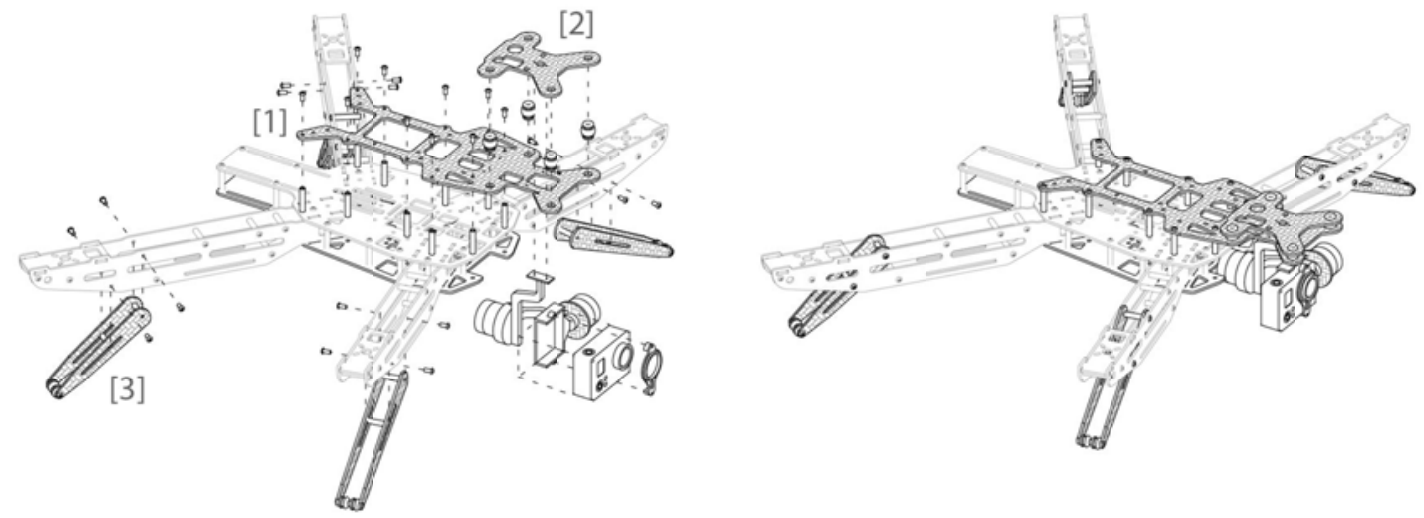

1 mount custom cnc cut carbon fiber top plate

2 mount gimbal mounting plate with rubber bushings

3 mount trimmed carbon fiber landing gear legs 


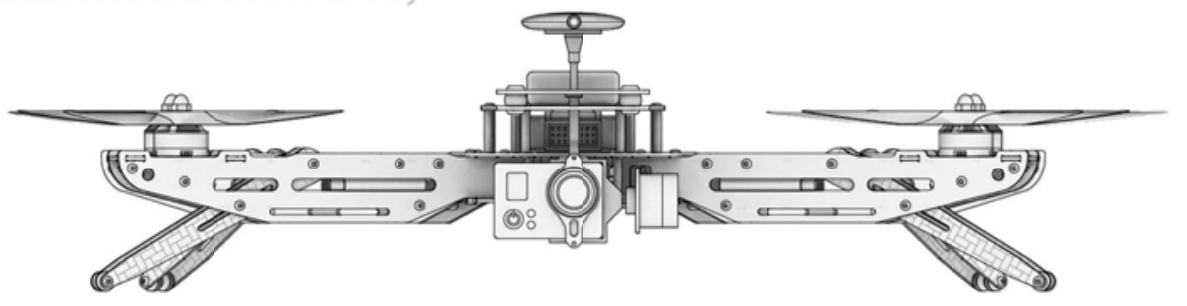

[017]

Front Elevation

$1: 5$

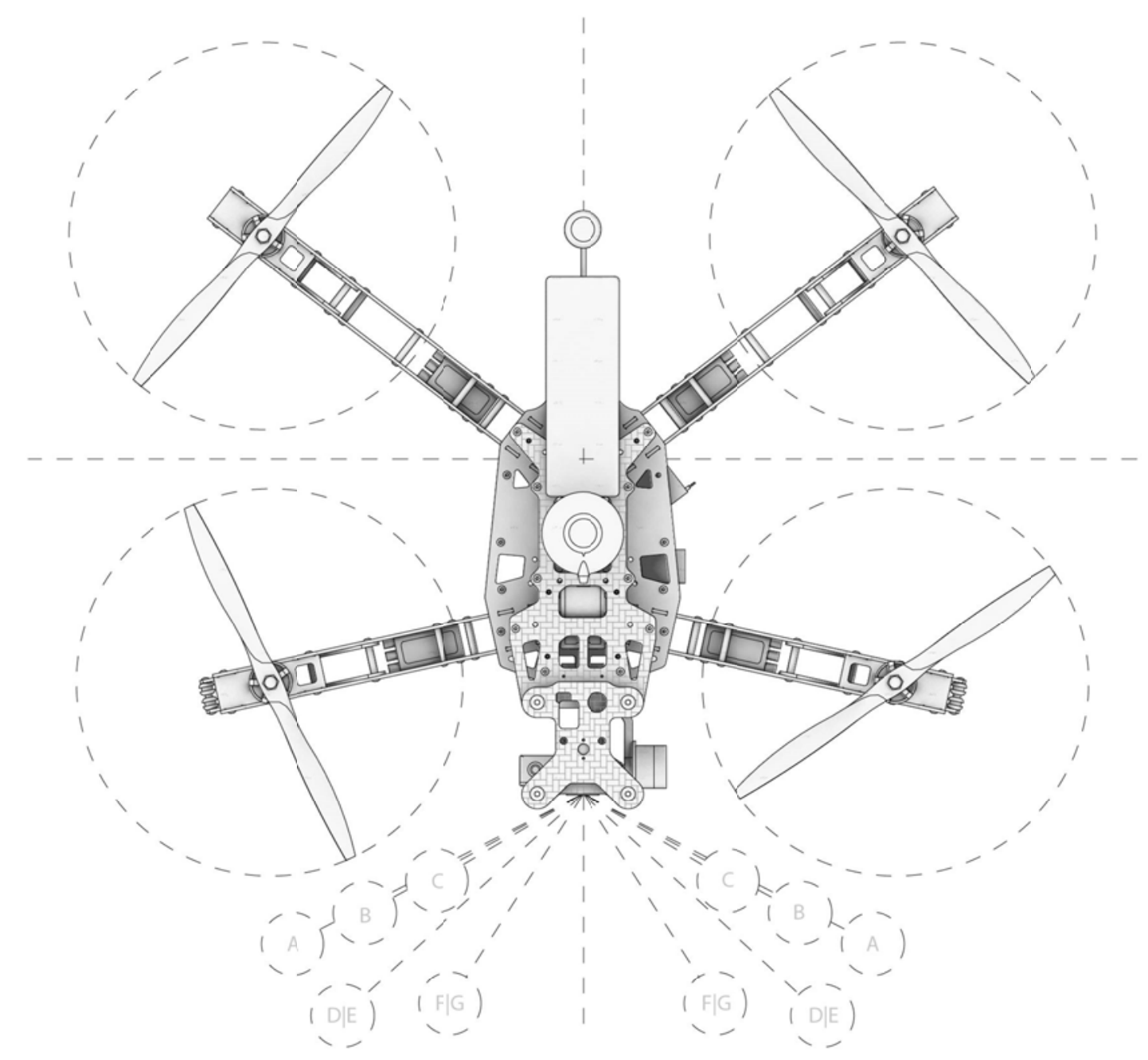

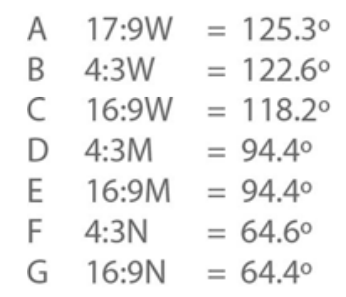

A $17: 9 \mathrm{~W}=125.3^{\circ}$

B $4: 3 \mathrm{~W}=122.6^{\circ}$

C $16: 9 \mathrm{~W}=118.2^{\circ}$

D $4: 3 \mathrm{M}=94.4^{\circ}$

E $16: 9 \mathrm{M}=94.4^{\circ}$

$\mathrm{F} \quad 4: 3 \mathrm{~N}=64.6^{\circ}$

G $16: 9 \mathrm{~N}=64.4^{\circ}$

\section{GoPro Hero3}

Field of View [FOV]

$\mathrm{W}=14 \mathrm{~mm}$ [wide]

$\mathrm{M}=21 \mathrm{~mm}$ [medium]

$\mathrm{N}=28 \mathrm{~mm}$ [narrow]
[018]

Plan

$1: 5$ 


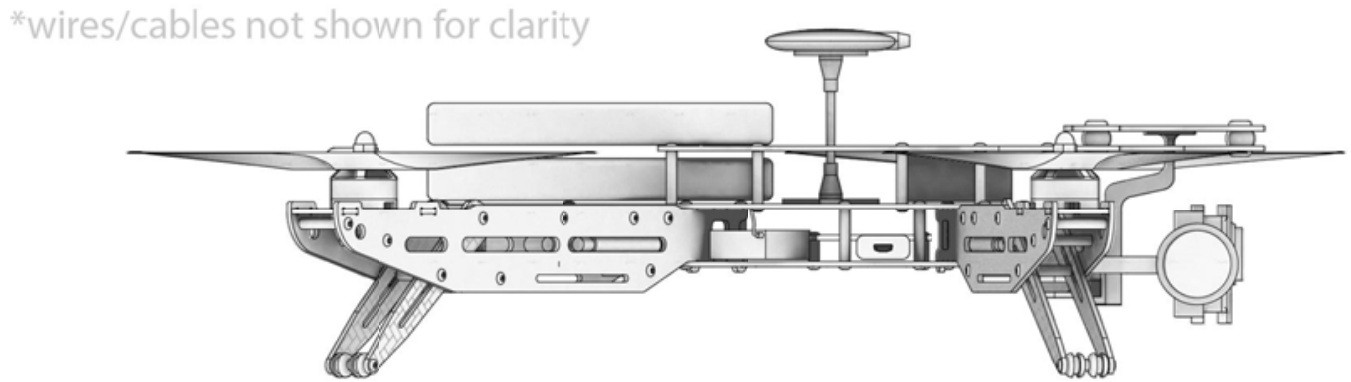

Side Elevation

$1: 4$

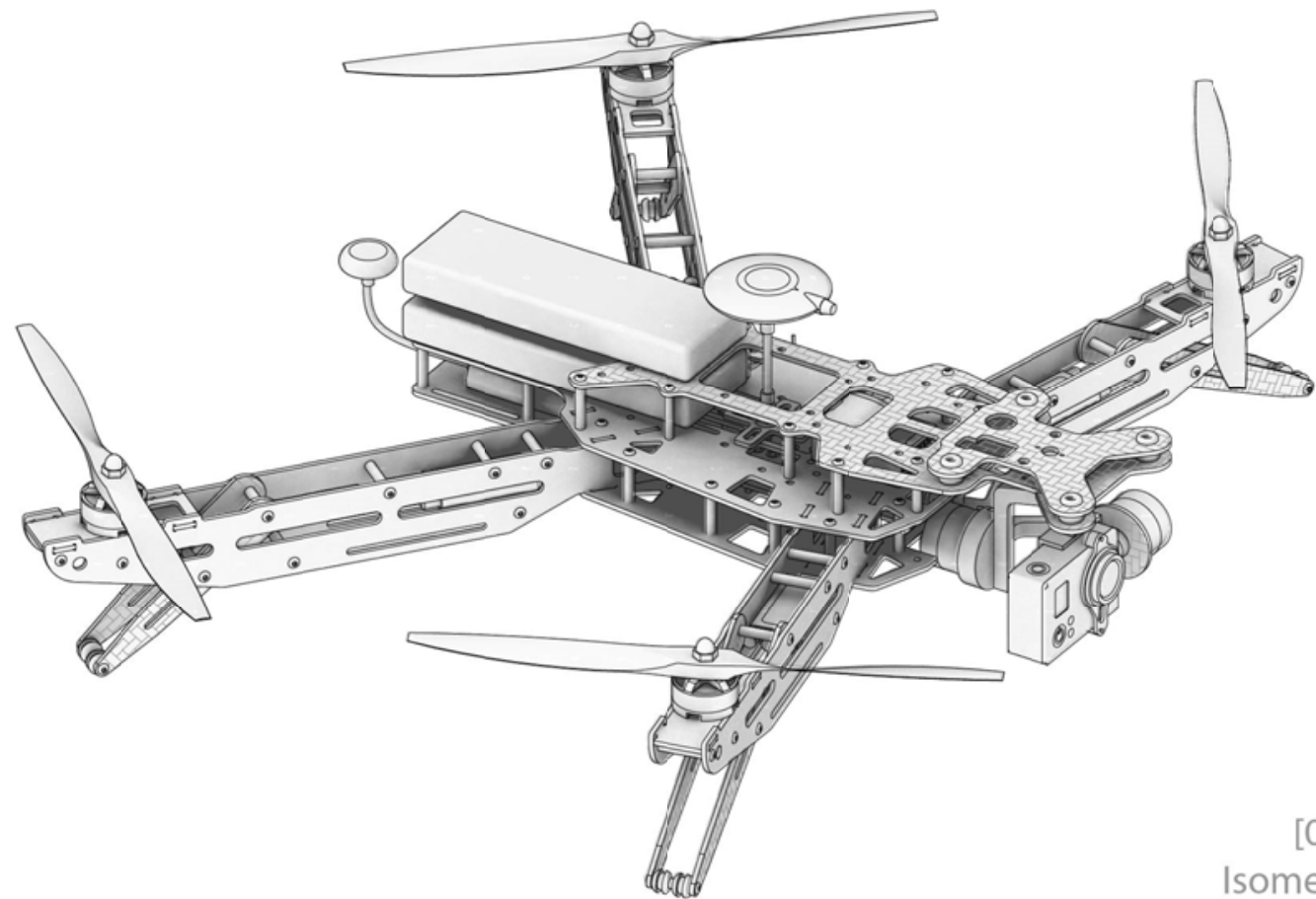
Isometric

$1: 4$

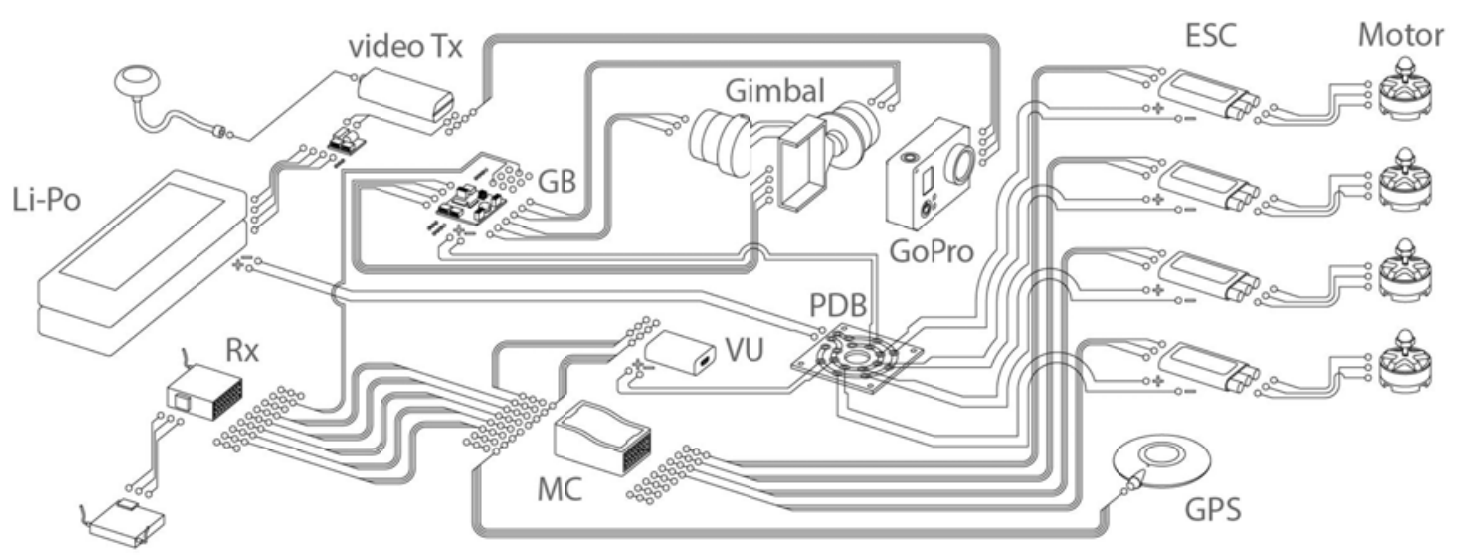


*wires/cables not shown for clarity

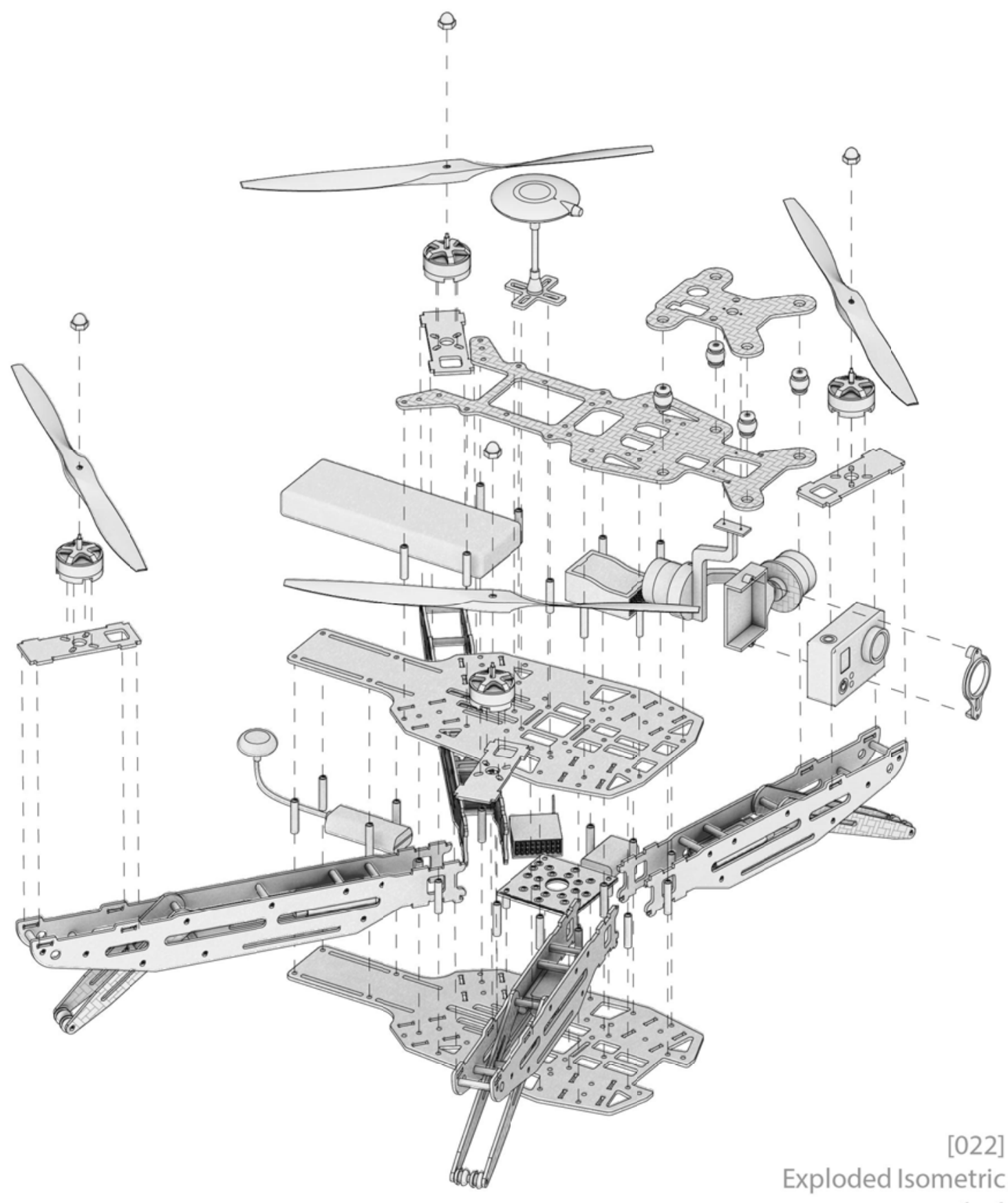

$1: 4$ 


\section{UAV Components}

- Batteries [rechargeable];

- Drone:

Li-Po 11.1V 3200mAh 25C - 3 Cell

- FPV Goggles:

Li-Po 7.4V 1000mAh - 2 Cell

- Camera:

Li-Ion Polymer 3.7V 1050mAh 3.885Wh

- Battery Straps

- Camera [HD]:

- Flight Controller:

$$
\text { GoPro }{ }^{\circledR} \text { Hero3 Black Edition }{ }^{285}
$$

DJI Naza-M ${ }^{286}$

- GPs unit

- Main Controller [MC]

- Accelerometer

- Altimeter

- Compass

- Gyroscope

- On-board Voltage Sensor

- Versatile Unit [VU]

- Frame [quadcopter]:

HT-FPV by HoverThings. com $^{287}$

- Gimbal:

Tarot T-2D Brushless Gimbal ${ }^{288}$ [see fig023-025]

- Motors [x4]:

DJI 2212/920KV Brushless Motor

- Power Distribution Board [PDB]

- Propellers [x4]:

$10^{\prime \prime}$ x 3.8 DJI Prop Set

- Servo Connection Cables

- Speed Controllers [ESC X4]:

- Transmitter [Tx]:

- Video Tx:

DJI 30 Amp ESC

Spektrum ${ }^{\circledR}$ DX7s [7-channel $2.4 \mathrm{GHz}$ System] ${ }^{289}$

- Including Reciever [Rx]

ImmersionRC A/V Tx [5.8GHz $600 \mathrm{~mW}]^{290}$

\section{UAS Components}

- FPV Goggles:

Fatshark Predator V2 291

- Laptop Computer

- Software;

- Video Capture and Streaming:

EasyCAP [USB 2.0 Video/Audio]

- Autopilot Programming:

DJI Assistant Software

- Various Tools [wrenches, screwdrivers...]

- Li-Po Charging System

- Portable Voltage Sensor

- Protective Carrying Case[s]

\footnotetext{
285 (GoPro, Inc. 2014)

${ }^{286}$ (DJI Innovations 2014)

${ }^{287}$ (HoverThings, Magento 2011)

${ }^{288}$ (Tarot RC 2012)

289 (Spektrum, Horizon Hobby LLC 2005-2014)

290 (ImmersionRC 2014)

${ }^{291}$ (Fatshark RC Vision Systems 2010-2015)
} 


\section{Capabilities}

Select features of the DJI Naza-M autopilot system ${ }^{292}$;

- GPS stabilized flight [in winds up to $30 \mathrm{~km} / \mathrm{h}$ ];

The GPS measures the drift caused by the wind, and then the autopilot automatically compensates to maintain position at altitude [when in GPS mode].

- Self leveling when controls are released [via the autopilot system]

Select features of the Tarot T-2D Brushless Gimbal ${ }^{293}$

- 2-Axis [tilt and roll] Gyro-stabilized camera

- Manual tilt control

- Vibration dampening rubber mounts

Tarot T-2D Gimbal

Gyro-stabilized camera mount

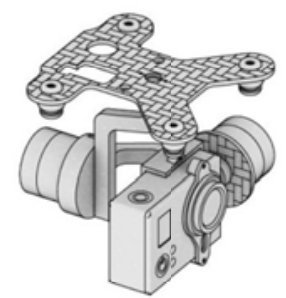

[023]

Gimbal Isometric

$1: 4$
ROLL

$\left[-45^{\circ}\right]$ to $\left[+45^{\circ}\right]$

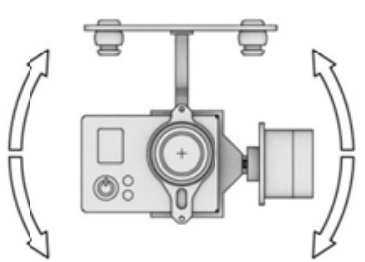

[024]

Front Elevation

$1: 4$
TILT

$\left[-135^{\circ}\right]$ to $\left[+90^{\circ}\right]$

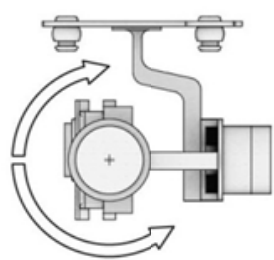

[025]

Side Elevation

$1: 4$

\section{Fail-safes}

Select Fail-safes of the DJI Naza-M autopilot system ${ }^{294}$;

- Audible Low-Voltage Warning

- Auto-landing when batteries reach critical level

- Position-hold when contact is lost with Tx

- Return-to-home function when batteries reach critical level;

When a home base is set [i.e. on the shore if flying over a lake], the UAV will fly up to a specified height, return to the home base [via GPS unit], then initiate Auto-land.

\section{Applications [specific to the PFK Drone]}

\section{Current/Past Uses ${ }^{i i i}$ [as of September 2014];}

- $\quad$ Action Sport Documentation [kayaking, rock climbing, skiing/snowboarding...]

292 (DJI Innovations 2013)

293 (Tarot RC 2012)

294 (DJI Innovations 2013) 
- Aerial Photography [architects, developers, real estate agents]

- Aerial Video [for promotional purposes]

- High Resolution Mapping [farmland and crops]

- Photogrammetric Scanning [proof of concept]

\section{Potential Future Uses;}

- Various Surveying [bridges, landscapes, roof tops, 3D scanning]

\section{Future Modifications [next steps]}

- Addition of a telemetry data transmission/recording system

- Collision avoidance system [though these are not yet available]

- Upgrade to a fully autonomous autopilot system [ArduPilot with GPS, for open-source Arduino hardware]

- Flight planner [GPS waypoints] and ground station integration; This will fully automate the drone, removing manual inputs during flight.

- Upgrade the Tx and Rx antennas for increased range

- Vacuum form a frame enclosure [weather-proofing] 


\title{
Drone Applications [specific to architects]
}

\author{
Aerial Surveying
}

Slate Roof Survey in Ottawa, Ontario [2012]

While working for a heritage conservation firm in 2012, I worked on several building surveys. These surveys often required a crane, scaffolding [fig026] or repelling from the roof, to survey areas of the building that are typically hidden from view at grade level. Roofing materials, chimneys, eaves, flashing, hips, valleys, parapets, ledges, exterior sills are all problem areas that require maintenance or repairs throughout a buildings lifespan. A higher vantage point is required to inspect these areas effectively.

The survey pictured in fig026 required bringing in an external consultant from out of town. This consultant had previous experience with the building and also specialized in slate roofing. The client had to pay for the crane rental [several thousand dollars per day] and the consultant's travel, time, accommodations and expenses. These disbursements were additional to our fee for completing the survey as part of a building condition report.

The survey took approximately 6 hours to complete. We took several hundred photographs and related notes. The adjacent parking lot owned by neighbouring condos had to be closed for the crane. An encroachment permit from the city was also required to clear street parking and provide crane access to the site. 


\section{[026]}

\section{Current Methods of Surveying}

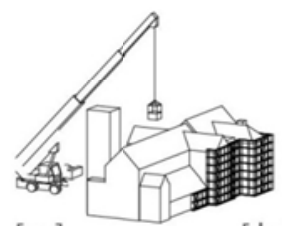

[a ]

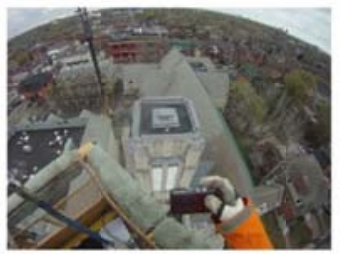

[a] Crane: Expensive, dangerous, imposing on site, limited range, risk of damage to property, time consuming.

[b] Scaffolding: Expensive, labour intensive, time consuming, aesthetically undesirable.

*Repelling [not shown]: Dangerous for workers, requires structural anchors, risk of damage to eaves troughs [from cable and rope] and delicate roofing materials [by incorrectly walking on them] like slate or clay tile.

\section{[027]}

\section{UAV Aerial Surveying}
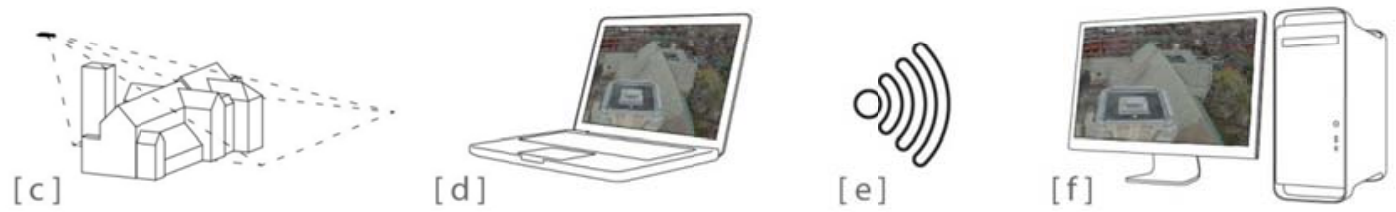

[c] Drone/UAV:

Fast, economical, less invasive [on-site], unconstrained range, no onboard personnel.

[d] Ground Station: Live view from the UAVs perspective [on-site ground station].

[e] Live-Streaming: Transmission of the live feed to a remote location [off-site]

[f] Remote Viewing: Live-stream [video conference] surveys and inspections to off-site stakeholders or consultants. Real-time feedback and remote instruction is now possible.

*note:

At present, there is still considerable risk involved with this scenario. Various site conditions [obstacles, neighbouring properties, tight spaces...] may render this approach ineffective. 
If we were able to use a UAV to complete the survey [fig027], we could have saved the client the cost of the crane rental, city permits, travel related expenses of the consultant.

Detailed surveys could be conducted similarly to how current video conferencing is used today; receiving instructions from an off-site third party to inspect specific areas of the building, or a survey could be conducted with the aim of recording HD video that would represent $100 \%$ coverage of the target. This second option would shorten the onsite surveys duration, by allowing the detailed analysis to be conducted off site later.

*note:

This type of commercial work would require some form of liability insurance. An SFOC permit from Transport Canada would also be required.

\section{D Topographic Mapping in Caledon, Ontario [2013]}

The camera can look directly down. The images can then be stitched together to generate large high-resolution images. This is useful in the agriculture sector. These detailed images can illustrate where crops are browning and determine under-irrigated areas. Inefficient irrigation systems can be redesigned and rerouted to increase crop yields and reduce crop waste. Similar application can be useful in Search and Rescue operations, fighting forest fires and managing wildlife populations. 


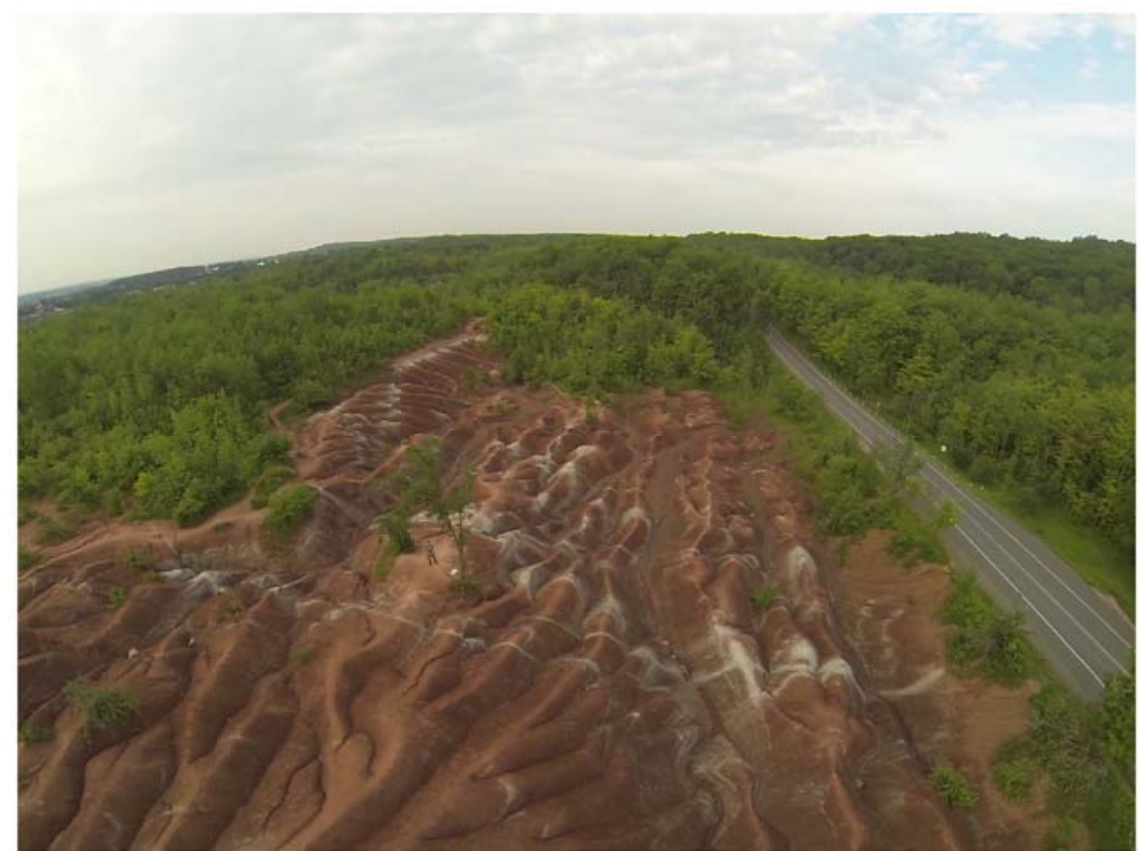

Cheltenham Badlands, Caledon, Ontario Video Still Frame

[028]
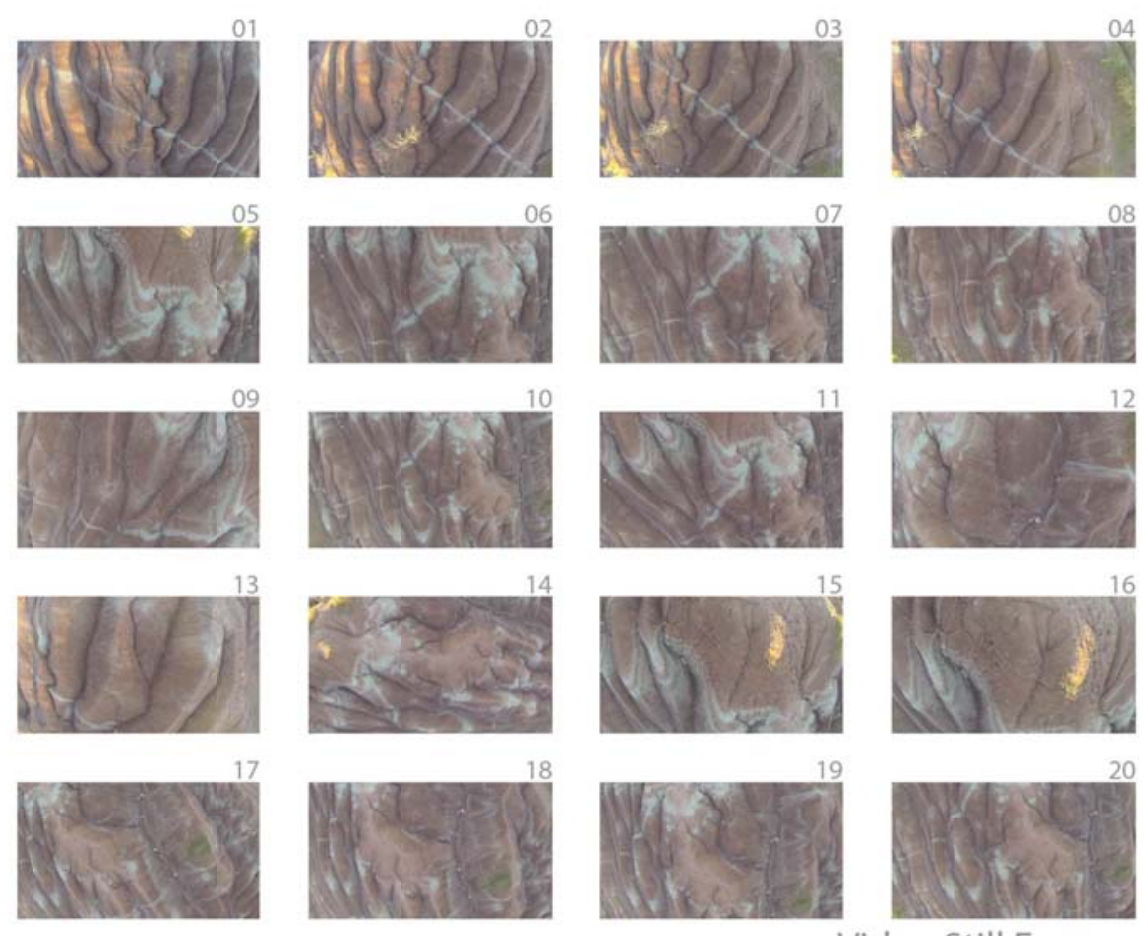

Video Still Frames

[029] 


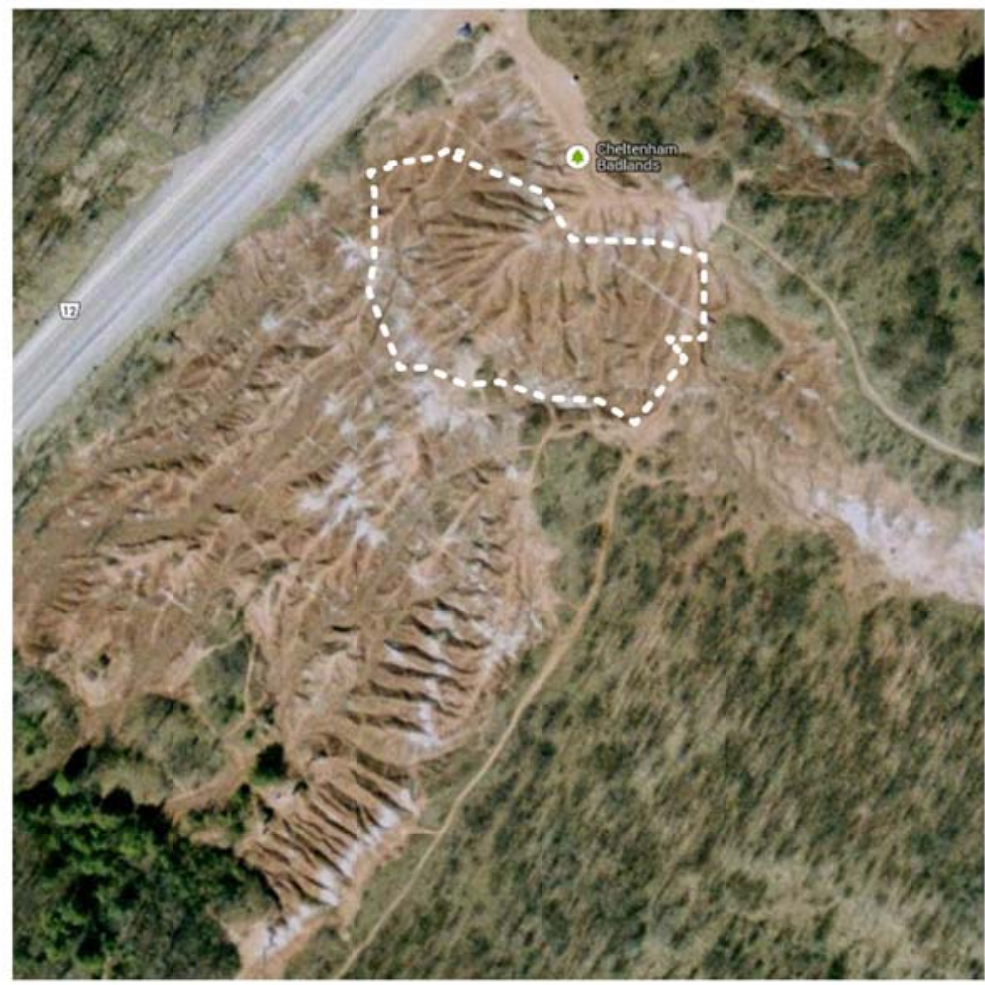

$1: 1500$

Google Maps Satellite View [030]

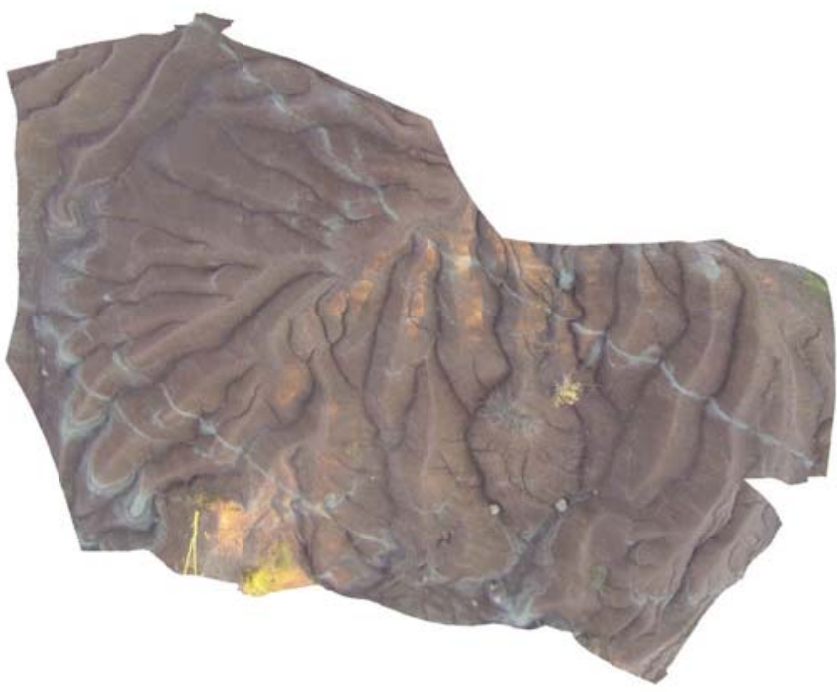




\section{Thermal Imaging}

Similar to the previous section [Aerial Surveying] where gaining a higher perspective can be advantageous. Thermal Imaging from grade is often used to determine problematic areas of energy loss in a buildings envelope ${ }^{\mathrm{iv}}$. As heat rises, often these areas are on the roof and around the eaves of the building. Institutions that own several buildings - like a university - can use this information to plan and prioritise maintenance and repairs of their aging building inventory.

For example; if there are 4 or 5 buildings all with roofing that is scheduled to be replaced in the next few years. A thermal scan could provide useful information that would typically not be available. This could provide a basis for prioritising repairs. If a roof is less efficient [losing more heat], it may be beneficial to schedule repairs or a replacement earlier than an older roof that is more energy efficient.
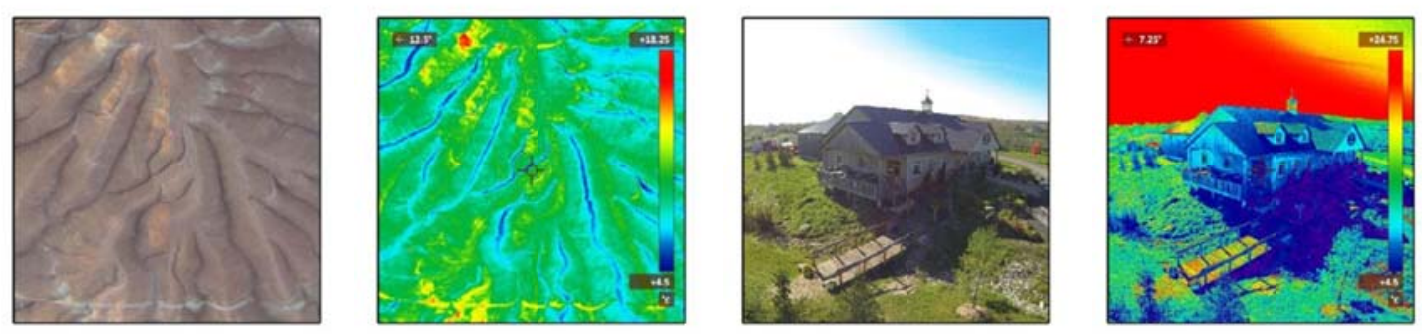

Thermal Imaging Examples

*not genuine thermal scans

*gradient map filter 


\section{D-Scanning [via photogrammetry]}

Photogrammetry is a method of 3D-scanning. ${ }^{v}$ Several overlapping 2-Dimensional photographs are taken of a single subject. These are used to create a digital mesh surface of the subject in 3-Dimensions. Specialized software [in this case, Agisoft Photoscan ${ }^{295}$ ] uses trigonometry to calculate relative distances between common reference points [in multiple photographs] and the camera. This operation is performed millions of times to generate a high-resolution point cloud model of the object being photographed [or scanned].

Laser-scannign is another form of 3D-scanning. A laser-scanner is a very expensive device [several tens of thousands of dollars]. Laser-scanning is incredibly accurate because it is a direct measurement for each point from a stationary source. Due to this, more time on-site is required to scan a particular location or building. The resulting point-cloud files are enormous and can be difficult to work with without sufficient processing power. This level of accuracy is not always required. Another downside is the stationary location, typically mounted on a tripod. Multiple scans are required to ensure $100 \%$ coverage of the subject. If scanned from only above or below, the scanner cannot detect points beyond its direct line of sight. This means that critical information is omitted, typically above or below windowsills, ledges and parapets.

By comparison, photogrammetric scanning can be performed with ANY camera. The files are considerably smaller and less accurate than laser scanning. With the camera

${ }^{295}$ (Agisoft LLC 2006-2014) 
mounted on a UAV, you can [in theory] scan objects of an infinite scale. This is how NASA and Google scan planetary objects via orbiting satellites.

A fantastic example is of this is demonstrated by Jean-Christophe Zufferey [CEO] and his team at SensFly, an École Polytechnique Fédérale De Lausanne spin-off company now owned by French drone company Parrot. ${ }^{296}$ SensFly 3D-scanned the Matterhorn in Switzerland. 3 drones flying a total combination of only 6 hours, took approximately 3,000 images to create a digital scan of the mountain. ${ }^{297}$

A notable drawback is the registration and scaling of photogrammetric scans. The data generated is scaled relative only to its self. External base points are then required to scale and orient the 3D point-cloud file correctly.

It would be ideal to use a combination of these two 3D-scanning methods because each accels where the other fall short. With photogrammetry the equipment and the stationary vantage point do not limit you. Meaning that the areas missed by a laserscanner can be filled in. A laser-scanned point cloud [even at low resolution] can be used to scale and orient a photogrammetric point cloud.

\section{D Topographic Scanning in Caledon, Ontario [2013]}

Using the orthographic photos in Fig029 the software can calculate a ' $Z$ ' coordinate [altitude] for each point. This process is repeated millions of times. The result is a pointcloud that can be modified and used in various ways. The scan can produce accurate and detailed surveys or used digitally during the design process.

\footnotetext{
${ }^{296}$ (Barraud 2013)

297 (Ibid)
} 

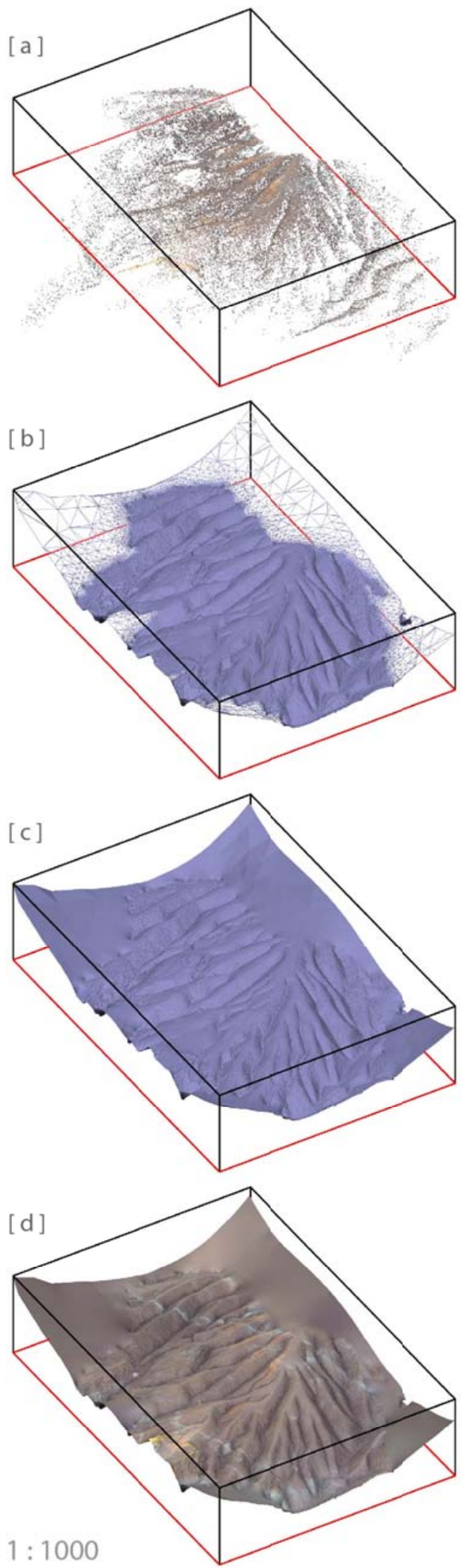

$<$ [033]

Drone 3D Topography Scan
a point cloud
b wireframe
c mesh surface
d photo projection

[034] >

Drone 3D Topography Scan Detail

point cloud a wireframe $b$ mesh surface $c$ photo projection $d$ 
[a ]

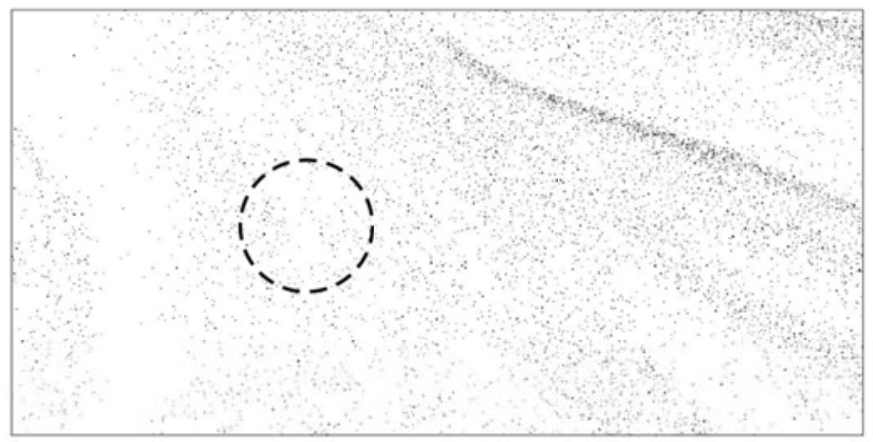

[b]

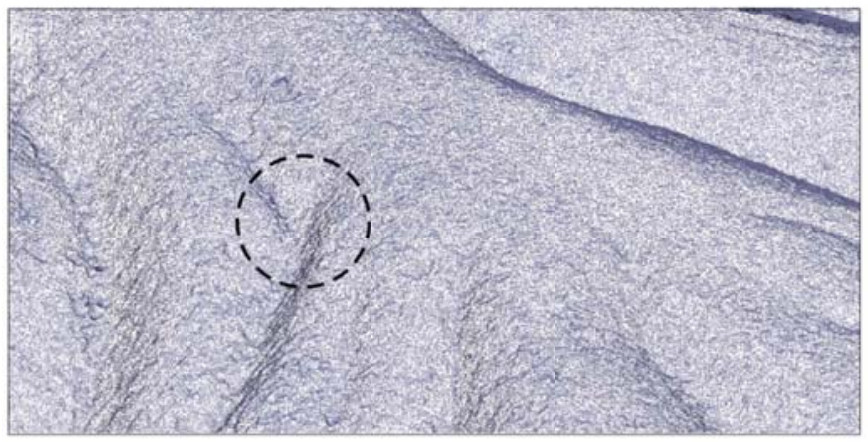

[c]

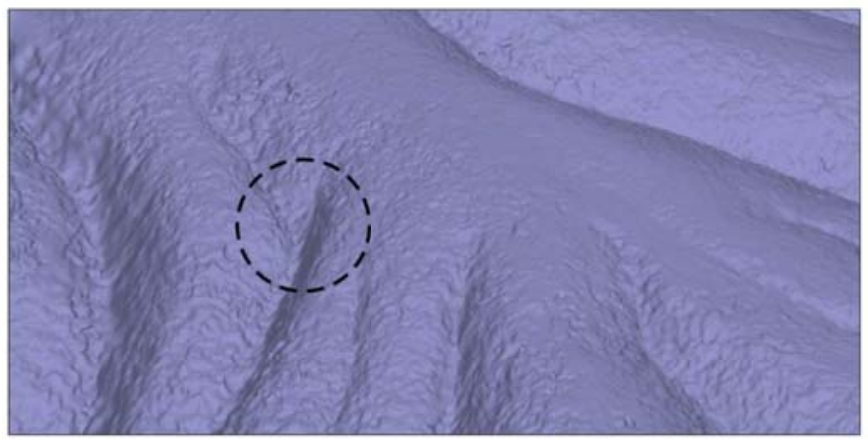

[d]

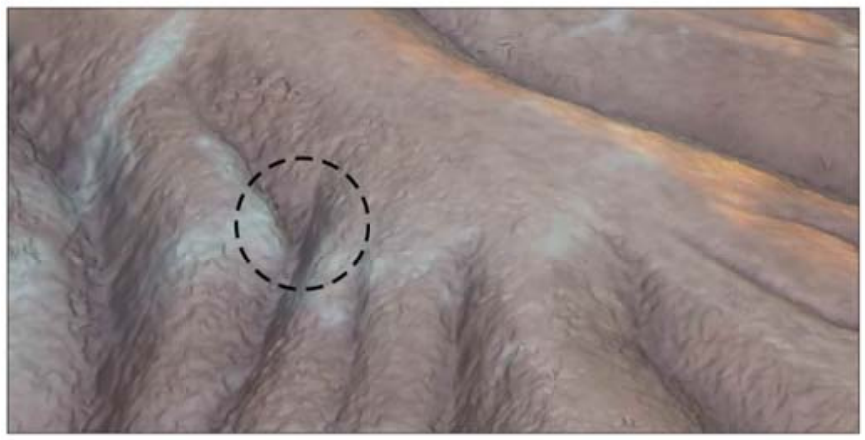

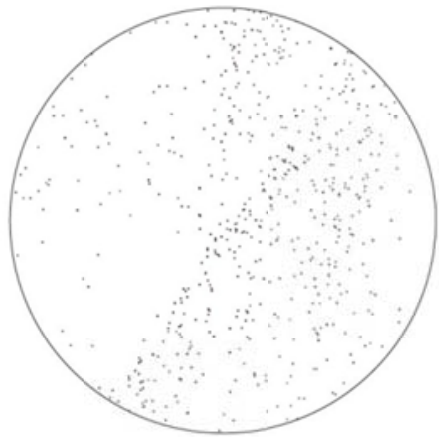
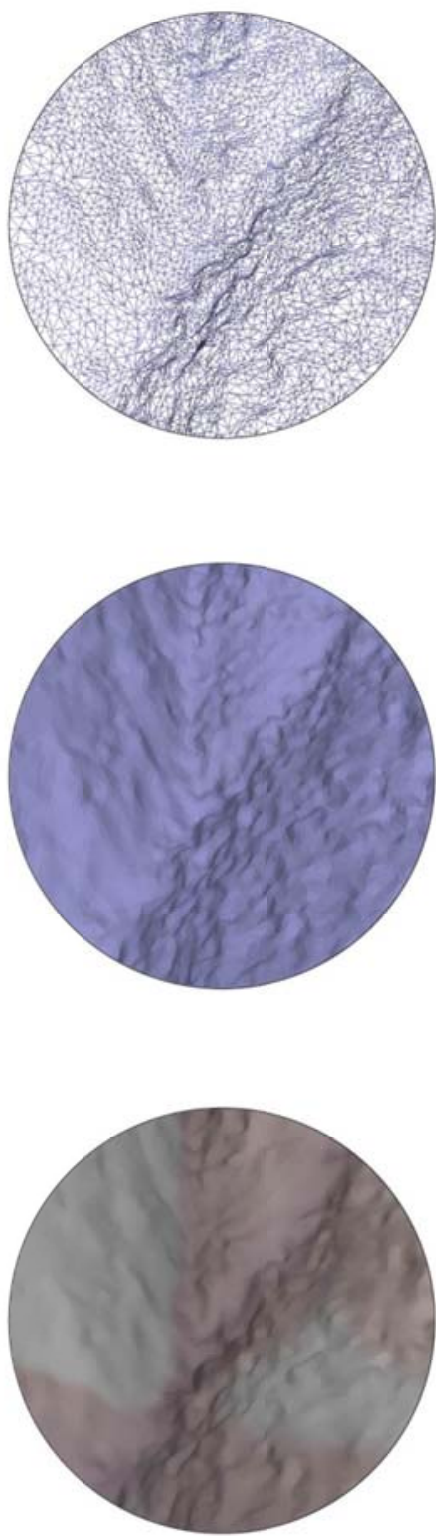


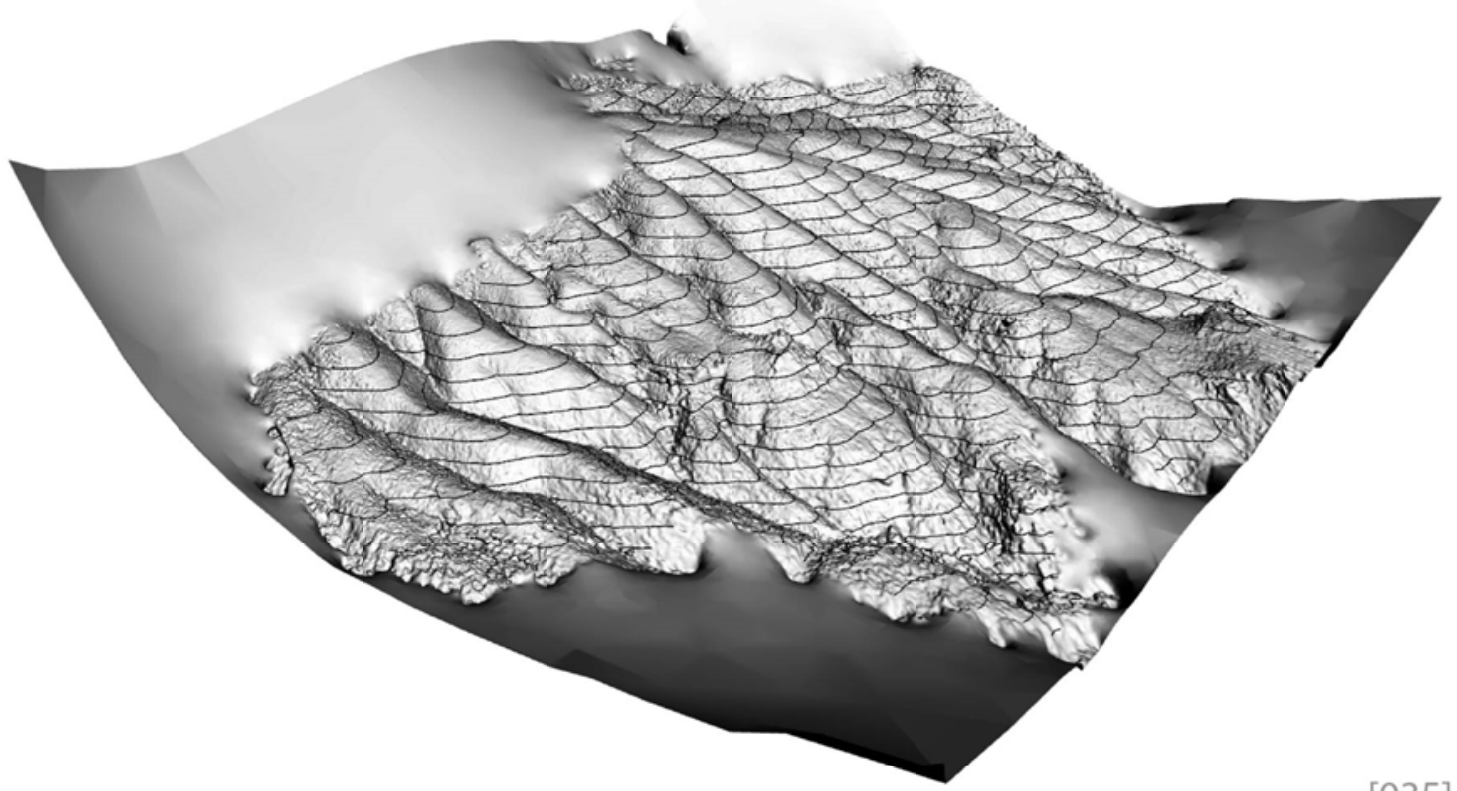

n.t.s.

Contour [0.5m] Digital Surface

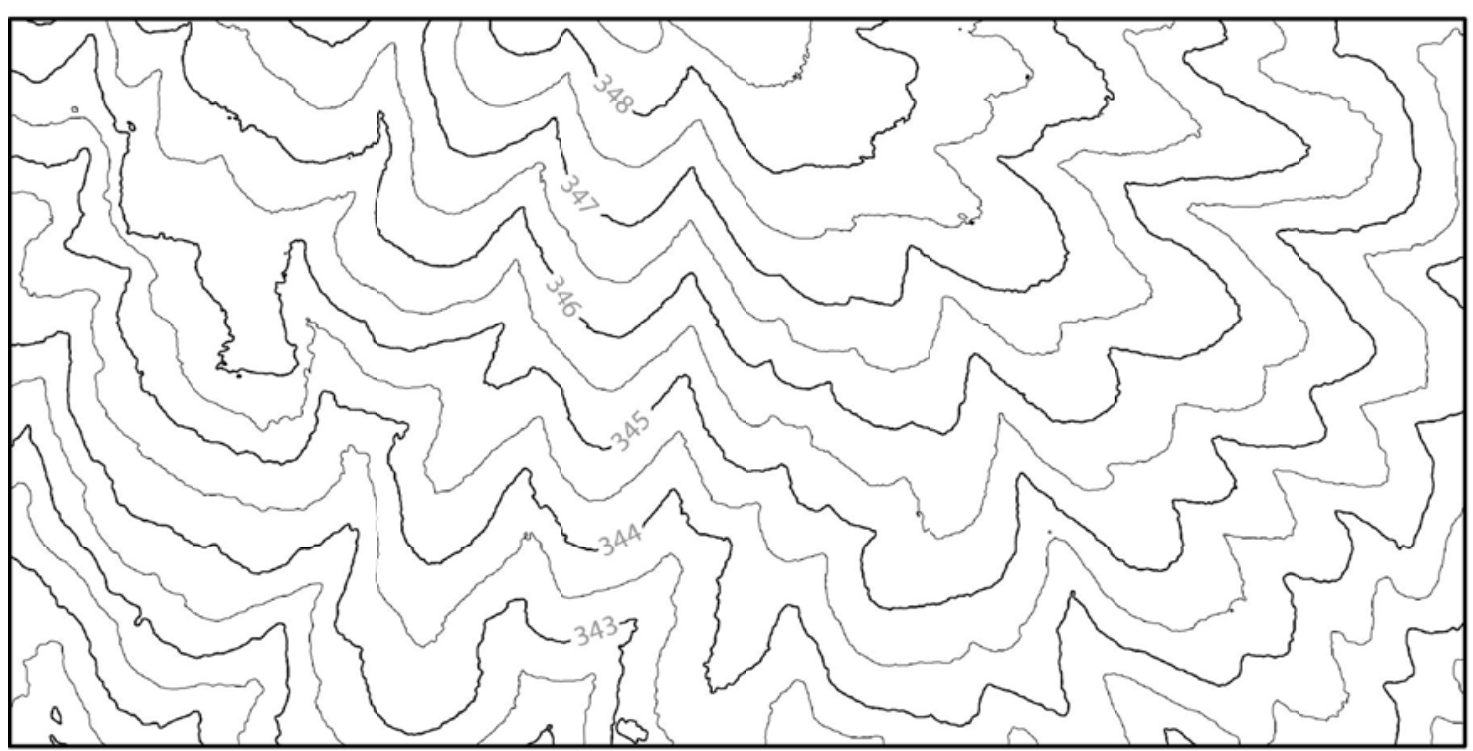


[037]

CNC Cut Mode

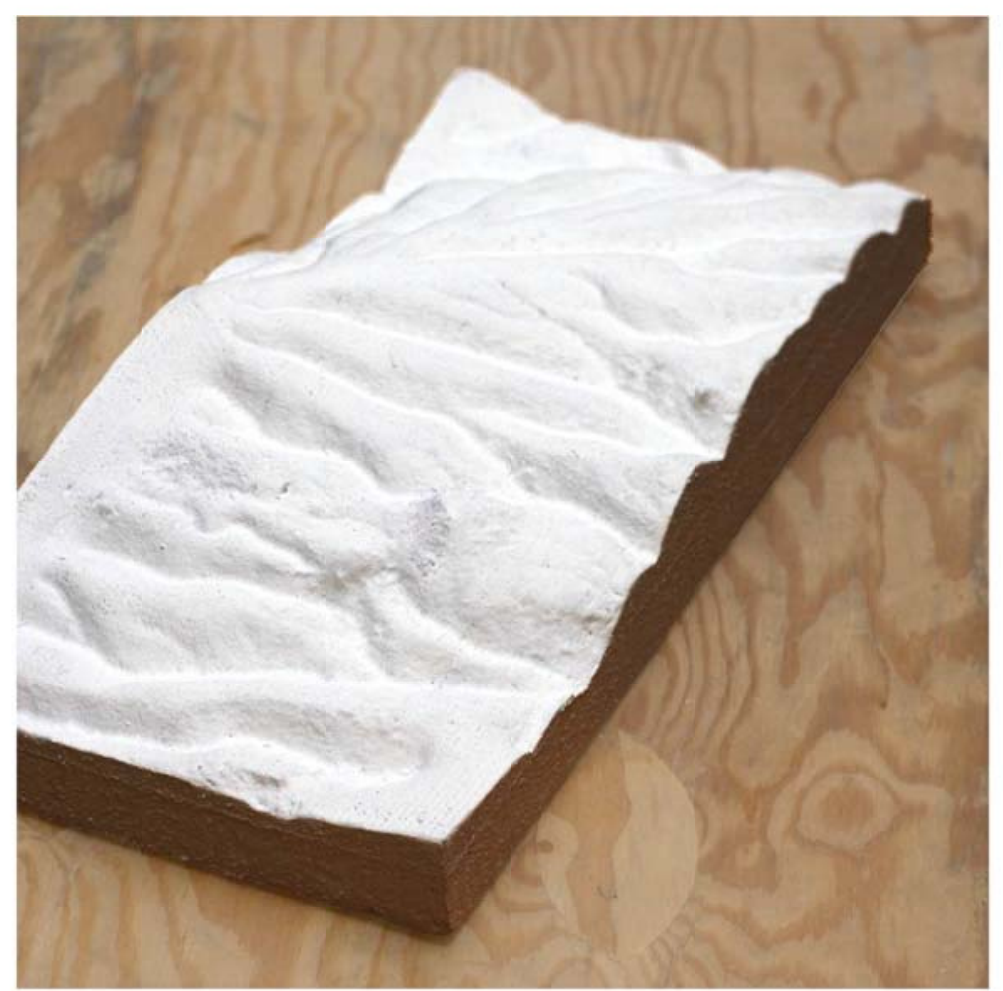




\section{Augmented Reality}

The following application is currently not a reality, but is technically feasible with available technology. The following illustrations will outline how such a method could be applied within the field of architecture.

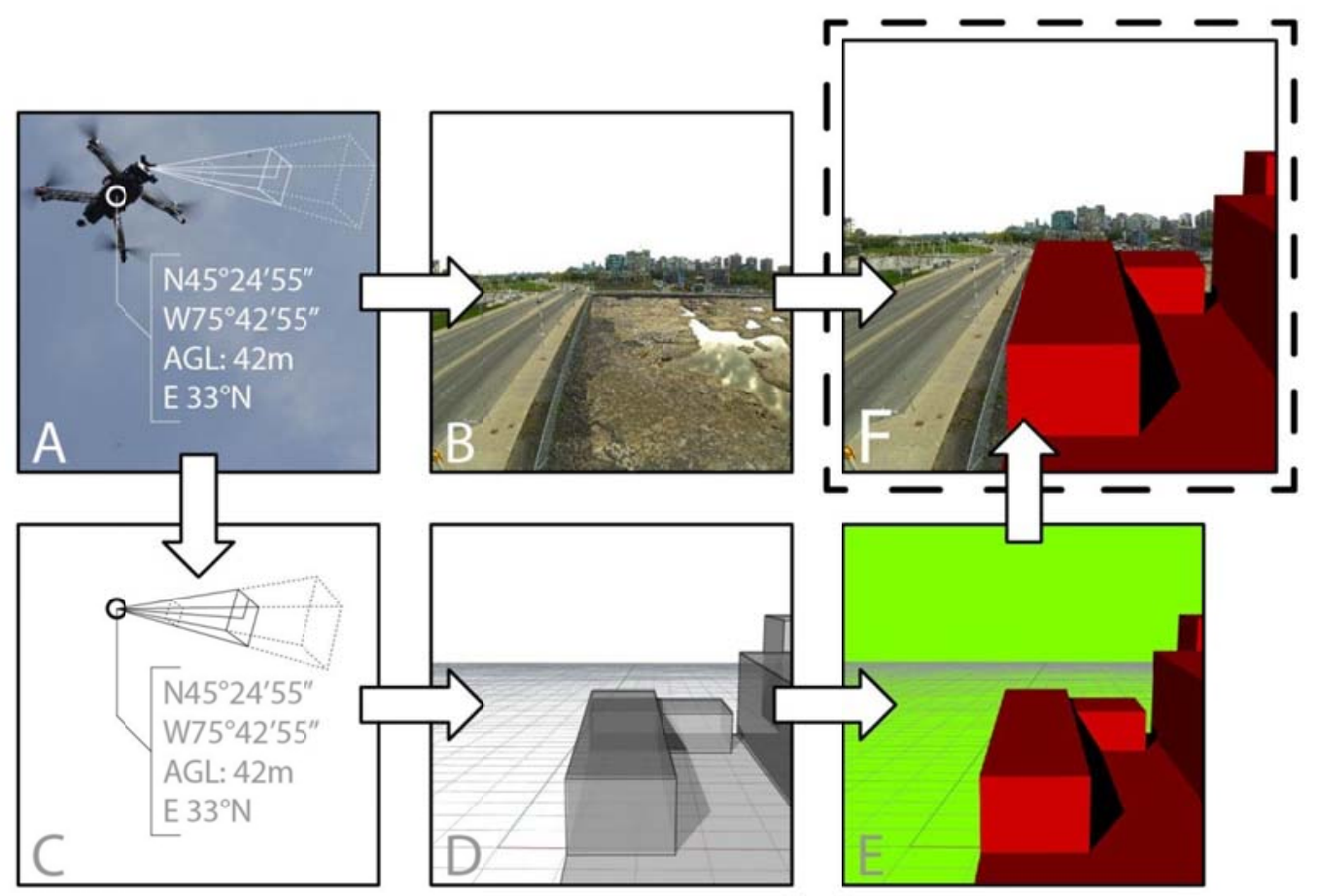

Augmented Reality Visualization [sequence of data collection] [038]

[A] Live Telemetry Data from UAV GPS Coordinates, Compass Orientation, Altitude, Camera Data [ FOV+Roll+Tilt ]

[B] Live Drone Perspective [FPV] Video Output

[C] Virtual Cloned Camera [geographically located] Refreshes the Live Telemetry Data [A] as Location of Virtual Camera

[D] Clone Camera Perspective Virtual Perspective in Geographically Located Virtual Space

[E] Video Export Digital Output with Transparent Background [not literally a green screen]

[F] Resulting Augmented Reality Final Composite Image or Video in Real Time 
Architects often insert digital renderings into photographic representations of our sites. Typically, we match/estimate the perspectives in programs like Adobe Photoshop. What if we could accurately measure and clone the perspective from a specific point in both reality and virtual 3-dimensional space? This would remove the guesswork and inaccuracy of artificially matching perspectives afterward.

Current methods of visiting sites remotely by available aerial or satellite imagery are useful. Unfortunately, we are missing the critical location data and specs of the camera that are necessary to provide this accuracy. The flexibility of controlling the cameras vantage point is also not available.

By using a drone, we can technically measure the exact 3-dimensional location of the drone's camera [via GPS, telemetry and altitude data]. The cameras specifications and settings [focal length, compass direction, camera attitude and angle] are all known or measurable information. When this information is available at the time of capture/render, we can clone this camera in our virtual space. Overlaying the resulting images produces a composite image that is a measured and accurate representation of the future construction. 


\title{
Part ii: TOWARD AN AERIAL INFRASTRUCTURE
}

The social landscape is far from seamless and free of conflict when new technologies are introduced and implemented. ${ }^{298}$ Technology is not a panacea for all of the world's problems, but can provide the necessary tools to begin tackling these issues. Globally, our technology allows us to strive for new efficiencies. There are many truths in the globalized world; our population will continue to rise, ${ }^{299}$ we will continue to urbanize ${ }^{300}$ and will continue to automate.

\begin{abstract}
"Architecture is the manifestation of the spirit of an age, seizing upon its technical conquests. It imparts to what is to become the face of the land, that aspect of youth and honesty which revives the spirit, stimulates creative activity, and constitutes the new links of the unbroken chain of tradition, that chain whose every link was at one time an act of creative optimism, a forward step, a constructive effort." ${ }^{301}$
\end{abstract}

- Le Corbusier

Entire economies are structured on the movement of three things; people, information and physical goods [raw, processed or manufactured]. With the internet, we revolutionized how we transfer, move and share information. Our existing infrastructures successfully move people around, though there is room for improvement. Until now the movement of things, stuff, matter is largely reliant on the movement of people that control the transfer of goods. We now possess the technological capacity to automate many of these processes, creating new efficiencies.

\footnotetext{
298 (Katja Franko Aas 2009, 8)

${ }^{299}$ (Ricky Burdett 2011, 36-37)

300 (Ibid, 9)

${ }^{301}$ (Corbusier, Aircraft 1967, 27)
} 
Designing net-zero architecture has been a goal in sustainability for some time now, but we do not discuss the possibility of a net-zero networks of transportation. Current examples of net-zero transportation only include walking, bicycles and sailboats, each with considerable limitations. Electric cars are a good start, but even if every car on the road became electric overnight, this would not address congestion in our cities or solve our global demand for energy. In eastern Canada to have a large portion of our electricity is provided by hydro-electric powerstations. Unfortunately the vast majority of the planet burns coal to produce electricity. The real problem is the car as a model for the transporting goods.

"1909 theorem: the Skyscraper as utopian device for the production of unlimited numbers of virgin sites on a single metropolitan location."^302*

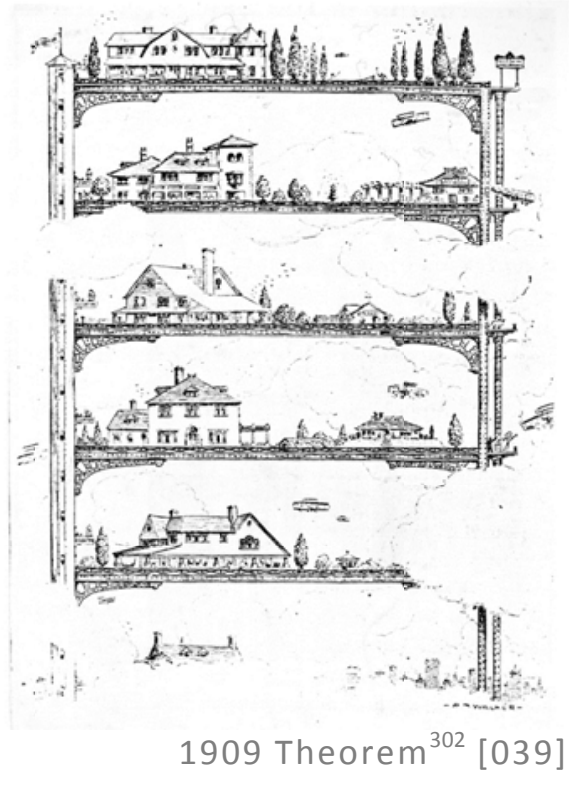

Our buildings can now reach for the skies, but our daily transportation was left grounded. Increasing population density has led to the congestion we associate with our urban centers. The desire for our transportation infrastructure to mimic the verticality of our buildings has been around for over 100 years. Futurists of the time 302 (Koolhaas, Delirious New York: A Retroactive Manifesto for Manhattan 1994, 83) 
were optimistic that airplanes and dirigibles would make this a reality. In hindsight the proposals are inherently flawed due to the limitations of manned aircraft. With UAVs, are we able to reinterpret this original ambition and desire?

"THE COSMOPOLIS OF THE FUTURE. A weird throught of the frenzied heart of the world in later times, incessantly crowding the possiblities of aerial and inter-terrestrial construction, when wonders of $1908 \ldots$ will be far outdone, and the 1,000 foot structure realized; now nearly a million people do business here each day; by 1930 it is estimated the number will be doubled, necessitating tiers of sidewalks, with elevated lines and new creations to supplement subway and surface cars, with bridges between the structural heights. Airships too, many connect us with all the world. What will posterity develop?"

(Published by Moses King, rendered by Harry M. Petit.)^303*

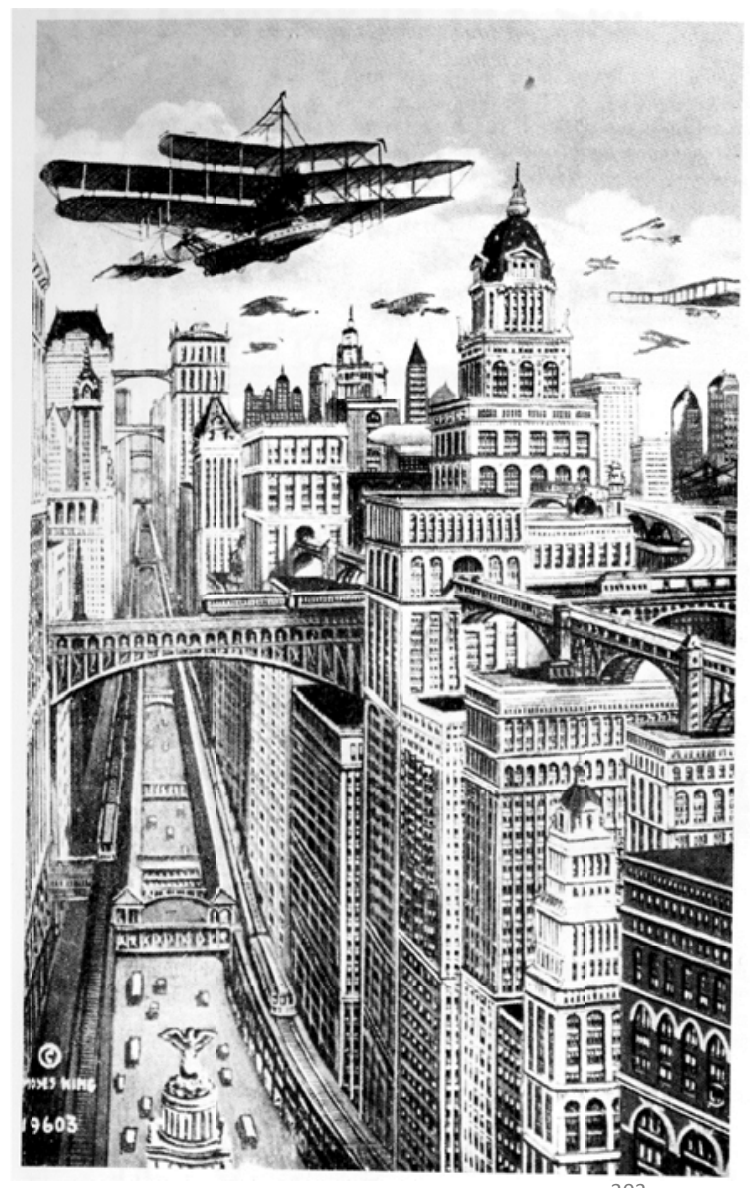

The Cosmopolis of the Future ${ }^{303}$ [040]

Drones are not thought of as a tool for minimizing energy consumption. A complex network of fully autonomous UAVs could be designed into our existing urban and rural landscape without destructive interventions. The vehicles are small, lightweight and completely adaptable. The average weight of an American car in 2004 was $1,800 \mathrm{~kg}$

${ }^{303}$ (Koolhaas, Delirious New York: A Retroactive Manifesto for Manhattan 1994, 84) 
$[4,000 \mathrm{lbs}] .^{304}$ Driving such a vehicle several kilometers to purchase and transport small loads [under $5 \mathrm{~kg}$ ] is obscenely inefficient, but this is common today. A payload to weight ratio of 1:360. The vast majority of engergy comsumed by civilian transportation is wasted moving the people and vehicles themselves. Not the desired goods we need to relocate.

Amazon and Matternet are separate entities that approach these issues in dramatically different contexts and with varying ambitions. First, Matternet wants to impliment this form of transportation over rural areas in developing regions of the globe. Second, Amazon is proposing a similar system for comercial distribution in urban centers.

\section{Case Study 1: Matternet ${ }^{305}$}

Andreas Raptopoulos is the founder of Matternet. Their goal is to create UAVs that perform as a leapfrog technology in developing nations where season road access is limited or unpredictable. ${ }^{306}$ Mobile communications are a recent example of a leapfrog technology. ${ }^{307}$ Previously isolated regions of the globe were unable to install telecommunication cables [landlines]. Now cellular networks connect these communities, allowing entire countries to skip over a generation of communication infrastructure development. Matternet hopes that their UAVs will have similar effect on transportation. $^{308}$

\footnotetext{
304 (Hakim 2004)

305 (Matternet Inc. 2014)

306 (Raptopoulos 2013)

307 (Ricky Burdett 2011, 61)

308 (Raptopoulos 2013)
} 
According to Raptopoulos, 1 billion people worldwide live in regions that become isolated seasonally due to flooding; primarily in Africa, India and inland China. ${ }^{309}$ When roads wash out, this makes getting critical supplies and medication impossible.

Matternet is proposing installing a network of drones in rural Lesotho to transport HIV/AIDS tests from remote clinics to centralized laboratories for analysis. The drones would fly autonomously along a specified route, docking at stations along the way to exchange batteries. This extends the overall range when carrying specialized cargo. ${ }^{310}$ Matternet calculated the cost to install a network of 50 nodes [charging stations], 150 UAVs that would connect 47 clinics to 6 labs in the district of Maseru. The network would cover nearly $140 \mathrm{~km}^{2}$ for less than $\$ 1$ million USD, the equivalent cost of a single lane highway $2 \mathrm{~km}$ long. ${ }^{311,312}$ The final cost to transport $2 \mathrm{~kg}$ a distance of $10 \mathrm{~km}$ is only $\$ 0.24$ USD. This includes the cost of the vehicle [\$0.03], batteries [\$0.09], ground stations $[\$ 0.10]$ and energy consumed $[\$ 0.02] .{ }^{313}$

Raptopoulos also speaks of integrating this type of network into large cities, but acknowledges the advantages to testing out this system in a remote rural location first. Risks of personal injury and damage to private property are reduced. As the system matures, the nodes can expand into new communities, growing the network organically. ${ }^{314}$

\footnotetext{
${ }^{309}$ (Raptopoulos 2013)

310 (Ibid)

311 (Ibid)

312 (Macguire 2013)

${ }^{313}$ (Macguire 2013)

${ }^{314}$ (Raptopoulos 2013)
} 


\section{Case Study 2: Amazon Prime Air ${ }^{315}$}

Amazon CEO Jeff Bezos revealed a research and development program that would deliver consumer products via drones, from their distribution centers in major cities. ${ }^{316}$ The news went viral immediately, sparking fear in some and excitement in others. Many viewed the radical idea as merely a publicity stunt. ${ }^{317}$ The FAA is currently is not open to the idea of delivering packages via drones and Bezos admits that the technology needs some refinement before it can be realized. Amazon has played an important role in revolutionizing retail with online shopping, warehouse/shipping automation and more recently in cloud-computing. ${ }^{318}$ Amazon has the resources available to invest in research and development, they have a lot to gain if they can make this a reality.

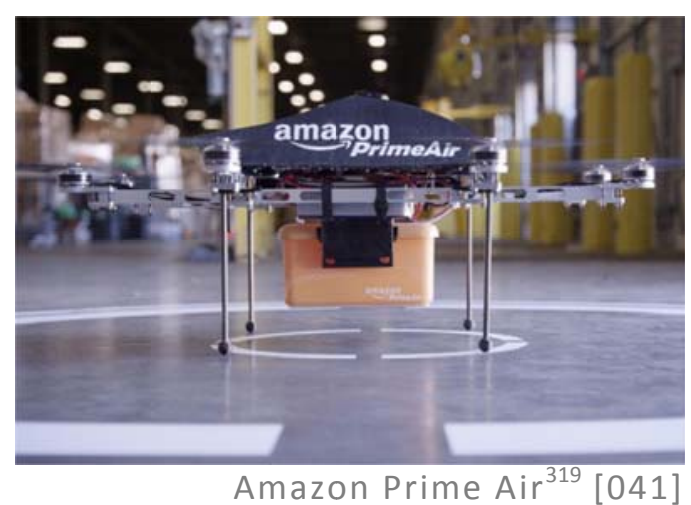

Details are scarce, but we do know that Amazon is actively seeking FAA approval to begin testing their UAV delivery system outdoors near Seattle. ${ }^{320}$

\footnotetext{
${ }^{315}$ (Amazon.com, Inc. 1996-2014)

${ }^{316}$ (Seetharaman 2014)

317 (Wohlsen, Even if the Feds Let Them Fly, Amazon's Delivery Drones Are Still Nonsense 2013)

318 (Wohlsen, Ground War: Tech Titans Take their Fight to the Streets 2014, 26)

319 (Amazon.com, Inc. 1996-2014)

${ }^{320}$ (Seetharaman 2014)
} 


\section{Toward an Aerial Infrastructure [continued]: The Last Mile}

These two examples demonstrate the wide variety of contexts - both rural and urban where UAVs have potential applications.

We know that the UAV's are rapidly evolving. A significant obstacle for Amazon is the interface where the UAV interacts with our built environment. In their initial promotional video release, the drone lands on the front lawn, drops a parcel and flies off. This scenerio would be dangerous to pedestrians and pets, the parcels are vulnerable to theft and damage when left unattended. This step appears to have been overlooked in each of our case studies. The vehicles and the network are developed, but the end nodes are less defined. This is where the architecture of the city or community can engage with this new form of transportation.

Traditional postal delivery services have had to radically restructure due to the expanson of the internet. Email has effectively killed off letter-mail, while simultaneously online shopping and therefore parcel delivery is now a rapidly growing market. Canada Post reported that mail volumes fell by $5.3 \%$ in 2013 continuing a decline that began in $2007,{ }^{321}$ conversely they delivered 5 million more parcels than the previous year [2012]. ${ }^{322}$

This direct-to-consumer delivery business model has struggled to overcome what is know as the last mile problem. It is when you can no longer aggregate packages being distributed. This is not an issue for mineral extraction, manufacturing and early

\footnotetext{
321 (Canada Post Corporation 2014)

322 (Ibid)
} 
distribution because material is shipped in bulk on trains or trucks. In Canada, this method of distribution ends at a retail or post office location.

Courier services still aggregate packages on deliveries beyond this point, this is were systemic inefficiencies become apparent. The last parcel delivered on a given route will have traveled a greater total distance than the direct distance from the post office to the recipient. Packages often do not fit in the mailboxes of homes or apartment buildings, these parcels are brought back to the post office to be picked up by the recipient at a later time.

Canada Post is experimenting with how to restructure their operation. They have announced that they will begin to phase out urban home delivery services. ${ }^{323}$ This is an effort to reverse the $\$ 269$ million operating loss posted in their 2013 annual report. ${ }^{324}$ Currently Canada Post delivers directly to the doors of approximately 5 million address nation wide. ${ }^{325}$ They deliver to an additional 10.1 million addresses in the form of community or apartment mailboxes. ${ }^{326}$

Unfortunately, the shift away from home delivery back to community mailboxes will disproportionally impact the disabled and the elderly. This is exacerbated by the preexisting deficiencies inherant in an obselete mailbox system. Parcels will not fit into community postal boxes and residents will have to retrieve them from the post office after an attempted delivery.

\footnotetext{
${ }^{323}$ (CBC News 2013)

${ }^{324}$ (Canada Post Corporation 2014)

${ }^{325}$ (CBC News 2013)

${ }^{326}$ (Ibid)
} 
There are several potential efficiencies created by an Aerial Infrastructure that incorporates UAV's. The direct to end-user distribution eliminates the excess distance parcels travel currently. The complex network of drones will operate autonomously, reducing the need for traditional ground-based delivery trucks. This system reduces the need for personal vehicles on the road to send and retrieve small payloads. Saving everyone time, reducing overall energy expenature and vehicular traffic on roadways.

It is impoortant to note that this requires radically rezoning our public airspace and these technologies need to continue to mature moving forward.

How would we begin to organize such a network? What would this virtual aerial network look like? Fig042 is an attempt to illustrate the possible principles that would be needed. Fig042 is an aerial view over downtown Ottawa, but a flexible system could be applied to any urban area. The system demands distinct distribution hubs, these are located at existing post offices though out the city. This allows us to use the existing ground networks for bulk distribution. From each node a payload could be delivered to any residence within a specific radius, determined by the UAV's flight capability. The UAV's would travel at various altitudes depending on their compass orientation. Individual UAV's would be virtually aware of nearby aerial vehicles to avoid collisions. These vehicle would fly at lower altitudes to avoid dangerous interactions with larger passenger aircraft. There would be a need to create No-Fly-Zones or Drone-Free-Zones. 


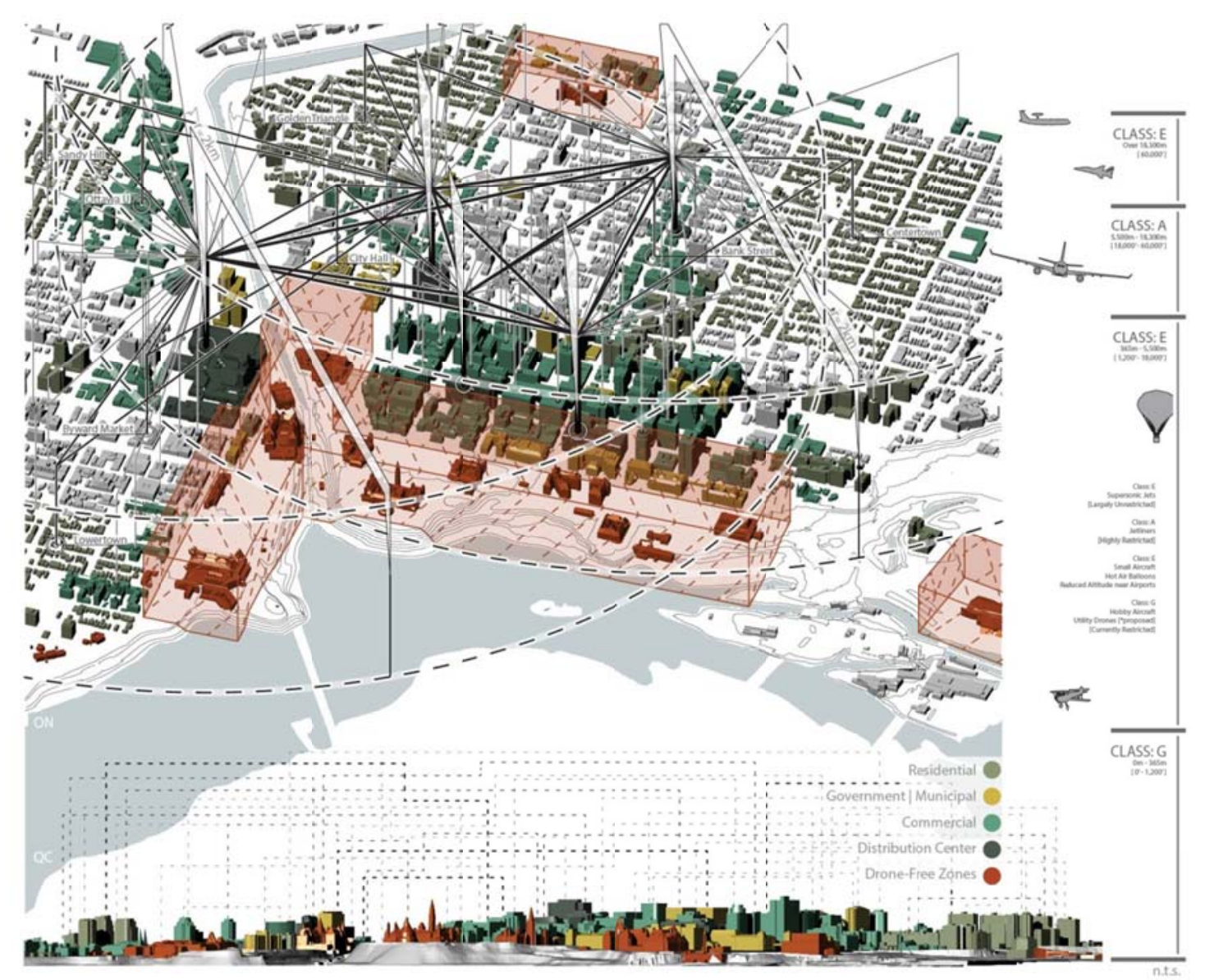

[042] Aerial Infrastructure: 3D City Map

UAV Virtual Transportation Network

PFK

Once rezoning is complete, our existing buildings will require a strategy to accept and interact with this new aerial distribution network. Fig043 illustrate a new method to receive and store parcels for pick-up by the intended recipient. This node would be scalable depending on the locations demand and population density. The system would borrow and improve existing technologies; ATMs and vending machines. Individual pods are larger than traditional mailboxes, but would not be assigned to a single 
address. Instead, each parcel is assigned to a retrieval code that is sent to the intended recipient. This reduces the overall number of pods needed. This system would typically be roof mounted in dense urban areas, limiting possible obstacles that would endanger the UAV during flight.

[a ] Power Source - Solar Array

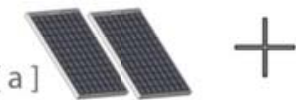

[b ]

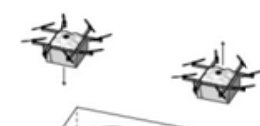

$[a]$

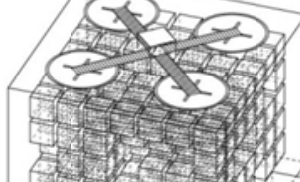

[c]

[d]

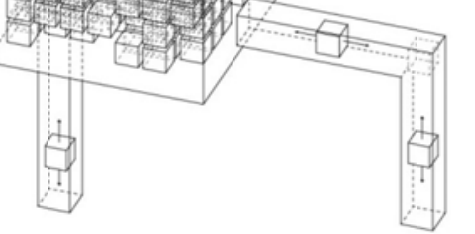

[e]

[ b ] Landing Pad - Recieving Port

[ c ] Postal Box Matrix - Scalable

*each individual unit can move freely within the matrix

[d] Option 1: Internal shaft to floors or ground level

[e ] Option 2: External shaft to floors or ground level

Aerial Infrastructure: Existing Building [043]

PFK

A similar strategy is applied to less densely populated communities, at a smaller scale.

Fig044 is an example of what would will replace a typical suburban community mailbox.

At first, it would not be necessary to have UAV receptacle nodes at individual addresses.

The minimal footprint would reduce the spatial impact on ground level. The structures canopy would contain the receptacle pods and provide a docking station on top. The 
structures enclosure is comprised of photovoltaic solar cells, producing electricity to operate the internal moving components. The faceted mass is designed to increase the surface area where the solar cells are exposed to the sun. The spiralling form ensures maximum exposed surface area at all times throughout the day and year.

[ a ] Power Source - Solar Array Facade *Form maximizes effective solar surface throughout the day

[b ]

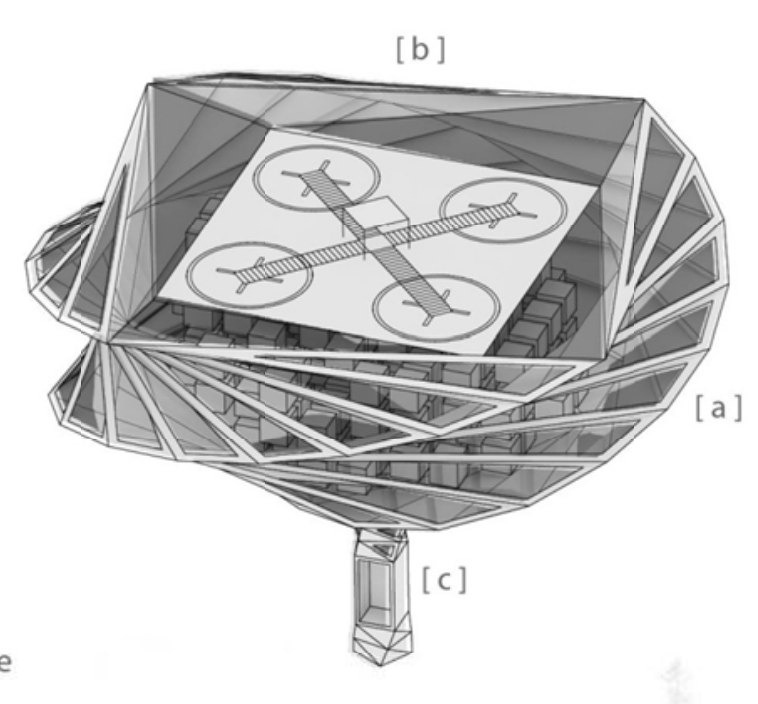

*Comination of an ATM + Vending Machine

[b ] Landing Pad - Recieving Port

[c] Receptacle

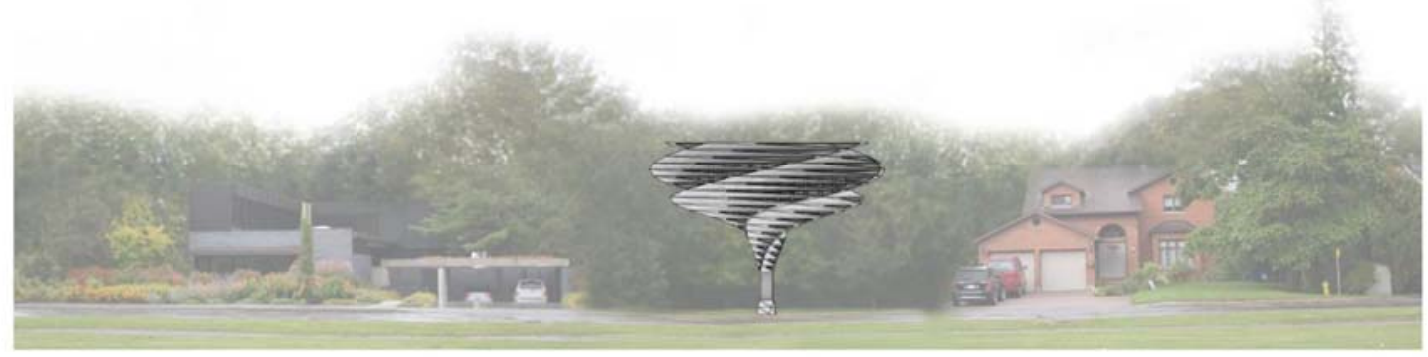

[044] Aerial Infrastructure: Community Parcel Box [Rural+Suburban] PFK

In semi-dense low-rise neighbourhoods were open public space is limited, other approaches can be undertaken. These nodes are scaled to meet the demand at any given location. In low-rise areas where roof mounted nodes would not service a sufficient user base. Fig045 is an example of what a node located above an 
urban intersection could appear. The vertical space is free from obstructions. While there is no available public space to locate an urban node, the intersection provides a unique address/location without required the addition or subdivision of existing lots or addresses. Each of these systems could be designed to both act as bidirectional nodes, where occupants could both send and received items transported via UAV.

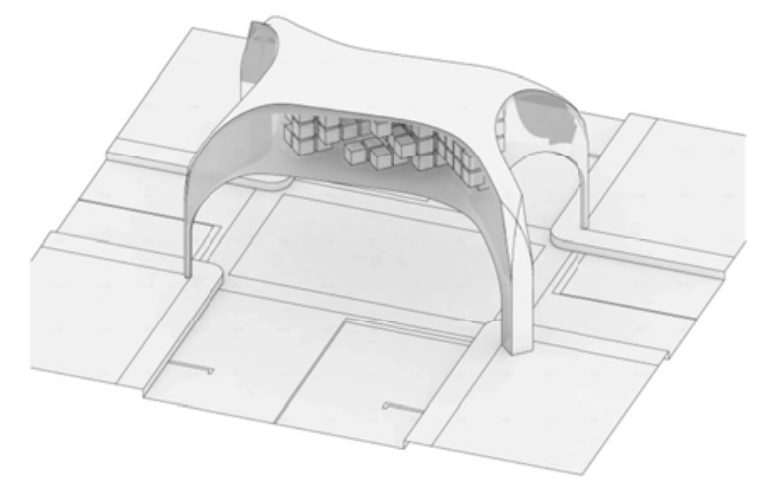

[045] Aerial Infrastructure: Community Parcel Box [Urban] PFK

Eventually it will be possible for hundreds, if not thousands of drones to be operating in our urban centers. Efficiently transporting goods around our cities to where they are needed. This form of automation will no doubt have an impact on certain professions. The development of an entirely new transportation network and typology also demands the creation of new jobs, markets and economies. The investigation into alternative transportation and technologies will become to increasingly important to address the demands of the growing metropolises globally. 


\section{EPILOGUE}

We rarely can predict how rapidly emerging technologies will evolve and which ones will radically alter our lives. The evolution of UAV technology is not exempt from such unpredictability. The UAV industry is aggressively pushing the boundaries of what is possible in the public realm. A select few Architects have begun experimenting with autonomous construction and assembly using drones. This text has demonstrated how UAV's have already proven useful to Architects for primitive applications; and outlined future uses that are on the horizon. Possible built strategies to interact with emerging UAV technologies are proposed for various urban conditions.

There is another critical perspective that is important to highlight. This particular technology has evolved out military surveillance applications. The nature of a fully autonomous vehicle requires that it sense and record its surroundings. Surveillance and architecture have long been intertwined, but the capabilities of these aircraft, far surpass those of traditional static CCTV camera systems. This form of emerging technology could enable incredible efficiencies, but they will also continue to raise concerns regarding the monitoring of public space. This is where our collective spatial consciousness may have to evolve. UAV's embody the amplification of both public and private spaces. The public realm is continuously regulated, controlled, monitored. When in public you are vulnerable to various forms of subtle surveillance. The desire for private space is amplified as a result. Jorge Rueda's photography Lolafile [Fig046] emphasizes this disparity between the public and private realms. 


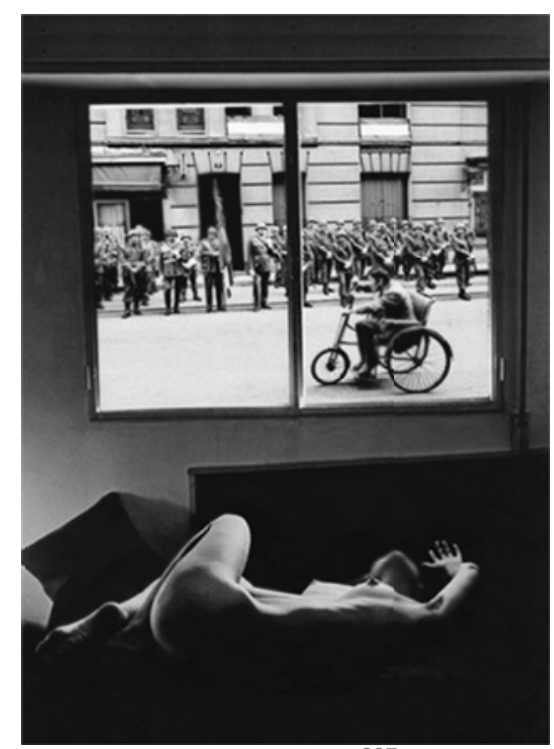

[046] Lolafile, $1973^{327}$

Jorge Rueda

Rueda clearly depicts the desire for an intimate private dwelling, isolated from the outside world and the militarization of the public streetscape. This process has been ongoing and largely enabled by innovative technologies from invention of film photography to satellite imagery and now drones.

Perhaps this is an over simplification, but what in our built environment is it that Architects are primarily responsible for? Is it the built form architecture takes on or is it the negative space left in between [Fig047]?

${ }^{327}$ (Erueda 2011) 


\section{"Form"}

- the Object

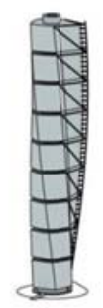

Turning Torso [2005]

Malmö, Sweden

Santiago Calatrava

[047] Space vs Form

PFK
"Space"

- the Negative

VS.

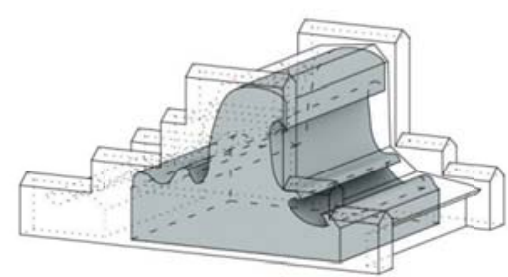

Bagsværd Church [1976]

Copenhagen, Denmark

Jørn Utzon

Obviously both are important aspects of what Architects shape and control. In the past, emerging material technologies altered what forms and spaces we could create, but these are not as directly challenged by an aerial infrastructure comprised of UAV's. It is the threshold between these realms that is challenged and in need of refinement.

Public

- implied voyeurism

\section{Private}

- intimate dwelling

[048] Public vs Private

PFK

The way the façade filters the relationship between both the public and private realms is critical. As the attitudes of these realms are amplified, our strategy to mitigate that relationship needs to evolve. The transition from iron to steel allowed us to internalize 
the structure and completely free up our façades [Fig049]. This is emphasized in the works of Le Corbusier [Dom-ino, fig049], Mies van der Rohe [Farnsworth House] and Philip Johnson's [Glass House]. These modern structures proved difficult and uncomfortable to inhabit, because the occupants were completely exposed.

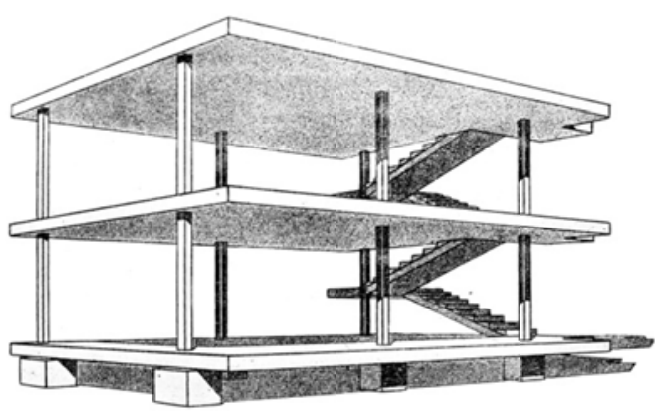

[049] Maison Dom-Ino, $1915^{328}$

Le Corbusier

There is a difficult balance that has to be found. Can we maintain openness, without leaving ourselves exposed and vulnerable; sheltered and protected, but not confined? This balance is different in determined by place and time. It is common to design a façade to control and filter the amount of solar exposure. UAV's present an additional challenge if were are to mitigate their ability to visually breach that threshold.

${ }^{328}$ (Frampton 2007, 153) 


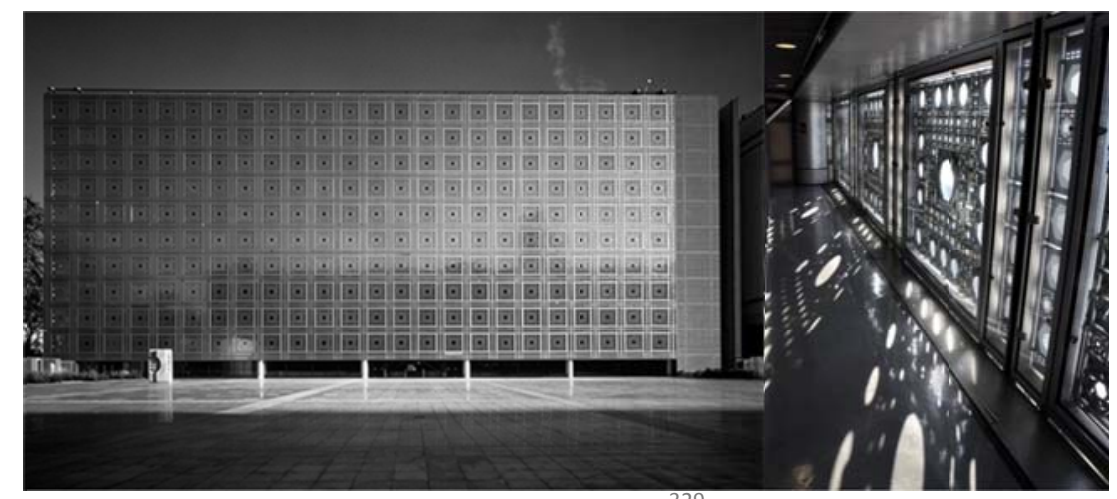

[050] Institut Du Monde Arabe, $1987^{32}$

Architect: Jean Nouvel

Paris, France

Architects will have to create entirely new methods of enclosure that will address these concerns. The contemporary curtain wall or traditional window as we experience them now will become as obsolete as the load-bearing masonry arch. Kinetic apertures, louvers, screening mechanisms and smart materials would become commonplace allowing the architect or the occupant to throttle that separation.

${ }^{329}$ (Institut Du Monde Arabe n.d.) 


\section{APPENDIX A: PRESENTATION PANELS $[i-i i]$}

Part i: Drones for Architects

Part ii: Towards an Aerial Infrastructure 


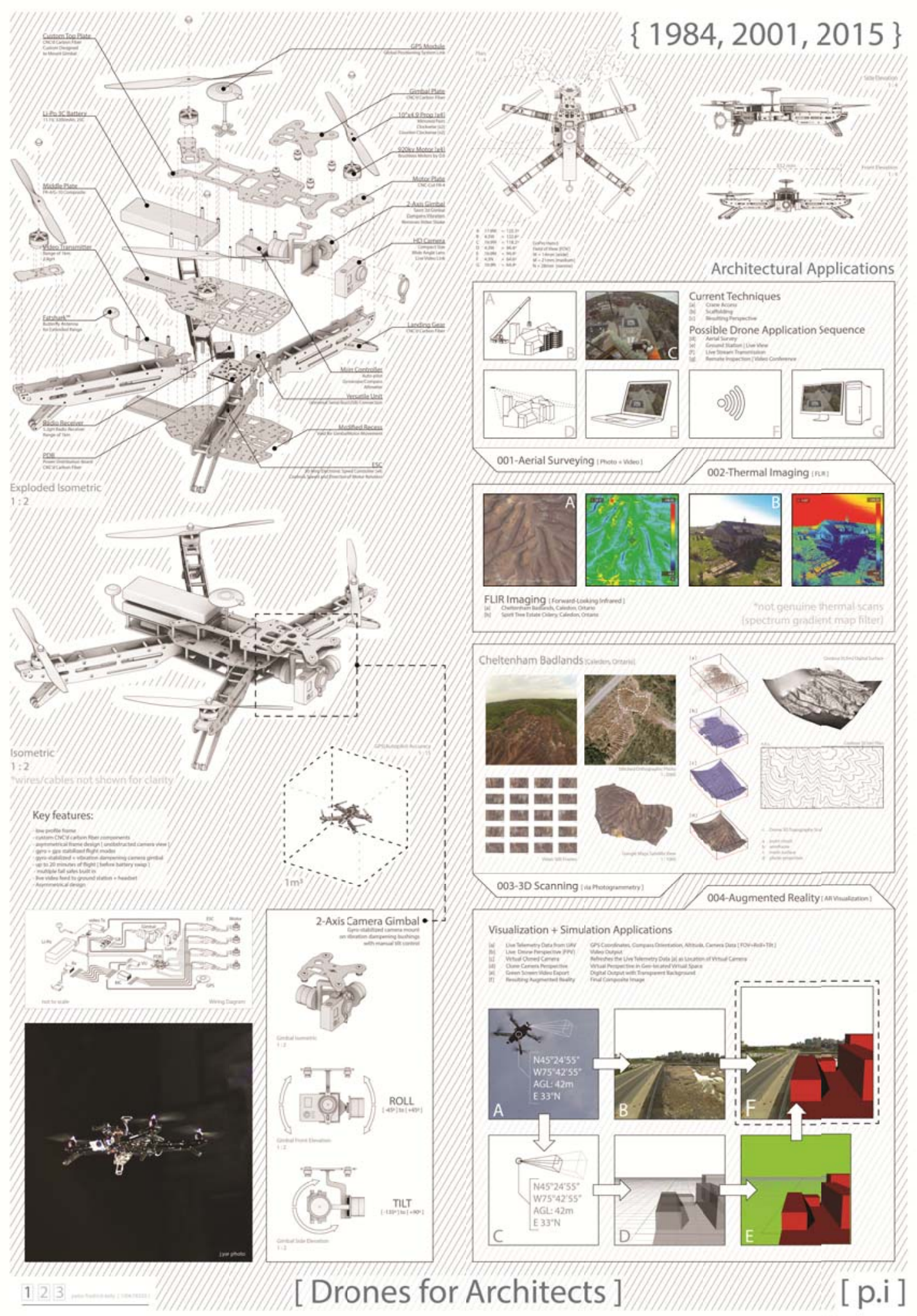



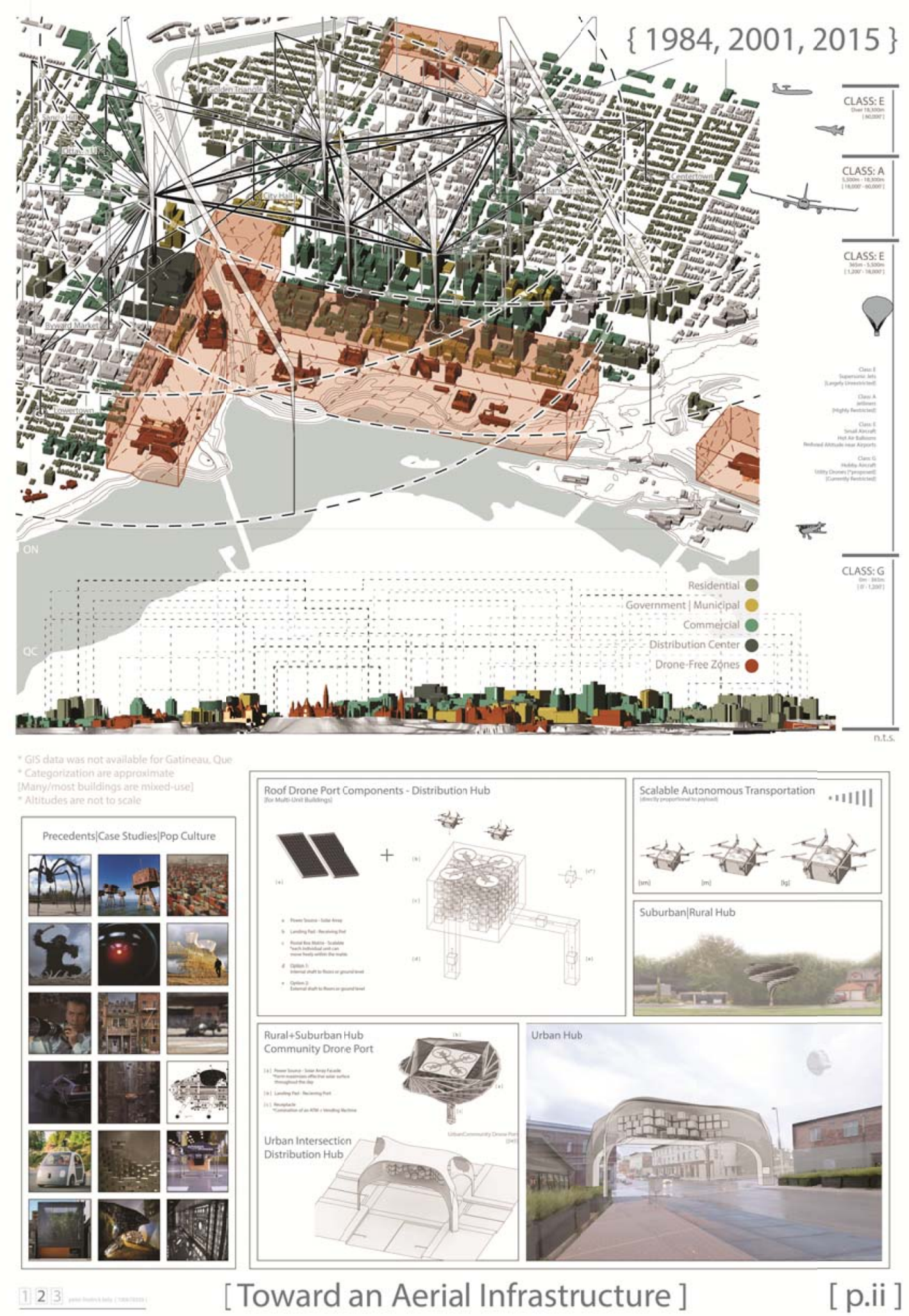


\section{BIBLIOGRAPHY}

3D Robotics Inc. About Us. 2013. http://3drobotics.com/about-us/ (accessed August 6, 2014).

A\&E Television Networks, LLC. 9/11 Attacks. 2014. http://www.history.com/topics/9-11attacks (accessed August 18, 2014).

Ackerman, Spencer. Drone Boosters Say Farmers, Not Cops, Are the Biggest U.S. Robot Market. February 5, 2013. http://www.wired.com/2013/02/drone-farm/ (accessed August 6, 2014).

ACLU. Reform the Patriot Act. 2011. https://www.aclu.org/reform-patriot-act (accessed August 20, 2014).

Aeromobil. Aeromobil. 2013. http://www.aeromobil.com/ (accessed August 5, 2014).

Agisoft LLC. 2006-2014. http://www.agisoft.ru/ (accessed July 30, 2014).

Ahmed, Murad. "Village Mob Thwarts Google Street View Car Times." Times, April 2, 2009.

AJ Software \& Multimedia. J. Robert Oppenheimer "Now I am become death...". 19982013. http://www.atomicarchive.com/Movies/Movie8.shtml (accessed August $15,2014)$.

Amazon.com, Inc. Amazon Prime Air. 1996-2014. http://www.amazon.com/b?node=8037720011 (accessed July 30, 2014).

Anderson, Chris. Bill Gates wants to use drones to deliver vaccines. November 5, 2012. http://diydrones.com/profiles/blogs/bill-gates-wants-to-use-drones-to-delivervaccines (accessed August 6, 2014).

-. Chris Anderson's Page. 2014. http://diydrones.com/profile/zlitezlite (accessed August 6, 2014).

Apple Inc. Mac Timeline. 2014. https://www.apple.com/30-years/ (accessed 0808 , 2014).

Associated Press. Canadian Jury Convicts Parliament Hill Bus Hijacker. March 6, 1990. http://www.apnewsarchive.com/1990/Canadian-Jury-Convicts-Parliament-HillBuss-Hijacker/id-4c128246ec32055c080b85cacddd262d (accessed August 5, 2014). 
Aubry, Michael. "Guards on Alert After Drone Fly-Over at Jail." The Ottawa Sun, November 27, 2013: 16.

Baran, Paul. "The Future Computer Utility." The Public Interest, 1967: 75-87.

Barraud, Emmanuel. The Matterhorn like you've never seen it. october 15, 2013. http://actu.epfl.ch/news/the-matterhorn-like-you-ve-never-seen-it/ (accessed August 6, 2014).

BBC News. Russia extends Snowden residency by three years. August 7, 2014. http://www.bbc.com/news/world-europe-28689231 (accessed August 20, 2014).

Bentham, Jeremy. The Works of Jeremy Bentham. Edited by John Bowring. Vol. IV. Edinburgh: John Bowring, 1843.

Berners-Lee, Tim. "A Magna Carta for the web." TED2014. Vancouver: TED, 2014.

Bjorkman, James. James Bond's Top Ten Gadgets. January 26, 2013. http://jamesbondreview.filminspector.com/2013/01/james-bonds-top-tengadgets.html (accessed August 6, 2014).

Boddy, Trevor. "Architecture Emblematic." In Indefensible Space: The Architecture of the National Security State, by Michael Sorkin, edited by Michael Sorkin. New York: Routledge, 2008.

Cadwalladr, Carole. Are the robots about to rise? Google's new director of engineering thinks so.... February 22, 2014.

http://www.theguardian.com/technology/2014/feb/22/robots-google-raykurzweil-terminator-singularity-artificial-intelligence (accessed August 6, 2014).

Campbell, Richard H. The Silverplate Bombers: A History and Registry of the Enola Gay and Other B-29s Configured to Carry Atomic Bombs. Jefferson, North Carolina: McFarland \& Company, 2005.

Canada Post Corporation. Annual Report 2013. 2014. http://www.canadapost.ca/cpo/mc/aboutus/corporate/annualreport.jsf (accessed August 11, 2014).

-. Canada Post Reaching Delivery Milestones Early. December 9, 2013. http://www.canadapost.ca/cpo/mc/aboutus/news/pr/2013/2013_delivery_mile stones.jsf (accessed August 7, 2014). 
Canada, Transport. Canadian Motor Vehicle Traffic Collision Statistics: 2010. December 10, 2013. http://www.tc.gc.ca/eng/motorvehiclesafety/tp-1317.htm (accessed August 10, 2014).

Casey, Brad, and Jonathan Hobin. Jonathan Hobin Recreates the World's Most Infamous Tragedies with Children. April 29, 2013. http://www.vice.com/en_ca/read/jonathan-hobin-recreates-the-worlds-mostinfamous-tragedies-with-children (accessed August 5, 2014).

Cassidy, John. No Contest: Edward Snowden is Person of the Year. December 9, 2013. http://www.newyorker.com/news/john-cassidy/no-contest-edward-snowden-isperson-of-the-year (accessed August 10, 2014).

CBC News. Canada Post: Mail volume, costs, and other quick facts. December 11, 2013. http://www.cbc.ca/news/canada/canada-post-mail-volume-costs-and-otherquick-facts-1.2459693 (accessed August 5, 2014).

Center for Strategic and International Studies. Net Losses: Estimating the Global Cost of Cybercrime. June 2014. http://www.mcafee.com/ca/resources/reports/rpeconomic-impact-cybercrime2.pdf (accessed August 1, 2014).

Chambers, Matt. Rise of the machines. March 7, 2012. http://www.theaustralian.com.au/news/features/rise-of-the-machines/storye6frg6z6-1226291014017?nk=27cb67e9df39fc1d7db6aeed87e0b3ae (accessed August 6, 2014).

Chappell, Bill. Pulitzer Prizes Are Out: 'Washington Post,' 'The Guardian' Win For NSA Stories. April 14, 2014. http://www.npr.org/blogs/thetwoway/2014/04/14/303002434/pulitzer-prizes-are-out-washington-post-theguardian-win-for-nsa-stories (accessed August 20, 2014).

Clarke, Arthur C. "Hazards of Prophecy: The Failure of Imagination." Profiles of the Future, 1962.

Corbusier, Le. Aircraft. London: Trefoil Publications, 1967.

-. Towards a New Architecture. Lexington: BN Publishing, 2008.

Coulson, William R. "'Big Brother' is Watching Apple: The Truth About the Super Bowl's Most Famous Ad." Dartmouth Law Journal, 2009: 106-115.

Crosby, Alfred W. Children of the Sun: A History of Humanity's Unappeasable Appetite for Energy. New York: W. W. Norton \& Company, 2006. 
Dagenais, Francine. "The Biomachinic Phylum: The Drones in the Hive, Implications for Contemporary Art." In Drone: the automated image, by Paul Wombell, edited by Paul Wombell, 184-194. Montréal, Quebec: Kerber Verlag, 2013.

D'Andrea, Raffaello. Dynamic Works. 2014. http://raffaello.name/ (accessed August 7, 2014).

-. Flight Assembled Architecture. 2012. http://raffaello.name/projects/flightassembled-architecture/ (accessed August 7, 2014).

-. Flying Machine Enabled Construction. December 2011.

http://www.idsc.ethz.ch/Research_DAndrea/Archives/Flying_Machine_Enabled_ Construction (accessed August 7, 2014).

Department of Defence. Unmanned Aircraft Systems (UAS) Roadmap 2005-2030. August 4, 2005. http://fas.org/irp/program/collect/uav_roadmap2005.pdf (accessed August 5, 2014).

DeSantis, Nicholas. "Skyscraper Airport for the City of Tomorrow." Popular Science, November 1939: 70-71.

Dizikes, Peter. The Case of the Missing Gas Mileage. MIT News Office. January 4, 2012. http://newsoffice.mit.edu/2011/cars-on-steroids-0104 (accessed August 15, 2014).

DJI Innovations. 2014. http://www.dji.com/ (accessed July 30, 2014).

-. Naza-M. Jan 24, 2013. http://wiki.dji.com/en/index.php/Naza-M (accessed July 30, 2014).

Dodson, Brian. Terrafugia Flying Car Completes First Phase of Flight Testing. July 1, 2012. http://www.gizmag.com/terrafugia-flying-car-test-flight/23141/ (accessed August 6, 2014).

Dougherty, Dale. "Mind Your Drone." Make:, February/March 2014.

DuckDuckGo. About. 2014. https://duckduckgo.com/about (accessed August 3, 2014).

—. duckduckgo.com. 2014. https://duckduckgo.com/ (accessed August 3, 2014).

E.Mensel, Robert. "Kodakers Lying in Wait: Amateur Photography and the Right to Privacy in New York, 1885-1915." American Quarterly, 1991. 
Enikeev, Ruslan. The Internet Map. February 13, 2013. http://internet-map.net/ (accessed August 5, 2014).

Erik Brynjolfsson, Andrew McAfee. Race Against the Machine. Lexington: Digital Frontier Press, 2011.

-. The Second Machine Age. New York: W. W. Norton \& Company, 2014.

Erlanger, Steven. Julian Assange Says He Will Leave Embassy 'Soon'. August 18, 2014. http://www.nytimes.com/2014/08/19/world/europe/julian-assangeembassy.html?_r=0 (accessed August 20, 2014).

Erueda, Jorg. 1973 Lolafil. 2011. http://www.jorgerueda.es/?page_id=19 (accessed August 5, 2014).

FAA. Busting Myths about the FAA and Unmanned Aircraft-Update. March 7, 2014. http://www.faa.gov/news/updates/?newsld=76381 (accessed August 7, 2014).

FAA. "Integration of Civil Unmanned Aircraft Systems (UAS) in the National Airspace System (NAS) Roadmap." First Edition, U.S. Department of Transportation, Federal Aviation Administration, Washington, 2013.

-. Press Release - FAA Announces Nevada UAS Test Site Now Operational. June 9, 2014. http://www.faa.gov/news/press_releases/news_story.cfm?newsld=16334 (accessed August 6, 2014).

-. Press Release - FAA Approves First Commercial UAS Flights over Land. June 10, 2014. http://www.faa.gov/news/press_releases/news_story.cfm?newsld=16354 (accessed August 6, 2014).

-. Unmanned Aircraft Systems. July 24, 2014. http://www.faa.gov/uas/ (accessed August 7, 2014).

-. What Can I Do With My Model Aircraft? June 25, 2014. http://www.faa.gov/uas/publications/model_aircraft_operators/ (accessed August 7, 2014).

Fatshark RC Vision Systems. 2010-2015. http://www.fatshark.com/ (accessed July 30, 2014).

Blade Runner. Directed by Ridley Scott. Performed by Harrison Ford. 1982. 
Foucault, Michel. Discipline and Punish: The Birth of the Prison. Translated by Alan Sheridan. Great Britain: Penguin Books Ltd, 1977.

Back to the Future. Directed by Robert Zemeckis. Performed by Michael J. Fox and Christopher Lloyd. 1985.

Frampton, Kenneth. Modern Architecture: A Critical History. Fourth. London: Thames \& Hudson Ltd, 2007.

Friedman, Megan. Quotes: Ken Jennings on Watson's 'Jeopardy' Victory. February 17, 2011. http://newsfeed.time.com/2011/02/17/quotes-ken-jennings-on-watsonsjeopardy-victory/ (accessed August 27, 2014).

Frosh, Paul. "The Public Eye and the Citizen-Voyeur: Photography as a Performance of Power." Social Semiotics, 2001: 43-59.

Geeksphone. http://www.geeksphone.com/. 2014. http://www.geeksphone.com/ (accessed August 6, 2014).

GoComics. Calvin and Bobbes. 2014.

http://www.gocomics.com/calvinandhobbes/1989/12/30\#.U-GUI_IdV8E (accessed August 5, 2014).

Goodman, Marc. A View From The Unfriendly Skies: How Criminals Are Using Drones. November 21, 2013. http://ideas.ted.com/2013/11/21/attack-of-the-drones-aview-from-the-unfriendly-skies/ (accessed August 6, 2014).

—. "A Vision of Crimes in the Future." TEDGlobal. Edinburgh: TED, 2012.

Google. Earth. 2014. http://www.google.com/earth/ (accessed August 5, 2014).

-. Maps. 2014. https://www.google.com/maps (accessed August 5, 2014).

-. Privacy and Security. 2013. http://maps.google.com.au/help/maps/streetview/privacy.html.

-. Street View. 2014. https://www.google.com/maps/views/streetview?gl=ca (accessed August 5, 2014).

GoPro, Inc. 2014. http://gopro.com/ (accessed July 30, 2014).

Government of Canada. Canadian Aviation Regulations SOR/96-433. June 12, 2014. http://laws-lois.justice.gc.ca/eng/regulations/SOR-96-433/FullText.html\#s602.41 (accessed August 5, 2014). 
Gramazio \& Kohler Architects. Flight Assembled Architecture. 2011-2012.

http://www.gramaziokohler.com/web/e/projekte/209.html (accessed August 7, 2014).

Grant, R.G. Flight: The Complete History. New York: DK Publishing, 2007.

Greene, Kate. Tracking Traffic with Cell Phones. November 11, 2008.

http://www.technologyreview.com/news/411169/tracking-traffic-with-cellphones/ (accessed August 4, 2014).

GSMK. GSMK CryptoPhone. 2014. http://www.cryptophone.de/en/ (accessed August 6, 2014).

Hadfield, Chris. An Astronaut's Guide to Life on Earth. Toronto: Random House Canada, 2013.

Hakim, Danny. Average U.S. Car Is Tipping Scales at 4,000 Pounds. May 5, 2004. http://www.nytimes.com/2004/05/05/business/05weight.html (accessed August 6, 2014).

Harris, Trevor. "Who is the Father of the Internet? The case for Donald Watts Davies." Edited by Yorgo Pasadeos. 6th International Conference on Media. Athens: Variety in Mass Communication Research, 2009. 1-12.

Haynes, Marc. King's Cross Airport. October 23, 2011.

http://darkestlondon.com/2011/10/23/kings-cross-airport-1931/ (accessed August 5, 2014).

Hijiya, James A. "The Gita of J. Robert Oppenheimer." Proceedings of American Philosophical Society, June 2000: 123-161.

HoverThings, Magento. 2011. http://www.hoverthings.com/ (accessed July 30, 2014).

IFI CLAIMS Patent Services,. Electronic still camera. 2012. http://www.google.com/patents/US4131919 (accessed August 6, 2014).

ImmersionRC. 2014. http://www.immersionrc.com/ (accessed July 30, 2014).

Institut Du Monde Arabe. Architecture. n.d. http://www.imarabe.org/architectureinstitut-du-monde-arabe (accessed August 5, 2014). 
Institute, Statistic Brain Research. Google Annual Search Statistics - Statistic Brain. January 1, 2014. http://www.statisticbrain.com/google-searches/ (accessed August 3, 2014).

Intel Corporation. Transistors to Transformations: From Sand to Circuits - How Intel Makes Chips. 2012. http://www.intel.com/content/dam/www/public/us/en/documents/corporateinformation/museum-transistors-to-transformations-brochure.pdf (accessed August 6, 2014).

INTERPOL. Cybercrime. 2014. http://www.interpol.int/Crimeareas/Cybercrime/Cybercrime (accessed August 2, 2014).

Jakobsson, Markus, ed. The Death of the Internet. Hoboken: John Wiley \& Sons , 2012.

Jones, Richard. "Checkpoint Security: Gateways, Airports and the Architecture of Security." In Technologies of InSecurity: The Surveillance of Everyday Life, by Helene Oppen Gundhus, Heidi Mork Lomell Katja Franko Aas, edited by Helene Oppen Gundhus, Heidi Mork Lomell Katja Franko Aas. New York: RoutledgeCavendish, 2009.

Kaijima, Momoyo, Junzo Kuroda, and Yoshiharu Tsukamoto. Made in Tokyo: Guide Book. Tokyo: Kajima Institute Publishing Co., 2001.

Katja Franko Aas, Helene Oppen Gundhus, Heidi Mork Lomell, ed. Technologies of InSecurity: The Surveillance of Everyday Life. New York: Routledge-Cavendish, 2009.

Keats, Jonathon. "Forget Google Glass - For Now." Wired, July 2014: 84.

Kelly, Kevin. "The Next 5,000 Days of the Web." EG Conference. Los Angeles: TED, 2007.

Kirby, Jason. "Future Imperfect." Maclean's, January 6, 2014.

Knittel, Christopher R. "Automobiles on Steroids: Product Attribute Trade-Offs and Technological Progress in the Automobile Sector." American Economic Review, December 2011.

Koebler, Jason. Drone Journalism Is a First Amendment Right, Major Media Companies Say. May 6, 2014. http://motherboard.vice.com/read/drone-journalism-is-afirst-amendment-right-says-coalition-of-media-giants1?trk_source=recommended (accessed August 6, 2014). 
-. Drones Are About to Take Over One of the World's Most Dangerous Jobs. May 16, 2014. http://motherboard.vice.com/read/drones-are-about-to-kill-aprofession?trk_source=recommended (accessed August 6, 2014).

Koolhaas, Rem. Delirious New York: A Retroactive Manifesto for Manhattan. New York: The Monacelli Press, 1994.

Koolhaas, Rem, and Hans Ulrich Obrist. Project Japan: Metabolism Talks... London: Taschen, 2011.

2001: A Space Odyssey. Directed by Stanley Kubrick. 1968.

Kurzweil Accelerating Intelligence. Ray Kurzweil biography. 2014. http://www.kurzweilai.net/ray-kurzweil-biography (accessed August 3, 2014).

Kurzweil, Ray. The Age of Spiritual Machines: When Computers Exceed Human Intelligence. Penguin Books, 2000.

Legrady, George. "Reflections on the Computational Photograph." In Drone: the automated image, by Paul Wombell, edited by Paul Wombell, 208-218. Montréal, Quebec: Kerber Verlag, 2013.

Lewis, Paul. You're Being Watched: There's one CCTV Camera for every 32 people in the UK. Gaurdian. March 2, 2011. http://www.theguardian.com/uk/2011/mar/02/cctv-cameras-watchingsurveillance (accessed August 4, 2014).

Lyon, David. "Bentham's Panopticon: From Moral Architecture to Electronic Surveillance." In Surveillance, Crime and Social Control, by Clive Norris, 583. Burlington: Ashgate Pub Co, 2006.

Lyon, David. "Globalizing Suveillance: Comparative and Socialogical Perspectives." In Surveillance, Crime and Control, by Clive Norris, 583. Burlington: Ashgate Pub Co, 2006.

—. The Electric Eye: The Rise of Surveillance Society. Cambridge: Polity Press, 1994.

Macguire, Eoghan. Road to nowhere: Could drones be the highways of the future? June 4, 2013. http://www.cnn.com/2013/05/31/tech/innovation/matternet-dronesnetworks-gateway/ (accessed August 6, 2014).

Make:. "By Wing, Wheel and Wave." Make:, February/March 2014. 
Marx, Gary T. "I'll Be Watching You: Reflections on the New Surveillance." In Surveillance, Crime and Social Control, by Clive Norris, edited by Dean Wilson, 583. Burlington: Ashgate Pub Co, 2006.

Matternet Inc. 2014. http://matternet.us/ (accessed July 30, 2014).

Meyer, Michael. Evgeny vs. the Internet. January 2, 2014.

http://www.cjr.org/cover_story/evgeny_vs_the_internet.php?page=all (accessed August 6, 2014).

Miles, Melissa. "Privacy in Google Street: Webcams, Street View, and the Transformation of Photography and Privacy in Public." In Drone: the automated image, by Paul Wombell, edited by Paul Wombell, 174-182. Montréal, Quebec: Kerber Verlag, 2013.

Misener, Dan. Browser cookies: How they could be undermining your privacy. April 8, 2014. http://www.cbc.ca/news/technology/browser-cookies-how-they-couldbe-undermining-your-privacy-1.2602095 (accessed August 6, 2014).

Moller International. FAQ. 2013. http://moller.com/dev/index.php/about-us/faq\#4.3 (accessed August 5, 2014).

-. Skycar Info. 2013. http://moller.com/dev/index.php/sky-car (accessed August 5, 2014).

Moore, Gordon E. Moore's Law or How Overall Processing Power for Computers will Double Every Two Years. n.d. http://www.mooreslaw.org/ (accessed August 5, 2014).

Morozov, Evgeny. Personal Web Site. 2013. http://www.evgenymorozov.com/ (accessed August 6, 2014).

-. The Net Delusion: The Dark Side of Internet Freedom. New York: PublicAffairs, 2011.

-. The Real Privacy Problem. October 22, 2013.

http://www.technologyreview.com/featuredstory/520426/the-real-privacyproblem/ (accessed August 6, 2014).

-. To Save Everything, Click Here: The Folly of Technological Solutionism. New York, New York: PublicAffairs, 2014.

Mostafavi, Moheses. Ecological Urbanism. Edited by Gareth Doherty. Zürich: Lars Müller Publishers $\mathrm{GmbH}, 2010$. 
Munroe, Randall. Google's Datacenters on Punch Cards. 2012-2014. http://www.whatif.xkcd.com/63/ (accessed August 5, 2014).

-. What If? 2012-2014. www.what-if.xkcd.com (accessed July 5, 2014).

Nabokov, Vladimir. "Lance." The New Yorker, 1952: 21.

Nellis, Mike. "24/7/365: Mobility, Locatability and the Satelite Tracking of Offenders." In Technologies of InSecurity: The Surveillance of Everyday Life, by Helene Oppen Gundhus, Heidi Mork Lomell Katja Franko Aas, edited by Helene Oppen Gundhus, Heidi Mork Lomell Katja Franko Aas. New York: Routledge-Cavendish, 2009.

Neyland, Daniel. "Mundane Terror and the Threat of everyday Objects." In Technologies of InSecurity: The Surveillance of Everyday Life, by Helene Oppen Gundhus, Heidi Mork Lomell Katja Franko Aas, edited by Helene Oppen Gundhus, Heidi Mork Lomell Katja Franko Aas. New York: Routledge-Cavendish, 2009.

Nicks, Denver. Amazon Wants to Test-Fly Its New Delivery Drones. July 11, 2014. http://time.com/2976103/amazon-drones-prime-air-test-flights/ (accessed August 6, 2014).

-. Amazon's Drone Strike. December 2, 2013.

http://business.time.com/2013/12/02/amazons-drone-strike/ (accessed August 6, 2014).

-. Google Will Start Encrypting Your Searches. March 13, 2014. http://time.com/23495/google-search-encryption/ (accessed August 6, 2014).

Niemann, Christoph. "Infrastructure." New York Times Magazine, June 14, 2009: Table of Contents.

Day After Trinity. Produced by Jon Else. Performed by J. Robert Oppenheimer. 1980.

Popular Mechanics Magazine. "Hiller's Aerial Sedan." Popular Mechanics Magazine, July 1957.

Popular Mechanics. The Top 50 Inventions of the Past 50 Years. December 1, 2005. http://www.popularmechanics.com/technology/gadgets/news/2078467 (accessed August 5, 2014).

Raptopoulos, Andreas. "No roads? There's a drone for that." TED. Edinburgh: MATTERNET, 2013. 
Rice-Oxley, Mark, Leila Haddou, and Frances Perraudin. Edward Snowden voted Guardian person of the year 2013. December 9, 2013. http://www.theguardian.com/world/2013/dec/09/edward-snowden-votedguardian-person-of-year-2013 (accessed August 15, 2014).

Ricky Burdett, Deyan Sudjic, ed. Living in the Endless City. London: Phaidon Press, 2011.

Rise of the Drones. Produced by Steve Taylor. 2012.

Roberts, Dan. FBI admits to using surveillance drones over US soil. June 19, 2013. http://www.theguardian.com/world/2013/jun/19/fbi-drones-domesticsurveillance (accessed August 6, 2014).

Robinson, Eugene. Edward Snowden was the person of the year. December 23, 2013. http://www.washingtonpost.com/opinions/eugene-robinson-edward-snowdenwas-the-person-of-the-year/2013/12/23/34551caa-6c13-11e3-a523fe73f0ff6b8d_story.html (accessed August 15, 2014).

Rohe, Ludwig Mies van de. "Technology and Architecture." In Programs and manifestoes on 20th-century architecture, by Ulrich Conrads, 154. Cambridge: The MIT Press, 1964.

Savage, Charlie, and Emmarie Huetteman. Manning Sentenced to 35 Years for a Pivotal Leak of U.S. Files. August 21, 2013. http://www.nytimes.com/2013/08/22/us/manning-sentenced-for-leakinggovernment-secrets.html?pagewanted=all (accessed August 20, 2014).

Schilling, David Russell. 10,000 Drones In Congested US Airspace by 2018. May 29, 2013. http://www.industrytap.com/10000-drones-in-congested-us-airspace-by2018/3659 (accessed August 6, 2014).

SciShow. Moore's Law and The Secret World Of Ones And Zeroes. July 12, 2014. https://www.youtube.com/watch?v=1qQE5Xwe7fs (accessed July 13, 2014).

Seetharaman, Deepa. Amazon seeks FAA permission to test drones outdoors near Seattle. July 11, 2014. http://www.reuters.com/article/2014/07/11/us-amazoncom-drones-idUSKBNOFG08B20140711 (accessed August 6, 2014).

SGP Technologies. blackphone. 2014. https://www.blackphone.ch (accessed August 6, 2014). 
Sheffield, Carrie. Edward Snowden Is Not 'Person Of The Year'. December 18, 2013. http://www.forbes.com/sites/carriesheffield/2013/12/18/edward-snowden-isnot-person-of-the-year/ (accessed August 15, 2014).

Silent Circle. The World's Solution to Mobile Privacy. 2014. https://silentcircle.com/ (accessed August 6, 2014).

Slobogin, Christopher. "21 Public Privacy: Camera Surveillance or Public Places and the Right to Anonymity." Mississippi Law Journal, 2002: 87.

Smith, Kevin. The Flying Car. Directed by Kevin Smith. Produced by Big Dog Productions; NBC Studios. 2002.

Snowden, Edward. "Here's how we take back the Internet." TED2014. Vancouver: TED, 2014.

Sorkin, Michael, ed. Indefensible Space: The Architecture of the National Security State. New York: Routledge, 2008.

Spektrum, Horizon Hobby LLC. 2005-2014. http://www.spektrumrc.com/ (accessed July $30,2014)$.

Statista. FedEx Corporation's revenue from FY 2008 to FY 2014. 2014. http://www.statista.com/statistics/267501/revenue-of-fedex/ (accessed August 11, 2014).

Statistic Brain Research Institute. Number of Letters Mailed Each Year. Novemer 23, 2013. http://www.statisticbrain.com/number-of-letters-mailed-each-year/ (accessed August 10, 2014).

Suarez, Daniel. "The Kill Decision Shouldn't Belong to a Robot." TEDGlobal. Edinburgh: TED, 2013.

Tarot RC. 2012. http://www.tarot-rc.com/ (accessed July 30, 2014).

Taylor, Nick. "State Surveillance and the Right to Privacy." In Surveillance, Crime and Social Control, by Clive Norris, 583. Burlington: Ashgate Pub Co, 2006.

Terrafugia. Terrafugia. 2013. http://www.terrafugia.com/ (accessed August 5, 2014).

The Associated Press. Google buys drone maker Titan Aerospace. April 15, 2014. http://www.cbc.ca/news/technology/google-buys-drone-maker-titanaerospace-1.2610691 (accessed August 6, 2014). 
The Guardian. The Guardian. 2014.

http://www.theguardian.com/ukhttp://www.theguardian.com/uk (accessed August 15, 2014).

The Intercept. About. 2014. https://firstlook.org/theintercept/about/ (accessed August 20, 2014).

The Manhattan Project Heritage Preservation Association, Inc. The Hiroshima Mission. August 03, 2005. http://www.mphpa.org/classic/HISTORY/H-07L.htm (accessed August 14, 2014).

-. The Nagasaki Mission. August 03, 2005. http://www.mphpa.org/classic/HISTORY/H07m.htm (accessed August 10, 2014).

theguardian.com. Bradley Manning - timeline. July 30, 2013. http://www.theguardian.com/world/2013/jul/30/bradley-manning-timeline (accessed August 20, 2014).

Thompson, Cadie. Your Amazon Delivery Won't Arrive By Drone Anytime Soon.

December 2, 2013. http://www.cnbc.com/id/101239210 (accessed August 6, 2014).

Tor. Tor: Overview. 2014. https://www.torproject.org/about/overview.html.en (accessed August 6, 2014).

Transport Canada. Unmanned Air Vehicle. May 3, 2010. http://www.tc.gc.ca/eng/civilaviation/standards/general-recavi-brochures-uav2270.htm (accessed August 6, 2014).

Turing, Alan M. "Computing Machinery and Intelligence." Mind: A Quarterly Review of Psychology and Philosophy LIX, no. 236 (1950): 433-460.

Waddell, Laurence Austin. Amung the Hilalayas. Westminster: A Constable \& Co., 1899.

Warren, Samual D., and Louis D. Brandeis. "The Right to Privacy." Harvard Law Review, December 15, 1890: 193-220.

Waterman, Shaun. Drones over U.S. get OK by Congress. February 7, 2012. http://www.washingtontimes.com/news/2012/feb/7/coming-to-a-sky-near-you/ (accessed August 6, 2014). 
Whitlock, Craig. Close encounters on rise as small drones gain in popularity. June 23, 2014. http://www.washingtonpost.com/sf/investigative/2014/06/23/closeencounters-with-small-drones-on-rise/ (accessed August 6, 2014).

WikiLeaks. WikiLeaks. 2014. https://wikileaks.org/ (accessed August 15, 2014).

Winner, Langdon. Autonomous Technology: Technics-out-of-Control as a Theme in Political Thought. Cambridge: MIT Press, 177.

Wohlsen, Marcus. Even if the Feds Let Them Fly, Amazon's Delivery Drones Are Still Nonsense. December 2, 2013. http://www.wired.com/2013/12/amazon-drone/ (accessed August 6, 2014).

-. "Ground War: Tech Titans Take their Fight to the Streets." Wired Magazine, July 2014: 25-28.

Wombell, Paul, ed. Drone: the automated image. Montréal, Quebec: Kerber Verlag, 2013.

World Health Organization. Global Status Report on Road Safety 2013. Geneva: World Health Organization, 2013.

Yakabuski, Konrad. Taxes pay for robots, but robots don't pay taxes. April 14, 2014. http://www.theglobeandmail.com/globe-debate/taxes-pay-for-robots-butrobots-dont-pay-taxes/article17942327/(accessed August 6, 2014).

Yang, Craig Timberg and Jla Lynn. Google is encrypting search globally. That's bad for the NSA and China's censors. March 12, 2014. http://www.washingtonpost.com/blogs/the-switch/wp/2014/03/12/google-isencrypting-search-worldwide-thats-bad-for-the-nsa-and-china/?wpisrc=nl_eve (accessed August 6, 2014).

Nova: Rise of the Drones. Directed by Peter Yost. 2013. 


\section{ENDNOTES}

\footnotetext{
' This version of the quote is from the television documentary The Decision to Drop the Bomb broadcast by NBC in 1965 . There are many interpretations of the original source material, but this is Oppenheimer's own translation from Sanskrit (Hijiya 2000, 125).

ii PFK worked for an Architectural office in Ottawa that specialized in Heritage Conservation from September 2011 - August 2012. He was the primary technician responsible for the construction documents of the infill walls and associated ironwork, landscaping.

iii Aerial footage from the PFK Drone can be viewed at https://vimeo.com/user1951365 [or by searching "PFK Aerial" on vimeo].

iv PFK worked for an Architectural office in Ottawa that specialized in Heritage Conservation from September 2011 - August 2012. He worked on several prominent heritage buildings in the Capital Region.

$\checkmark$ PFK has experimented with photogrammetry on several occasions, through research with the CIMS Lab at Carleton University and for personal use.
} 